\title{
Extremal problems on planar point sets
}

\author{
Ph.D. thesis
}

\section{Viola Mészáros}

\author{
Supervisors: \\ Péter Hajnal, University of Szeged \\ Pavel Valtr, Charles University in Prague
}

Doctoral School in Mathematics and Computer Science University of Szeged, Bolyai Institute

Szeged, 2011 



\section{Contents}

$\begin{array}{ll}\text { Introduction } & 1\end{array}$

1 Noncrossing Alternating Paths in Convex Point Sets 5

1.1 Introduction . . . . . . . . . . . . . . 5

1.2 Notations . . . . . . . . . . . . . . . . . . . . . 6

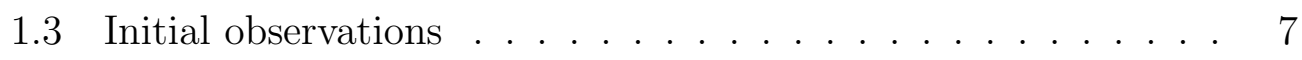

1.4 Previous methods . . . . . . . . . . . . . . . . . . . . . . 9

1.5 Improved lower bound . . . . . . . . . . . . . . . . . . . 10

1.6 Limits of the known methods . . . . . . . . . . . . . . . . . . 12

1.7 New constructions . . . . . . . . . . . . . . . . . . 13

1.8 Further questions . . . . . . . . . . . . . . . . . . . . 16

2 Separated Matchings in Colored Convex Sets 17

2.1 Introduction . . . . . . . . . . . . . . . . . 17

2.2 Notations . . . . . . . . . . . . . . . . . . . . . . . . . 18

2.3 Constructions and theorems . . . . . . . . . . . . 20

2.4 Proofs . . . . . . . . . . . . . . . . . . . . . 21

2.5 Low discrepancy . . . . . . . . . . . . . . . . . . . . . . . . . . . . . . . . . . 35

2.6 Open problems . . . . . . . . . . . . . . . . . . . . . . 30

3 Hamiltonian Alternating Paths on Bicolored Double-Chains 31

3.1 Introduction . . . . . . . . . . . . . . 31

3.2 Proof of Theorem $[16] \ldots \ldots \ldots$

$3.2 .1 \quad$ Notation used in the proot . . . . . . . . . . . . 32

3.2 .2 Proof in the even case . . . . . . . . . . . . . . 34

3.2.3 Proof in the odd case . . . . . . . . . . . . . . . . . . . 39

3.3 Unbalanced double-chains with no good path . . . . . . . . . . 39

3.4 Open problems . . . . . . . . . . . . . . . . . 43

4 Solution of Peter Winkler's Pizza Problem 44

4.1 Introduction . . . . . . . . . . . . . . . . . 44 
4.2 The lower bound . . . . . . . . . . . . . . . . . . . . 47

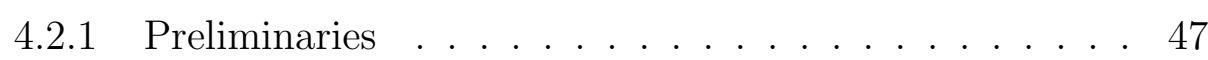

4.2 .2 Minimal triples . . . . . . . . . . . . . . . . . . 50

4.2 .3 An auxiliarv one-iump strategy . . . . . . . . . . . 52

4.2 .4 A two-iump strategy . . . . . . . . . . . . . . . . . . 53

4.2 .5 Two phases of the game . . . . . . . . . . . . . . 54

4.2 .6 Alice's strategy in the first phase . . . . . . . . . . . . 54

4.2 .7 Alice's strategy in the second phase . . . . . . . . . . 56

4.2 .8 Analvsis of Alice's gain . . . . . . . . . . . . . . . 56

4.2 .9 Proof of the lower bound . . . . . . . . . . . 57

4.3 The upper bound . . . . . . . . . . . . . . . . . . . . 58

4.4 Fixed number of slices . . . . . . . . . . . . . . . . . 61

4.5 Cuttings into 15 and 21 slices . . . . . . . . . . . . 62

4.6 One-iump strategies $\ldots \ldots \ldots$. . . . . . . . . . . . . . . . . 64

4.6 .1 Lower bound . . . . . . . . . . . . . . . . . 65

4.6 .2 Upper bound . . . . . . . . . . . . . . . . . . 67

4.7 Algorithms . . . . . . . . . . . . . . . . . . . . . 70

4.7 .1 Linear algorithm . . . . . . . . . . . . . . . 70

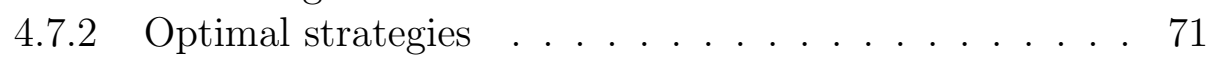

\begin{tabular}{ll}
\hline Acknowledgement & 73
\end{tabular}

\begin{tabular}{ll}
\hline Bibliography & 74
\end{tabular}

$\begin{array}{ll}\text { Summary } & 77\end{array}$

$\begin{array}{ll}\text { Összefoglaló } & 81\end{array}$ 


\section{Introduction}

One of the basic problems in geometric graph theory is to decide if a given graph can be drawn on a given planar point set by pairwise noncrossing straight line edges. It is an easy observation that any planar point set in general position admits a noncrossing Hamiltonian path. In a more demanding version of the problem, the points and the vertices of the graph are colored and each vertex has to be placed in a point of the same color (see the survey [18] for further references). Interesting and not so easy questions arise already if the points are colored by two colors and we want to embed a path where the colors are alternating. Several authors have focused on this question recently and obtained appealing results.

Consider an arbitrary $2 n$-element equicolored ( $n$ points red and $n$ points blue) point set in the plane. We would like to determine or estimate the number of points on the longest noncrossing path such that edges join points of different color and are straight line segments. We call such two-colored paths where edges connect points of different color alternating.

For the case when our points are in general position there are very few results. We know that if the color classes are separated by a line, then there is a noncrossing, alternating Hamiltonian path on the point set [1]. The same result holds if one of the color classes is exactly the set of vertices of the convex hull [1]. If the color classes are not separated by a line, then there are colored point sets with no noncrossing, alternating Hamiltonian path for $n \geq 8$, even if the points are in convex position.

Kaneko et al. [19] considered point sets with odd cardinality as well. An equitable coloring means that the sizes of the two color classes differ by at most one. They proved that any equitably colored set of at most 12 points or of 14 points admits a noncrossing, alternating Hamiltonian path. On the other hand, Kaneko et al. [19] gave examples of equitably colored sets of $n$ points admitting no noncrossing, alternating Hamiltonian path for any $n>12, n \neq 14$.

The existence of halving lines and the result in [1] imply that for any equicolored point set of $2 n$ points there are at least $n$ points on the longest 
noncrossing, alternating path.

Erdős [11] asked what happens if we restrict the points to be in convex position.

$$
\ell(\mathcal{P})=\max _{U \text { is a noncrossing alternating path }} \ell(U),
$$

where $\ell(U)$ is the number of points on $U$.

$$
\ell(n)=\min _{\mathcal{P} \text { is equicolored }} \ell(\mathcal{P}),
$$

where $\mathcal{P}$ is any colored planar $2 n$-element convex point set.

Without loss of generality we may assume that the points are on a circle. Erdös conjectured that the following configuration was asymptotically extremal. Let $n$ be divisible by four. Divide the circle into four intervals that consist of $\frac{n}{2}$ red, $\frac{n}{4}$ blue, $\frac{n}{2}$ red and $\frac{3 n}{4}$ blue points, respectively. In this configuration there are $\frac{3 n}{2}+2$ points on the longest noncrossing, alternating path.

Kynčl, Pach and Tóth 23] disproved the above conjecture of Erdős with a single construction in 2008 and gave the $\frac{4}{3} n+O(\sqrt{n})$ upper and the $n+$ $\Omega(\sqrt{n / \log n})$ lower bound. At about the same time Abellanas et al. showed a very similar construction for the same upper bound [2]. The upper bound is conjectured to be asymptotically tight.

In my Ph.D. thesis I include my results in this area. In the first two chapters I investigate the convex case. I describe several constructions presenting more classes of configurations among them. I also give an improvement for the lower bound to $n+O(\sqrt{n})$ [17]. The proof of the lower bound in [23] is based on arcs which contain significantly more points from one color class than from the other. At the same time the number of alternations between the colors is small along the circle. We do the same using a completely different idea and we obtain a better result.

I show a class of configurations exihibiting the upper bound $\frac{4}{3} n+O(\sqrt{n})$ [17]. This class contains the [23] construction in its extremal position. Otherwise, our class differs from the two earlier constructions in a considerable feature. While the previous constructions allowed only one interval with alternating short monochromatic arcs, ours allows two of them.

The methods used in the proofs introduced the notion of separated matchings. These are special geometrically noncrossing matchings where all matched pairs of points can be separated by a single line. In other words, there is a line that intersects all the edges of the matching.

I give several new constructions with at most $\frac{4}{3} n+O(\sqrt{n})$ points in any separated matching [25]. Among them there is a class of configurations 
that significantly differs from all known previous constructions. It contains arbitrary many intervals of alternating short monochromatic arcs. I also present a type of coloring such that among these colorings in the optimal one any separated matching contains at most $\frac{4}{3} n+O(\sqrt{n})$ points.

These results emphazise the importance of the separated matching conjecture [23] that can be formulated as follows. Let $2 k$ denote the number of alternations between the two colors in a 2n-element point set on the circle. Then for any fixed $k$ and large $n$, any configuration admits a separated matching that contains at least $\frac{2 k-1}{3 k-2} 2 n+o(n)$ points.

Separated matchings have further advantages compared to alternating paths. They are simpler. Moreover, every alternating path consists of a separated matching part and side edges completed to a path. If we consider examples with small discrepancy coloring (that is, the difference in cardinality of the color classes is bounded on any interval) that alone guarantees a long noncrossing, alternating path. This is a consequence of the frequent alternations of colors along the circle caused by small discrepancy. Regarding separated matchings small discrepancy coloring is a case that we should consider. It might even lead to a deeper understanding of the problem.

Furthermore, investigating colorings with small discrepancy might yield an improvement at the lower bound. I prove that for any coloring with dicrepancy $d \leq 3$ there is a separated matching containing at least $\frac{4 n}{3}$ points [25].

In the third chapter we consider the colored point set to be in a special position [7]. Here we will allow that the difference of the color classes is at most one. Our point set will be on a double-chain which we define as follows. A convex or a concave chain is a finite set of points in the plane lying on the graph of a strictly convex or a strictly concave function, respectively. A double-chain consists of a convex chain and a concave chain such that any line determined by any of the chains does not intersect the other chain. We prove [7] if both chains of the double-chain contain at least one fifth of all the points, then there exists a noncrossing, alternating Hamiltonian path. On the other hand, the above property does not hold if one of the chains contains at most $\approx 1 / 29$ of all the points [7]. This result is so far the strongest evidence by it that the convex setting of our point set might be an extremal case.

In the fourth chapter of my thesis I introduce a combinatorial game played on a cycle with weights assigned to its vertices. This game was devised by Peter Winkler who posed it at the conference Building Bridges, honouring the 60th birthday of László Lovász, in Budapest in 2008.

Bob cuts a circular pizza into slices of not necessarily equal size and shares 
it with Alice by taking turns alternately. One slice is taken in each turn. The first turn is Alice's. She may choose any of the slices. In all other turns only those slices can be chosen that have a neighbor slice already taken. How much of the pizza can Alice gain?

There was a puzzle formulated by Dan Brown in 1996 asking whether Bob can get more than half of the pizza. Here Bob can easily ensure one half of the pizza for himself. For example, he may cut the pizza into an even number of slices of equal size where he will always obtain exactly one half. The pizza game described by Peter Winkler originates from this puzzle.

Peter Winkler conjectured that Alice can obtain 4/9 of the pizza for any cutting. We settled this conjecture in the affarmative [9]. Moreover, we characterized Alice's gain based on the number of slices. We also devised an algorithm that computes her strategy in $\mathrm{O}(\mathrm{n})$ time for a given cutting of the pizza into $n$ slices [9]. We described the minimal pizza cuttings (regarding the number of slices and also regarding the number of weights of slices) where Bob had a strategy to gain 5/9 of the pizza. We gave a quadratic algorithm that stores an optimal turn for the player on turn for each position of the game [9].

Finally, I would like to give a glimpse of further research not included in the thesis. In a follow-up paper we investigate generalizations of this game [8]. Instead of a cycle any graph $G$ can be considered. We restrict $G$ to be connected. We have some freedom how to set the rules. We may require the taken part to be connected, or the remaining part to be connected, or both. Note, in the original pizza game all the listed rules are equal. For any of the mentioned three rules and for any $k \geq 1$ we present a $k$-connected graph where Bob has a strategy to obtain almost all of the total weight. We also prove the PSPACE-completeness of some decision problems formulated in this context [8]. 


\section{Chapter 1}

\section{Noncrossing Alternating Paths in Convex Point Sets}

\subsection{Introduction}

All our graphs will be drawn in the plane. Furthermore, edges of a graph will be always straight line segments. It is an easy observation that any point set in general position in the plane admits a noncrossing Hamiltonian path. In case our point set is colored we get to new interesting problems. Consider an equicolored $2 n$-element planar point set, that is, let $n$ points be red and $n$ points be blue. We will restrict edges to connect points of different colors.

In this chapter we will investigate the Erdös' version of the problem. The root of our discussion is going to be a convex setting of the equicolored $2 n$ element point set. We will be searching for long noncrossing paths. As edges have endpoints of different color each path will be alternating in the point set. The goal is to give an estimate or determine the number of points on the longest noncrossing, alternating path.

We state the problem formally below:

$$
\ell(\mathcal{P})=\max _{U \text { is a noncrossing alternating path }} \ell(U),
$$

where $\ell(U)$ is the number of points on $U$.

$$
\ell(n)=\min _{\mathcal{P} \text { is equicolored }} \ell(\mathcal{P}),
$$

where $\mathcal{P}$ is any colored planar $2 n$-element convex point set.

Without loss of generality we may assume that the points are on a circle. Erdös constructed a configuration that he thought to be asymptotically extremal, see in the Introduction. It contained a noncrossing, alternating path of $\frac{3 n}{2}+2$ points but not longer. 
Kynčl, Pach and Tóth 23] disproved the above conjecture in 2008 by a single construction proving the $\frac{4}{3} n+O(\sqrt{n})$ upper bound. In [23] they also showed the $n+\Omega(\sqrt{n / \log n})$ lower bound. The only other result towards the Erdős problem was a very similar also isolated construction in [2].

In this chapter I include our proof of the improvement on the lower bound. We showed that there are at least $n+\Omega(\sqrt{n})$ points on the longest noncrossing, alternating path [17]. Here we present a class of configurations for the $\frac{4}{3} n+O(\sqrt{n})$ upper bound [17] as well. This class was also found by Jan Kynčl [22] using computer search.

If the alternations among the color classes are very frequent along the circle, then it ensures a long noncrossing, alternating path. Therefore it is advisable to restrict the number of alternations. However, all configurations that show the current best upper bound contain at least one interval where short monochromatic arcs alternate. Our construction exels because it is a class of configurations. In its extremes it coincides with the [23] construction.

\subsection{Notations}

Let $\mathbf{P}$ be a planar point set of $2 n$ points in convex position. We index our points according to their circular order along the perimeter of their convex hull: $P_{1}, P_{2}, \ldots, P_{2 n}$ where the arithmetics of the indices is the modulo $2 n$ arithmetics. Two elements of $\mathbf{P}, P_{i}$ and $P_{j}$, define two arcs (two subsets of $\mathbf{P}): a\left(P_{i}, P_{j}\right)=\left\{P_{i}, P_{i+1}, \ldots, P_{j}\right\}$ and $a\left(P_{j}, P_{i}\right)=\left\{P_{j}, P_{j+1}, \ldots, P_{i}\right\}$. Let $A$ be an arc. The complement of $A$ (in $\mathbf{P}$ ) will be also an arc: the complement of arc $a\left(P_{i}, P_{j}\right)$ is the arc $a\left(P_{j+1}, P_{i-1}\right)$. The closed straight line segment determined by $P_{i}$ and $P_{j}$ is denoted by $\left[P_{i} P_{j}\right]$. Segments $\left[P_{i} P_{j}\right]$ and $\left[P_{k} P_{l}\right]$ are crossing if and only if the four indices are pairwise different, furthermore $P_{k}$ and $P_{l}$ lie in different arcs determined by $P_{i}$ and $P_{j}$. It is easy to see that "to be crossing" is a symmetric relation. A path in $P$ is just an ordered subset of $\mathbf{P}: p_{1}, p_{2}, \ldots, p_{\ell}$. We can think about a path as the sequence of segments $\left[p_{i}, p_{i+1}\right]$. A path is noncrossing if it consists of pairwise noncrossing segments. The length of a path $P$ is the number of points in $P$, and we use the notation length $(P)$.

A coloring of $\mathbf{P}$ is a function $c: \mathbf{P} \rightarrow\{$ red, blue $\}$. The coloring $c$ is an equicoloring if $\mid c^{-1}$ (red) $|=| c^{-1}$ (blue) $\mid(=|\mathbf{P}| / 2=n)$. Let $\mathcal{R}=c^{-1}$ (red) and $\mathcal{B}=c^{-1}$ (blue). In the following $\mathcal{P}$ will denote a $2 n$-element convex planar point set $\mathbf{P}$ with an equicoloring $c$.

Observe, as we restricted edges to connect points of different colors, for each path $p_{1}, p_{2}, \ldots, p_{\ell}$ the color of $p_{i}$ is the same as the color of $p_{j}$ if and 
only if $i$ and $j$ are of the same parity. In other words, as we walk along the path the red and blue points alternate.

We can partition $\mathcal{P}$ into disjoint nonempty arcs in such a way that each arc is monochromatic and the sequence of these monochromatic arcs $R_{1}, B_{1}, R_{2}, B_{2}, \ldots, R_{r}, B_{r}$ along the perimeter is alternating in color. The arc $R_{i}$ is a red monochromatic arc and $B_{i}$ is the next blue monochromatic arc in the above sequence. Arcs $R_{i}$ and $B_{i}$ are called runs for every $i \in\{1, \ldots, r\}$. The common number of red runs and blue runs is called the run parameter of the colored point set, and it is denoted by $\operatorname{run}(\mathcal{P})$.

From the definitions above one can see that the problem is really a combinatorial question. For example we can assume that $\mathbf{P}$ is on a circle or on an ellipse.

In the next section we summarize the previous result. Finally we describe our improvement.

\subsection{Initial observations}

Let $s$ be any line that is disjoint from $\mathcal{P}$ and cuts our point set into two nonempty parts. Then $s$ determines two complementary arcs: $A$ and $A^{c}$. We call these arcs/point sets the sides of $s$.

The elements of a matching on the point set $\mathcal{P}$ are edges determined by two elements of $\mathcal{P}$. The endpoints of an edge are called matched points. A matching $M$ of $\mathcal{P}$ is a separated matching with axe $s$ if the following three properties are satisfied:

(a) any element of $M$ crosses the axe $s$ (that is, if we take two matched elements of $\mathcal{P}$, then they belong to different sides of $s$ );

(b) different elements of $M$ do not cross each other;

(c) the two endpoints of any element of $M$ have different colors (that is, our earlier rule that edges connect points of different colors apply here, too)

In other words, a matching is separated (with axe $s$ ) if and only if it matches pairs consisting of a red and a blue point from different sides of $s$ in a noncrossing way. The size of a separated matching $M$ is the number of points in $M$. We denote the number of elements of the set $M$ by $|M|$. Note, here it means the number of edges in $M$ as $M$ is a matching.

The elements of a separated matching can be easily joined to form a noncrossing path. Our next claim summarizes this observation. 
Observation 1. If $M$ is a separated matching, then we can find a noncrossing, alternating path of length $2|M|$.

This can be improved easily by using edges (if possible) that are not intersecting the line $s$. First we need a definition.

Let $M$ be a separated matching (with axe $s$ cutting our point set into two sides: $\operatorname{arcs} A$ and $A^{c}$ ). Let $\operatorname{alt}(M)$ be the number of alternations between the colors along $A$ following the perimetrical order. Note, that arc $A$ contains one endpoint of each element of $M$. We call a separated matching $M$ with $\operatorname{alt}(M)=0$ an Erdös matching.

For any separated matching $M$ there is a path $P$ on the point set of $M$ such that the edges of $M$ give the odd edges of $P$. Note, this path is not unique. There are exactly two such paths depending on it which color we choose to be the color of the first point of $P$. If we want to enlarge $P$, we may incorporate new points into $P$ if possible. The new edges we get may or may not cross the line $s$. If an edge does not $\operatorname{cross} s$, we call it a side edge.

Observation 2. ([23]) There exist side edges and a suitable Erdös matching so that they can be connected into a noncrossing, alternating path of $n+$ $\operatorname{run}(\mathcal{P})-1$ points.

The following lemma says that in certain sense every path is a separated matching improved by side edges.

Observation 3. Let $P$ be an arbitrary noncrossing, alternating path in $\mathcal{P}$. Take a line $s$ such that the first and last edge of $P$ are crossed by $s$. Then we can choose a separated matching $M$ with axe $s$ from the edges of $P$ in such a way that the size of $M$ is at least length $(P)-2 \operatorname{run}(\mathcal{P})$.

Note that the axe is not uniquely defined.

Proof. Throw away all edges of $P$ that are not crossed by the line $s$. Thus we obtain subpaths $P_{1}, \ldots, P_{l}$ of $P$. From each subpath of odd length delete the first edge. In the remainder of each subpath keep every other edge starting from the first edge. We get a separated matching $M$.

We will count how many points on $P$ participate in $M$. The side edges of $P$ form subpaths $S_{1}, \ldots, S_{l-1}$ where $S_{i}$ connects $P_{i}$ to $P_{i+1}$ on $P$ for $i \in$ $\{1, \ldots, l-1\}$. We constructed $M$ in such a way that at least one point from each $S_{i}$ participates in $M$ (the point in $P_{i} \cap S_{i}$ ). Each side edges has its endpoints in different runs. Hence, the number of disregarded points can be bounded from above by the total number of runs and the result follows. 
If someone considers the observed examples in the literature, then length $(P)$ is between $n$ and $2 n$, while $\operatorname{run}(\mathcal{P})$ is $o(n)$. If $\operatorname{run}(\mathcal{P})$ is linear in $n$, the longest noncrossing path beats the best known lower bound by Observation 2 . Hence, assuming $\operatorname{run}(\mathcal{P})=o(n)$ is reasonable, we should concentrate on separated matchings.

Let $m(\mathcal{P})$ denote the maximum size of the separated matchings on the point set $\mathcal{P}$.

\subsection{Previous methods}

The idea of the obvious lower bound is very simple.

Take any line $s$ that cuts the point set $\mathcal{P}$ into two parts. If $|A \cap \mathcal{R}|, \mid A^{c} \cap$ $\mathcal{B} \mid \geq t$, then take $t$ many points from $A \cap \mathcal{R}$ and $t$ many points from $A^{c} \cap \mathcal{B}$. The two $t$-element point sets are separated by the line $s$. We can match their elements in a noncrossing way and hence we obtain a separated matching of $2 t$ points.

Observation 4. There is an Erdös matching $M$ of size at least $n$ and hence a noncrossing, alternating path of length $n$.

All what we described was known to Erdős. He showed in the following way that it was easy to find a separated matching of size $n$. Take any halving line $s$ of the point set $\mathcal{P}$. Let $A$ be the arc with red majority $(|A \cap \mathcal{R}| \geq$ $|A \cap \mathcal{B}|)$. It turns out that $A^{c}$ must have blue majority. Hence, the parameter $t$ in the above argument is at least $n / 2$. We obtain a noncrossing alternating path of length at least $n$.

The main ingredient of the improvement is summarized in the following observation. First we need to introduce a simple notion. Let $A$ be an arc in $\mathcal{P}$ of even size. Then there is a unique partition of $A$ into two $\operatorname{arcs}$ of the same size that we call half-arcs.

Observation 5. (Implicit in [23]) If we can find an arc $A$, with half-arcs: $A=A_{r} \dot{\cup} A_{b}$ such that $\left|A_{r} \cap \mathcal{R}\right|-\left|A_{r} \cap \mathcal{B}\right| \geq t$ and $\left|A_{b} \cap \mathcal{B}\right|-\left|A_{b} \cap \mathcal{R}\right| \geq t$, then there is a separated matching $M$ of size at least $n+t$, moreover alt $(M) \leq 1$.

Proof. In other words, $A_{r}$ contains at least $t$ more red points than blue points and $A_{b}$ contains at least $t$ more blue points than red ones, while the size of $A_{r}$ and $A_{b}$ equals. Let $s$ denote this common size. In $A_{r}$ take the closest $\left\lceil\frac{s+t}{2}\right\rceil$ many red points to $A_{b}$. Similarly, in $A_{b}$ take the closest $\left\lceil\frac{s+t}{2}\right\rceil$ many blue points to $A_{r}$. We will match these red and blue points with each other so that we get a separated matching of size $2\left\lceil\frac{s+t}{2}\right\rceil$. We will increase this matching by adding further edges that we obtain by Erdős' method. Furthermore, we will 


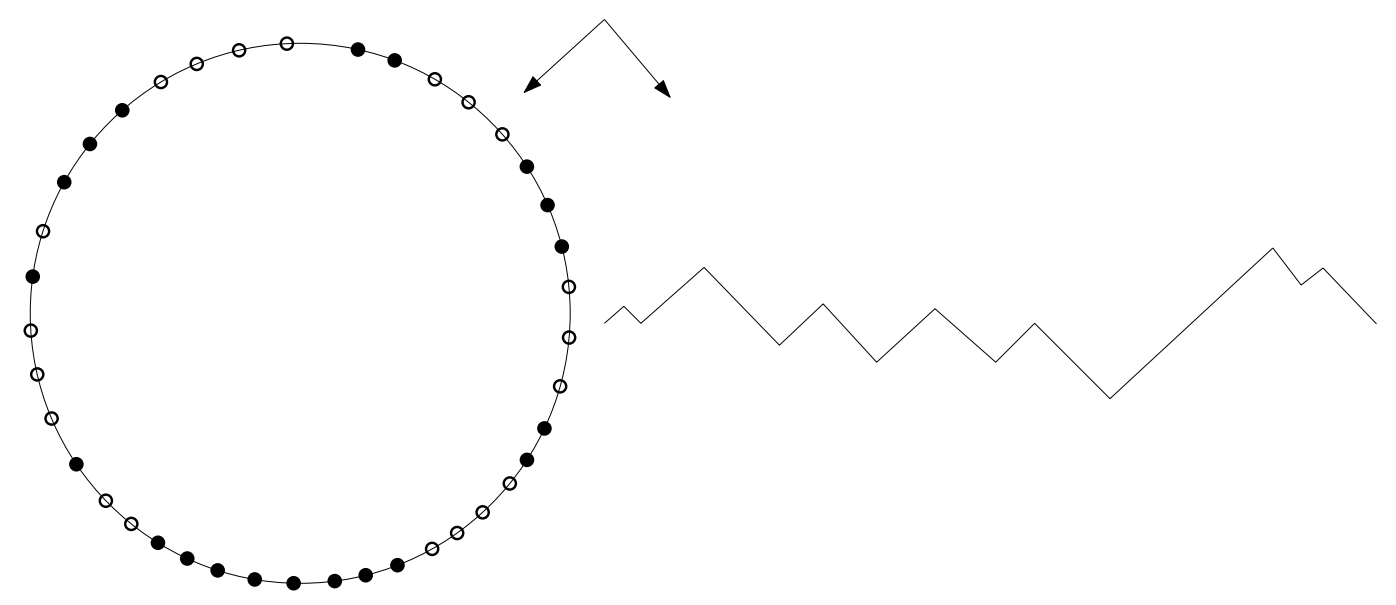

Figure 1.1: How to code $\mathcal{P}$ as a Dyck path

get a separated matching $M$ with alt $(M) \leq 1$ (there might be an alternation in color at the place where we attach the two matchings). Simple calculation gives that outside the two matched intervals there are at least $n-s$ red and $n-s$ blue points. Therefore, we can construct a separated matching $M$ of size at least $n+t$.

The essence of the proof of the lower bound in [23] is a clever way to define an $\operatorname{arc} A$, where the red-blue coloring is unbalanced assuming that $\operatorname{run}(\mathcal{P})$ is small. We do the same using a completely different idea and obtain a better result in the following section.

\subsection{Improved lower bound}

The basic idea of our improvement is a simple visualisation/coding of the colored $\mathcal{P}$. The code-diagram will be part of the grid $G$ consisting of the $(x, y)$ points with integer coordinates. We walk along the perimeter making steps from a point to the succeeding one. Depending on the color of the passed point we make a step on the grid $G$. Each step increases the $x$ coordinate by 1 . The change of the $y$ coordinate will code the color of the passed point: if it was red, then the step increases the $y$-coordinate by 1 ; if it was blue, then the step decreases the $y$-coordinate by 1 . We show an example for the coloring and coding on Figure 1.1.

So the height of the walk reflects how the colors are changing. Since we code an equicoloring the walk ends at the level of starting. We can fold our diagram to the surface of a cylinder to obtain a closed walk that reflects 
the circular behaviour of our geometric point set. We call the horizontal line through the lowest point of our diagram the 0-level. We choose our coordinate system in such a way that the 0 -level is the $x$-axis. For a nonnegative integer $h$ the line described by the equation $y=h$ is called $h$-level. Note, the $h$-level and $h^{\prime}$-level are neighboring levels if and only if $\left|h-h^{\prime}\right|=1$.

We cut the closed walk at any point that belongs to the 0-level. This way we obtain a Dyck path (for example see [27]) coding our colored point set. Actually, our code contains all the combinatorial information we need to consider the problem.

Our Dyck path has $2 n$ steps. Each step starts on a level and ends at a neighboring level. Walking through a run (monochromatic arc) our code changes its height monotonicly. Hence, for any $h$ there are at most $\operatorname{run}(\mathcal{P})$ many steps stepping up to the $h$-level and there are at most $\operatorname{run}(\mathcal{P})$ many steps stepping down to the $h$-level. We choose $t$ so that more than $n$ steps are above the $t$-level and $t$ is maximal among the levels with this property. The 0-level has all $2 n$ many steps above it. As we lift the level one by one we decrease the number of "steps above" by at most $2 \cdot \operatorname{run}(\mathcal{P})$. From this it is straightforward to derive that

$$
t \geq\left\lfloor\frac{n-1}{2 \cdot \operatorname{run}(\mathcal{P})}\right\rfloor .
$$

Let $\sigma$ be the $i$-th step of our Dyck path. Let $\sigma^{\prime}$ be the $2 n+1-i$-th step, the symmetric pair of $\sigma$. Note, $t$ is chosen in such a way that we can find a step $\sigma$ above $t$-level with its symmetric pair also above $t$-level. Indeed: if we consider each step below $t$-level and its symmetric pair, we cannot obtain all the steps. Any remaining step is suitable for $\sigma$.

Theorem 6. Let $\mathcal{P}$ be a 2 -element point set in convex position with an equicoloring. There is a separated matching $M$ with alt $(M) \leq 1$ and of size at least

$$
n+\left\lfloor\frac{n-1}{2 \cdot \operatorname{run}(\mathcal{P})}\right\rfloor .
$$

Proof. Let $t$ be the level as above. Let $\sigma$ and $\sigma^{\prime}$ be two symmetric steps of the coded $\mathcal{P}$ above $t$-level. Steps $\sigma$ and $\sigma^{\prime}$ correspond to two points $S$ and $S^{\prime}$ of $\mathcal{P}$. Then $\sigma$ and $\sigma^{\prime}$ define two complementary arcs $A$ and $A^{c}$ in $\mathcal{P}$. Let $F$ and $L$ be the points corresponding to the first and the last step, respectively, of the Dyck path. One of the two arcs, say $A$, contains the point $F$ and hence it contains the point $L$, a neighbor of $F$ on the Dyck path. According to the symmetricity of $\sigma$ and $\sigma^{\prime}, F$ and $L$ are the two middle points of $A$. Hence, $A=a\left(S^{\prime}, L\right) \dot{\cup} a(F, S)$ is the partition of $A$ into two half-arcs. As we 
walk from $F$ to $S$ the coding Dyck path raises from 0-level to above $t$-level. This color coding implies that $|a(F, S) \cap \mathcal{R}|-|a(F, S) \cap \mathcal{B}|>t$. Similarly, $\left|a\left(S^{\prime}, L\right) \cap \mathcal{B}\right|-\left|a\left(S^{\prime}, L\right) \cap \mathcal{R}\right|>t$.

By Observation 5 our claim is true.

The following corollary is immediate.

\section{Corollary 7.}

$$
\ell(n) \geq n-1+\sqrt{\frac{n-1}{2}}=n+\Omega(\sqrt{n}) .
$$

Proof. We know that $\ell(\mathcal{P}) \geq n+\operatorname{run}(\mathcal{P})-1$ and $\ell(\mathcal{P}) \geq n+\left\lfloor\frac{n-1}{2 \cdot \operatorname{run}(\mathcal{P})}\right\rfloor$. Hence, for arbitrary $\mathcal{P}$ we know that the average of the two lower bounds above is also a lower bound. The average of the two bounds is the promised bound by simple arithmetics.

\subsection{Limits of the known methods}

Let us assume that an adversary can fix the initial point of our path in a given $\mathcal{P}$. Erdös' method works in this case and we are guaranteed to find a noncrossing path of length $n$. But in the adversary version of the problem we cannot beat the trivial bound. To see this, devide our points into two complementary arcs of equal length. Points in one of the arcs obtain color red while points on the other arc will be blue. If the initial point is the middle point of the red arc, then the longest noncrossing path has length at most $n+2$.

Our method works more carefully. We code the coloring by a circular Dyck path and choose an arbitrary step starting at 0-level of this code as an initial point. So we narrow the set of possible initial points to the set of minimal points $D$. Assume that an adversary picks one element of $D$ and we are forced to start our path from there. Our lower bound is exhibited by a path starting at the point given by the adversary of length at least $n+\Omega(\sqrt{n})$. By this generous setting we cannot improve the order of magnitude of our lower bound. Consider the following coloring. Let $n=2 k$. Take $k$ red, $k$ blue points and then $\sqrt{k}$ red and $\sqrt{k}$ blue points alternating $\sqrt{k}$ many times on the circle. If the adversary party marks the first point of the red run of length $k$ (this point is beside a blue run of $\sqrt{k}$ points), then the longest noncrossing path has the promised length.

The number of alternations in the matching is bounded by a constant in the lower bounds. In the case of Erdös' bound alt $(M)=0$. In [23] and in our approach alt $(M) \leq 1$ for the constructed matching $M$. If we insist to 
come up with a matching part with constant alternation parameter, then we cannot beat the obvious bound $n$ by more than a constant: take the redblue completely alternating coloring (red, blue, red, blue,... ). If we do the alternation in blocks of length $\sqrt{n}$, then even the side edges cannot help and we cannot improve our lower bound of $n+\Omega(\sqrt{n})$ points.

So the moral of the above remarks is that we must choose the initial point of our path carefully and use a lot of alternations when we consider the matching part of the path. The present techniques are not fulfilling these requirements.

\subsection{New constructions}

In [23] the upper bound was proved by a single construction and by its analysis. There was even a conjecture that this construction and the construction of Abellanas (that is very much alike) are isolated constructions showing the upper bound of order $\frac{4 n}{3}$. We show a different - although - related way to construct a rich family of colored point sets exhibiting the 23] upper bound. We think that these constructions strengthen the belief that the [23] upper bound has the right order of magnitude and might guide the research towards a proof of that.

To describe a colored point set we use the following notation. Let $M_{r \times \ell}$ denote $r$ many consecutive runs altenating in color of length $\ell$. We call a building block of this type $M_{r \times \ell}$ a mixed run. Regarding the notion of run that we introduced before, in the following we usually say homogeneous run to stress that a run is monochromatic. The notations $B_{L}$ and $R_{L}$ denote a blue and a red run of length $L$, respectively. Let $\alpha \in[-1,1]$, and let $\mathcal{P}_{\alpha, \ell}$ be

$$
\begin{aligned}
\mathbf{B}_{\mathbf{2}}=B_{2 L}, \mathbf{R}_{\mathbf{3}} & =R_{(1+\alpha) L}, \mathbf{M}_{\mathbf{1}}=M_{r \times \ell}, \mathbf{R}_{\mathbf{4}}=R_{(1+\alpha) L}, \mathbf{B}_{\mathbf{1}}=B_{2 L} \\
\mathbf{R}_{\mathbf{1}} & =R_{(1-\alpha) L}, \mathbf{M}_{\mathbf{2}}=M_{r^{\prime} \times \ell}, \mathbf{R}_{\mathbf{2}}=R_{(1-\alpha) L}
\end{aligned}
$$

where $\ell$ is arbitrary and $r, r^{\prime}$ satisfy the following equalities $r \ell=(2-2 \alpha) L$ and $r^{\prime} \ell=(2+2 \alpha) L$. Hence, $\mathcal{P}_{\alpha, \ell}$ is an equicolored point set of $2 n=12 L$ points. We assume that $\alpha L$ is an integer. In the case of $\alpha=-1,1$ we get the [23] construction if we set $\ell=\Theta(\sqrt{L})$ (they considered this size in order to have $o(n)$ many runs).

On Figure 1.2 the number of points is proportional to the central angle of the arc. Note, that $M_{1}$ is the shorter among the mixed runs.

We claim that the size of the largest separated matching in $\mathcal{P}_{\alpha, \ell}$ has the same order of magnitude as the construction of [23].

Theorem 8. $m\left(\mathcal{P}_{\alpha, \ell}\right) \leq \frac{4 n}{3}+O(\ell)$. 


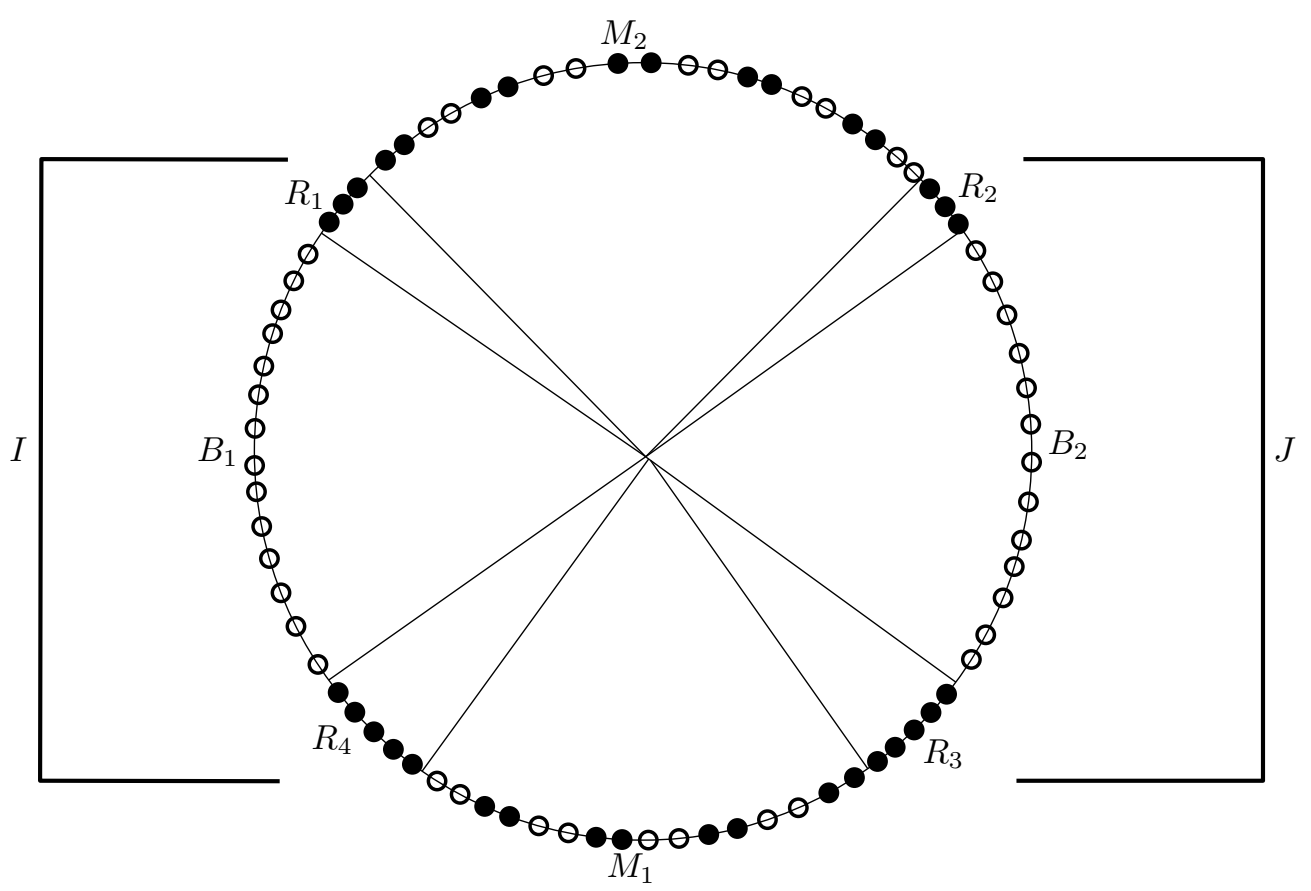

Figure 1.2: The coloring $\mathcal{P}_{\alpha, \ell}$

Proof. Let $M$ be an optimal separated matching on $\mathcal{P}_{\alpha, \ell}$. We assume that the axe of $M$ divides the point set into an upper and a lower side and the matched upper and lower points are ordered from left to right. We can partition the edges of the matching into classes in such a way that on each side (upper, lower) the endpoints belong to one run or one mixed run:

$$
M=e_{1}, e_{2}, \ldots e_{i_{1}}\left|e_{i_{1}+1}, \ldots e_{i_{2}}\right| \ldots \mid e_{i_{s}} \ldots e_{|M|} .
$$

In each block the upper endpoints of the matching come from the same run, similarly the lower endpoints do so as well. We consider the mixed runs as a periodic repetition of $M_{2 \times \ell}$. We will assume that no period of a mixed run contains two points that are matched in different blocks of $M$. To have this property, we might have to throw away $O(\ell)$ many edges from $M$ but this does not harm the claim of the Theorem. To do this initial decomposition of $M$, we need to have at most constant many blocks (here we have at most 9 ). It is useful to make the following straightforward observations.

Observation A If a mixed run is matched to a homogeneous run, at most half of the points will be matched in the mixed run.

Observation $\mathrm{B}$ If we have six points $P_{1}, P_{2}, P_{3}, P_{4}, P_{5}, P_{6}$ on $C$ in this order, then all three edges $\left[P_{1} P_{2}\right],\left[P_{3} P_{4}\right]$ and $\left[P_{5} P_{6}\right]$ cannot participate in a 
separated matching.

We intruduce two special arcs on $C$. Let $I=R_{4} \cup B_{1} \cup R_{1}$ and $J=R_{2} \cup B_{2} \cup R_{3}$, see Figure 1.2. We will consider a few different cases based on the edges of the separated matching.

1st case: There is no edge in $M$ that connects $I$ and $J$.

We define an arc $\widetilde{M}_{1}$ in $M_{2}$ such that $\widetilde{M}_{1}$ is of length $(2-2 \alpha) L$ and consists of full periods. If there is an edge in $M$ between $M_{1}$ and $M_{2}$, let $\widetilde{M}_{1}$ be an arc with the above properties that includes an endpoint of each edge between $M_{1}$ and $M_{2}$. As $M$ is optimal if there are two edges $e$ and $f$ connecting $M_{1}$ and $M_{2}$, we may assume that all points are matched between $e$ and $f$.

If there is no edge in $M$ connecting $M_{1}$ and $M_{2}$, we consider two cases. If there are two consecutive edges $e$ and $f$ with an endpoint in $M_{2}$ say on the upper side, such that $e$ has its other endpoint on $I \cup M_{2}$ and $f$ has its other endpoint on $J \cup M_{2}$, then we define $\widetilde{M}_{1}$ to contain a point from the arc of $M_{2}$ determined by the endpoints of $e$ and $f$ on the upper side.

If no edges like $e$ and $f$ exist, then as a consequence of Observations A and $\mathrm{B}$ there are at most $8 L=\frac{4 n}{3}$ points in $M$. In this case we are done.

Delete all edges from $M$ that include points of $M_{1} \cup \widetilde{M}_{1}$ and add a perfect matching between $M_{1}$ and $\widetilde{M}_{1}$. Our modification leads to a separated matching which we denote by $M^{\prime}$. Observe, the size of $M^{\prime}$ is at least the size of $M$. This follows by considering the decomposition of $M$ into blocks and by Observation A. Hence, in $M^{\prime}$ the points of $M_{1}$ and $\widetilde{M}_{1}$ will substitute the possible deleted points from $M$. By Observation B an easy calculation gives that the size of $M^{\prime}$ is at most $2(2-2 \alpha) L+2(1+\alpha) L+2(1+\alpha) L=8 L=\frac{4 n}{3}$. 2nd case: There is an edge in $M$ that connects $I$ and $J$.

We modify $M$ in the following way. We match $M_{1}$ fully to itself and $M_{2}$ as well. Then we add all edges of $M$ that connect $I$ to $J$. Observe, we get a separated matching $M^{\prime}$.

The set of edges connecting $I$ to $J$ divide all other edges of $M$ into two groups: egdes to the left, edges to the right. If to the left/right there is no edge in $M$ with both endpoints in $I$ or in $J$, then by Observation A the number of points in $M$ is obviously at most the number of points of $M_{i}$ to the left/right, respectively.

Suppose there is an edge within $I$ or $J$. Note, by Observation B there cannot be an edge within each of $I$ and $J$ to the left/right, respectively. Therefore, we may assume the edge is in $I$ and it is to the left (similar arguments hold in the other cases). By Observation B there is no edge from $M_{i}$ to $J$ nor any edge within $M_{i}$ where $M_{i}$ lies to the left of edges connecting $I$ and $J$. During the modification of $M$ the edges within $I$ were discarded. 
Take as many blue endpoints of the disregarded edges as $|M|-\left|M^{\prime}\right|$. Basic computing arguments show that these endpoints can be matched to $J$ (more precisely to $R_{i}$ that is neighboring to $M_{i}$ ). We add these additional edges to $M^{\prime}$.

A simple calculation gives that the size of $M^{\prime}$ is at most $(2+2 \alpha) L+(2-$ $2 \alpha) L+4 L=8 L=\frac{4 n}{3}$.

If we want to restrict the length of the longest noncrossing path we need to restrict the number of runs, too.

Observation 9. If $\ell=\Theta(\sqrt{n})$, then $\ell\left(\mathcal{P}_{\alpha, \ell}\right)=\frac{4 n}{3}+O(\sqrt{n})$.

Proof. In any path we can distinguish a separated matching and side edges connected in a suitable way. The size of the maximum separated matching is $\frac{4 n}{3}+O(\sqrt{n})$ by Theorem 8 . As the number of side edges is restricted to $O(\sqrt{n})$, we showed the desired bound.

The construction $\mathcal{P}_{\alpha, \ell}$ was found independently by Jan Kynčl [22] using computer search.

\subsection{Further questions}

Several directions of research remain open in the area. First of all we mention the main conjecture regarding alternating paths.

Conjecture. Every equicolored convex point set of $2 n$ points admits an alternating path of $\frac{4 n}{3}+o(n)$ points.

Our results emphasize the importance of the following conjecture.

Conjecture. ([23]) For any fixed $k$ and large $n$, every equicoloring of $2 n$ points admits a separated matching of size at least $2 n \frac{2 k-1}{3 k-2}+o(n)$ where $k$ is the run parameter of the point set.

The class of constructions that we gave in the previous section shows that the order of magnitude claimed above is feasible. 


\section{Chapter 2}

\section{Separated Matchings in Colored Convex Sets}

\section{$2.1 \quad$ Introduction}

So far we were considering alternating paths although in our methods separated matchings already appeared. Noncrossing, alternating paths and separated matchings are closely related to each other. Observation 1. and Observation 3. underline the importance of separated matchings. For the sake of completeness we repeat the definition of this notion: a separated matching is matching where edges do not intersect geometrically and there is a line that crosses all the edges.

The cited two observations imply that if the run parameter is $o(n)$, then the length of the longest noncrossing, alternating path is basically the same as the size of the maximum separated matching. In this chapter we only consider the problem of separated matchings for convex sets.

Formally:

$$
m(\mathcal{P})=\max _{M \text { is a separated matching in } \mathcal{P}} \operatorname{size}(M),
$$

where size $(M)$ is the number of points in $M$.

$$
m(n)=\min _{\mathcal{P} \text { is equicolored }} m(\mathcal{P}),
$$

where $\mathcal{P}$ is any colored planar $2 n$-element convex point set.

In this chapter we exhibit a new class of configurations allowing at most $\frac{4}{3} n+O(\sqrt{n})$ points in any separated matching. This class of configurations significantly differs from all known previous constructions. It contains arbitrary many intervals of alternating short monochromatic arcs which contrasts 
with the 23 construction containing one such interval and also with the construction in the first chapter containing two such intervals. We also present a type of coloring such that among these colorings in the optimal one any separated matching contains at most $\frac{4}{3} n+O(\sqrt{n})$ points.

An advantage of separated matchings is that we may consider point sets with low discrepancy. If we restrict the discrepancy (that is, the maximum difference in cardinality of color classes on any interval), we obtain an interesting result. For discrepancies two and three we prove that there are at least $\frac{4}{3} n$ points in the maximum separated matching [25]. So far no one was concerned with discrepancy since low discrepancy means many alternations among the two colors. If the run parameter is large that alone guarantees a long noncrossing, alternating path as a result of Observation 2. However, when we consider separated matchings, it is reasonable to investigate this case. We believe it might shed light on the difficulties of the original Erdös problem.

\section{$2.2 \quad$ Notations}

We introduce some basic definitions that are necessary to describe the constructions and that we use throughout the proofs.

Let our $2 n$-element equicolored convex point set be denoted by $P$. We may assume without loss of generality that our points are on the circle $C$. An arc is an interval of points on $C \cap P$. The size of an arc is the number of its elements. In an arc the points are ordered, we always read the order in clockwise direction. A run is a maximal set of consecutive points on $C$ of the same color. The length of the run is the number of its elements.

A matching is a set of pairwise disjoint edges. Note, that the notion of matching is meant in geometrical sense, that is, no two edges cross in it. The size of a matching is defined as the total number of points participating in it, which is twice the number of edges. A separated matching is a matching where all edges can be crossed by a line.

This crossing yields a natural ordering of the edges of the matching. Separated matchings are closely related to noncrossing, alternating paths. Observe, that for every separated matching $S$ on a convex point set, there is a noncrossing, alternating path $R$ such that the vertex set of $R$ coincides with the vertex set of $S$ and all edges of $S$ are contained in $R$. We construct $R$ in the following way. The edges of $S$ will follow each other on $R$ in their natural ordering. Hence, every other edge of $R$ will belong to $S$. The remaining edges of $R$ will connect differently colored endpoints of consecutive edges of $S$. As a consequence of the properties of the separated matching we can always 


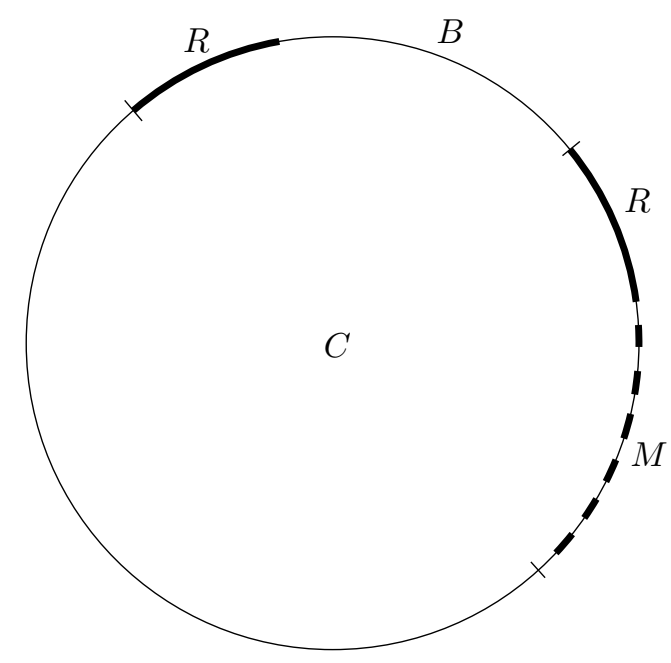

Figure 2.1: Two types of blocks

draw a noncrossing, alternating path $R$ in this way. We remark that $R$ is not unique. For every $S$ exactly two such paths exist depending on it which color will be chosen to be the color of the starting point of $R$.

The previous configurations contained long runs colored red or blue and at most two arcs consisting of alternating short runs of the two colors. Our class contains arbitrary many arcs of alternating short runs. The idea originates from the Kynčl-Pach-Tóth construction. We cut that construction into two pieces. We repeat the two pieces in arbitrary order an equal number of times along the circle.

We introduce some special arcs called blocks. They will be the building elements of our constructions. The first two types of blocks will be of the same size but they will contain a different number of points of the two color classes. However, altogether the number of red and blue points will be equal on the union of two blocks of different types. In the first two types of blocks the common size of blocks will be $3 s$. The bluish block will consist of a red run of length $s$ and a blue run of length $2 s$. We denote the bluish block by $(s, 2 s)$ block. The reddish block will consist of a red run of length $s$ followed by a mixed arc $M$. The mixed arc $M$ consists of $2 s$ points alternating in color, see Figure 2.1. Hence the reddish block will contain $2 s$ red and $s$ blue points. We denote the reddish block by $(s, s(1,1))$ block.

If needed we introduce notations $R$ and $B$ for red runs of size $s$, and for blue runs of size $2 s$, respectively. We call $R, B$ and $M$ subblocks as they are the main building elements of blocks.

An $(a s, b s)$ block consists of a red run of as points and a blue run of $b s$ 
points. An $s(b, a)$ block consists of a red run of length $b$ followed by a blue run of length $a$ and this $a+b$ colored points are repeated $s$ many times. Consequently, an $s(b, a)$ block consists of $s$ consecutive arcs of size $a+b$ of the same coloring pattern. We call the unit of this pattern of $a+b$ points a period. Specifically, an $s(2,1)$ block consists of the triple of two red and one blue point repeated $s$ many times. The period is two red points followed by a blue point.

We say that the discrepancy is $d$ if on any interval on the circle $C$ the difference between the cardinality of color classes is at most $d$. We will investigate the case of low discrepancy.

We say that an $\operatorname{arc} A$ faces $\operatorname{arcs} A_{1}, A_{2}, \ldots, A_{n}$ if all vertices of $A$ that participate in the separated matching $S$ have their pair in $S$ on one of the $\operatorname{arcs} A_{1}, A_{2}, \ldots, A_{n}$.

\subsection{Constructions and theorems}

We will describe two main constructions and then we give another one by generalizing one of them.

The first construction is $C_{1}(s, t)$ : Take $t$ consecutive $(s, 2 s)$ blocks on $C$ followed by $t$ many $s(2,1)$ blocks. Each block has size $3 s$. Of course the last $t$ many blocks can be considered as one st $(2,1)$ block.

The second construction is $C_{1}^{+}(a, b, s, t)$ : In $C_{1}(s, t)$ instead of $(s, 2 s)$ blocks we take $(a s, b s)$ blocks and instead of the $s$ triples we take $s(b, a)$ blocks. Note that $C_{1}{ }^{+}(1,2, s, t)=C_{1}(s, t)$. Each block has size $(a+b) s$.

The third construction is a class of coloring $\mathcal{C}_{2}(s, t)$ : Take $t$ many $(s, 2 s)$ blocks and $t$ many $(s, s(1,1))$ blocks in arbitrary order along $C$. In other words, the same number of bluish and reddish blocks are placed along the circle in an arbitrary order.

Theorem 10. In $C_{1}(s, t)$ the size of every separated matching is at most $\frac{4}{3} n+O(s+t)$.

The upper bound is optimal if we disregard the remainder term. To see it, let us construct the following separated matching. If we match the blue points of the first $t$ blocks (the bluish ones) to the red points of the last $t$ many blocks ( $s$ many reddish triples), then we obtain a separated matching of size $\frac{4}{3} n$.

Theorem 11. In $C_{1}{ }^{+}(a, b, s, t)$ the ratio of the size of the largest separated matching to the total number of points is

$$
\max \left\{\frac{2 \min \{a, b\}}{a+b}, \frac{\max \{a, b\}}{a+b}\right\}+O\left(\frac{(a+b)(s+t)}{n}\right) .
$$


It follows that the order of magnitude of the size of the largest separated matching is at least $\frac{4}{3} n$. Equality occurs when $\max \{a, b\}=2 \min \{a, b\}$. So $C_{1}(s, t)$ is optimal among $C_{1}{ }^{+}(a, b, s, t)$.

Theorem 12. Let $C_{2}$ be any coloring from $\mathcal{C}_{2}(s, t)$. Then the size of every separated matching in $C_{2}$ is at most $\frac{4}{3} n+O(s+t)$.

Theorem 13. Let $C_{3}$ be that coloring from $\mathcal{C}_{2}(1000, t)$ where the reddish and bluish blocks alternate. Then size of the largest separated matching in $C_{3}$ is at least $1.34 n$.

Note, that we refer to the $O(s+t)$ as remainder term. If $a$ and $b$ are constants, then we may do the following. Since $s \cdot t=O(n)$, we can choose $s$ and $t$ so that $s, t=O(\sqrt{n})$ and the order of magnitude of $O(s+t)$ becomes negligible. This is how the reader should think about the first three theorems.

The fourth theorem is an exception, there we choose a setting where $s$ is a large constant and $t$ is $\epsilon \cdot n$. So $O(s+t)$ is very small but not negligible. The reason for choosing such a setting is that in $C_{3}$ the discrepancy of the coloring is constant (2000). At the same time the size of the optimal matching is very close to the conjectured value. In the fifth section we finish the chapter with a few claims on coloring with low discrepancy.

\subsection{Proofs}

Take any separated matching $S$ in a coloring of $C$ from one of our theorems. Let line $l$ be the axe, that is, a line that crosses all members of $S$. We think of $l$ as a horizontal line deviding $C$ into an upper and lower part. We can assume that both the upper and lower part of $C$ consist of whole blocks by disregarding at most $O(s)$ edges of $S$. In case $a$ and $b$ are not constants, then we discard at most $O((a+b) s)$ edges.

The edges of the matching can be ordered according to their intersection with $l$. We can partition the edges of $S$ into classes in such a way that on each side (upper, lower) the endpoints belong to one subblock. The previous partition determines $O(t)$ pairs of arcs facing each other on $C$. Furthermore, if an arc $A$ determined by the partition belongs to a mixed subblock, then we achieve that $A$ contains complete periods. This can be done by removing at most $O(t)$ many edges. If the choice for $a$ and $b$ are not constants, then the previous disregarding affects at most $O((a+b) t)$ edges.

Let $S_{0}$ be the remainder of $S$. We call it the normalized matching. To prove the upper bounds of our theorems without loss of generality we may assume that we work with an arbitrary normalized matching. 
Proof of Theorem 10: We will show that the ratio of points in $S_{0}$ to all $2 n$ points on $C$ is at most $\frac{2}{3}$. Thanks to the simple structure of $C_{1}$ we partition the elements of the normalized matching $S_{0}$ into three classes. The first class contains edges with both endpoints in $(s, 2 s)$ blocks. Edges with one endpoint in an $(s, 2 s)$ block and the other endpoint in an $s(2,1)$ block belong to the second class. The remaining edges with both endpoints in $s(2,1)$ blocks we put in the third class. Note, some classes may be empty here. We can assume that borderlines between classes preserve complete blocks.

In the first and in the third class at most $\frac{2}{3}$ of the vertices are in $S_{0}$ because in both types of blocks $\frac{1}{3}$ of the points is of one color and $\frac{2}{3}$ is of the other color.

In the second class assume there are $L$ many $(s, 2 s)$ blocks facing a mixed coloring with period $(2,1)$. Let $x$ denote the ratio of matched points in the red subblocks to the total number of points in the red subblocks. Let $y$ be the same considering the blue subblocks. Hence, $x \cdot(L \cdot s)$ points are matched out of the $L \cdot s$ red points and $y \cdot(L \cdot 2 s)$ points are matched out of the $L \cdot 2 s$ blue points. The pairs of the $x \cdot(L \cdot s)$ red points in $S_{0}$ are blue points in the $(2,1)$-periodic part. Hence, these pairs are contained in at least $x \cdot(L \cdot s)$ many periods. Similarly, the pairs of $y \cdot(L \cdot 2 s)$ blue points come from $y \cdot(L \cdot 2 s) / 2$ many periods (each period contains 2 red points). To prove the upper bound we can assume that the whole point set is the $L(s, 2 s)$ blocks facing $x \cdot(L \cdot s)+y \cdot(L \cdot 2 s) / 2$ many periods. Hence, its size equals $3 L s+3 x L s+3 y L s$. The number of matched points is $2[x \cdot(L \cdot s)+y \cdot(L \cdot 2 s)]$. Their ratio is

$$
\frac{2 x L s+4 y L s}{3 L s+3 x L s+3 y L s}=\frac{2}{3} \cdot \frac{x+2 y}{1+x+y} \leq \frac{2}{3} \cdot \frac{x+2 y}{x+2 y}=\frac{2}{3} .
$$

This completes the proof of Theorem 10 .

Proof of Theorem 11: Estimating the upper bound is the same as above with a small technical difficulty. We analogously partion $S_{0}$ into three classes. We can bound the ratio of the number of matched points to the total number of points in each of the classes. In the case of edges from the first and third class the upper bound is

$$
\frac{2 \min \{a, b\}}{a+b} .
$$

In the case of edges from the second class the ratio is bounded above by

$$
f(x, y)=\frac{2}{a+b} \cdot \frac{a x+b y}{1+x+y} .
$$


It is not hard to see that $f(x, y)$ is a quasiconvex function over the $[0,1] \times[0,1]$ domain, that is, its sublevel sets

$$
S_{\alpha}=\{(x, y) \in[0,1] \times[0,1]: f(x, y) \leq \alpha\}
$$

are convex for all $\alpha$. So its maximum is attained in one of the vertices of its square domain:

$$
\begin{aligned}
f(x, y) & \leq \max \{f(0,0), f(0,1), f(1,0), f(1,1)\}=\max \left\{0, \frac{b}{a+b}, \frac{a}{a+b}, \frac{2}{3}\right\}= \\
& =\max \left\{\frac{\max \{a, b\}}{a+b}, \frac{2}{3}\right\} .
\end{aligned}
$$

The overall ratio can be bounded by

$$
\max \left\{\frac{2 \min \{a, b\}}{a+b}, \frac{\max \{a, b\}}{a+b}, \frac{2}{3}\right\}=\max \left\{\frac{2 \min \{a, b\}}{a+b}, \frac{\max \{a, b\}}{a+b}\right\} .
$$

The final equality is straightforward to check.

Finally, we claim that the upper bound is optimal. To see that we construct two matchings. We can assume that $a \leq b$. In the first matching the blue points from $t(a s, b s)$ will be matched with the red points from $t s(b, a)$. There will be $b s$ points matched in each block. The corresponding ratio is $\frac{b}{a+b}$. In the second matching the same types of blocks will be faced to each other. We pair up the half of the $(a s, b s)$ blocks with the other half of $(a s, b s)$ blocks. The matching will go between the pairs of blocks. The red subblock in a block will be matched to the blue subblock in its pair, and vice versa. Thus, in each block we can match 2 as points. We can do the same inside the $s(b, a)$ blocks considering the periods in the same way as subblocks above. The corresponding ratio is $\frac{2 a}{a+b}$.

This completes the proof of Theorem 11

Proof of Theorem 12: Take a maximal normalized separated matching $S_{0}$ on $C_{2}$ (an arbitray member of $\mathcal{C}_{2}(s, t)$ ). We will show that the size of $S_{0}$ is at most $\frac{4}{3} n$.

In each block the ratio between the color classes is $2: 1$. Hence, in each block we may call points of the major and the minor color class major and minor points, respectively. The number of minor points on $C_{2}$ is $\frac{2 n}{3}$. Our proof will be an assignment: to each edge of $S_{0}$ we injectively assign a minor point. When we assign the point $p$ to edge $e$, we say mark $p$ for $e$.

If one endpoint of an edge $e$ is minor point and the other endpoint is major point, then mark the minor point for $e$. If both endpoints of $e$ are 
minor points, then mark the blue endpoint for $e$. Note, in this case the blue endpoint is in a mixed $M$ subblock. Non-marked minor points give the set of free vertices. Observe, the set of free vertices is changing during the procedure of marking new points.

If both endpoints of $e$ are major points, we distinguish two cases. If the major red point is in a mixed subblock, then we mark for $e$ the free blue point that is in the same period with the red endpoint of $e$. Otherwise, we call $e$ a bad edge. Note, in this case one endpoint of $e$ is in a blue $B$ subblock and the other endpoint of $e$ is in a red $R$ subblock which is in an $(s, s(1,1))$ block. Bad edges are grouped according to blue subblocks. We can assume that $B$ is on the upper side of $l$. Take a blue subblock $B$ and consider the bad edges incident to it. Let $R$ be the red subblock pair of $B$, that is, $R$ and $B$ form a block together. We distinguish different cases.

Case 1: Subblock $R$ contains only free vertices. Let $k$ denote the number of bad edges incident to $B$. If the red endpoints of the $k$ bad edges are in the same red subblock, then $k \leq s$ and we can mark different elements of $R$ for each of the bad edges.

If the red endpoints come from different subblocks (of reddish blocks), then consider the mixed subblock $M$ in the block of the rightmost bad edge's lower endpoint. Let $j$ be the number of vertices matched in $M$. Consequently, we have $s-j$ free vertices in $M$ and $s$ free vertices in $R$, altogether $2 s-j$ free vertices. As $k+j \leq 2 s$, we get $k \leq 2 s-j$ as desired. Hence, we can mark a different free vertex for each bad edge in $B$.

Case 2: There is a non-free vertex in $R$. Let this non-free vertex be incident to edge $e$. Let $B^{\prime}$ be the blue subblock of the low endpoint of $e$ and $R^{\prime}$ the red subblock pair of $B^{\prime}$, see Figure 2.2, Let $k, M$ and $j$ be defined as previously. Let $m$ be the number of vertices matched in $R^{\prime}$. Therefore, the number of free vertices is $s-j$ on $M$ and $s-m$ on $R^{\prime}$ which gives $2 s-j-m$ free vertices altogether.

If $m>0$ or no vertex in $M$ is matched to a vertex in $R$, then $j+k+m \leq 2 s$, it follows that $k \leq 2 s-j-m$ as desired. Hence, we can mark a different free vertex for each bad edge incident to $B$.

If $m=0$ and there is a vertex in $M$ matched to a vertex in $R$, then $k \leq s$. In this case mark different vertices of $R^{\prime}$ for each bad edge incident to $B$.

For each blue subblock $B$ we marked free vertices in the subblock pair of $B$ or in a subblock which was facing $B$ (that is, these points were in $R$, or in $M$ in case $M$ was facing $B$, or in $R^{\prime}$ which necessarily faced $B$ ). Therefore, for each blue subblock the set of the possible free vertices was well defined and disjoint of the set of free vertices for any other blue subblock.

This completes the proof of Theorem 12 . 


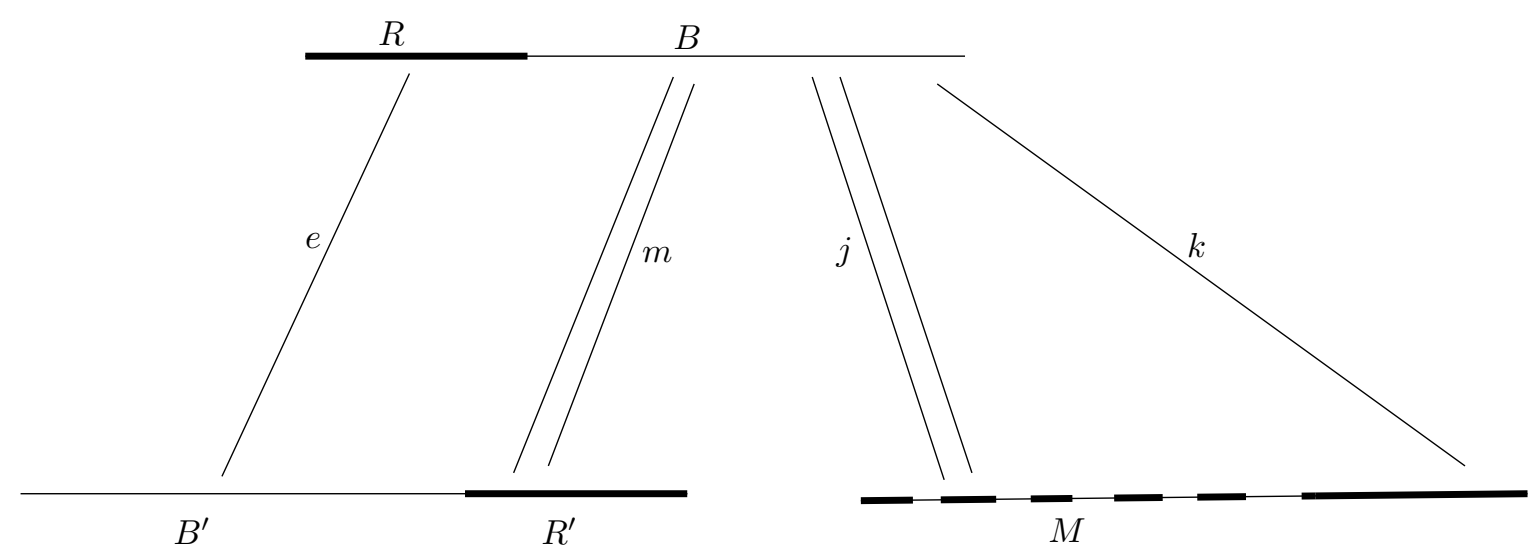

Figure 2.2: Case 2

Proof of Theorem 13: This is a special case of Theorem 12. The constants in front of $s$ and $t$ are small as a consequence of the number of disregarded edges in the normalization procedure. The claim of the theorem is immediate.

Although our goal is to investigate seperated matchings, we mention that if the choices for $a$ and $b$ in $C_{1}^{+}(a, b, s, t)$ are not constants, then for suitable choice we can achieve that the run parameter of the coloring is $o(n)$ and at the same time the remainder term is $o(n)$, too. So we also gain new constructions for colored point set with short alternating paths.

\subsection{Low discrepancy}

When the discrepancy $d$ is rather small we found the following lower bounds for the size of the maximum separated matching. For $d=1$ the coloring is alternating, hence all $2 n$ points participate in the maximum separated matching.

The case of discrepancy at most 2 is little bit more technical.

Theorem 14. For any coloring with dicrepancy $d=2$ there is a separated matching of size at least $\frac{4 n}{3}$.

Proof. We describe a new way how to visualize the colored point set: we introduce for each red point a unit up line segment and for each blue point a unit down line segment. This corresponds to the drawing scheme in [17]. (When the discrepancy is 1, then these up and down segments alternate.) 


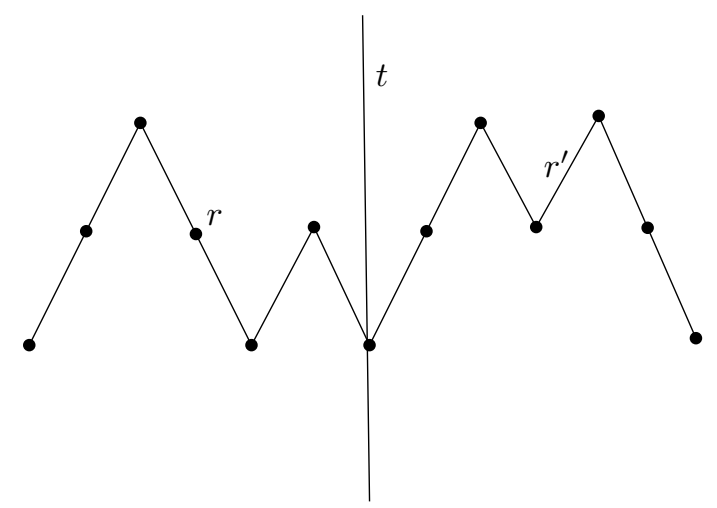

Figure 2.3: Discrepancy 2: At most $\frac{1}{3}$ of all the points can be lost.

Actually, we will not choose a good axe. We can be given any axe that halves the number of runs and we will construct the separated matching of the desired size.

Since $d=2$, there will be two types of runs: runs of length 1 and runs of length 2. Consequently, there will be at most two up and at most two down segments in each run, see Figure 2.3. Let us take a drawing for any case of $d=2$ and halve the number of runs by taking an axe $t$. Then we pair up all the runs. The run $r$ will have pair run $r^{\prime}$ if $r$ and $r^{\prime}$ are on different sides of $t$ but for the same distance to $t$ regarding the number of runs. We make the separated matching $S$ so that each run will face only its pair. All runs of length 1 will be fully covered in $S$. Consider the runs of length 2 . If a run $r$ of length 2 faces a run $r^{\prime}$ of length 1 , then $\frac{2}{3}$ of the vertices of $r$ and $r^{\prime}$ will be in $S$. Otherwise, the run $r$ is also fully covered in $S$. Hence, there exists a separated matching of size at least $\frac{4 n}{3}$.

For $d=3$ we have the same result.

Theorem 15. For any coloring with $d=3$ there is a separated matching of size at least $\frac{4 n}{3}$.

The proof of this theorem is similar to the previous proof. Unfortunately, we need a more sophisticated pairing for runs. We do not give the full case analysis. We only give the pictures of the cases: the left and right hand side of the picture correspond to intervals of the colored point set that will be faced to each other. We always face one specific side to the other side where we mark the ratio of points that can be matched on the considered intervals, see Figure 2.4, Figure 2.5 and further pictures below. Some of the endpoints can vary on the sides and in that case we put the corresponding ratios to the 

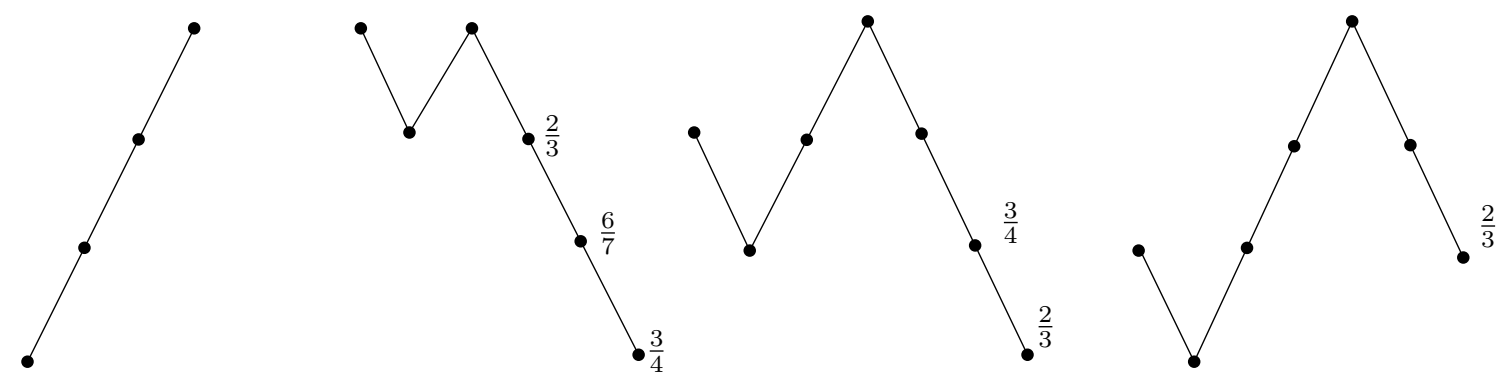

Figure 2.4: The arc of three red points on the left faces the three arcs on the right, respectively. The number at a vertex on the right side shows the ratio of matched points in case the corresponding point is an endpoint of its run.
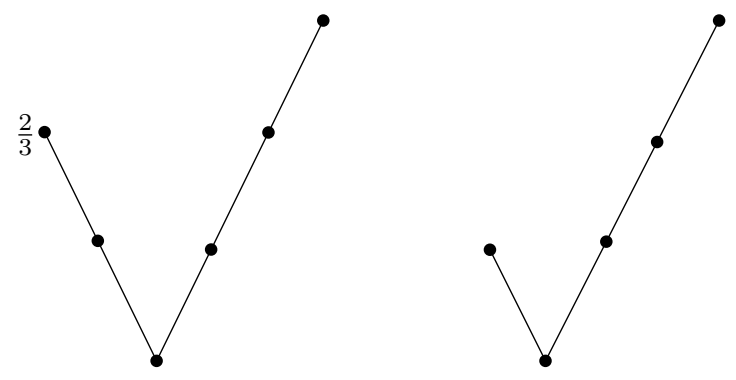

Figure 2.5: The right arc faces the left arc.

alternate endpoints. On Figure 2.4 we merge more cases. There the left side contains a sigle interval while the right side contains three intervals. We face the left side to the intervals on the right, respectively.

Note that the number of points altogether on the two intervals that face each other in the case analysis is at most 14 . Observe, the sketch of the case analysis on the pictures. 

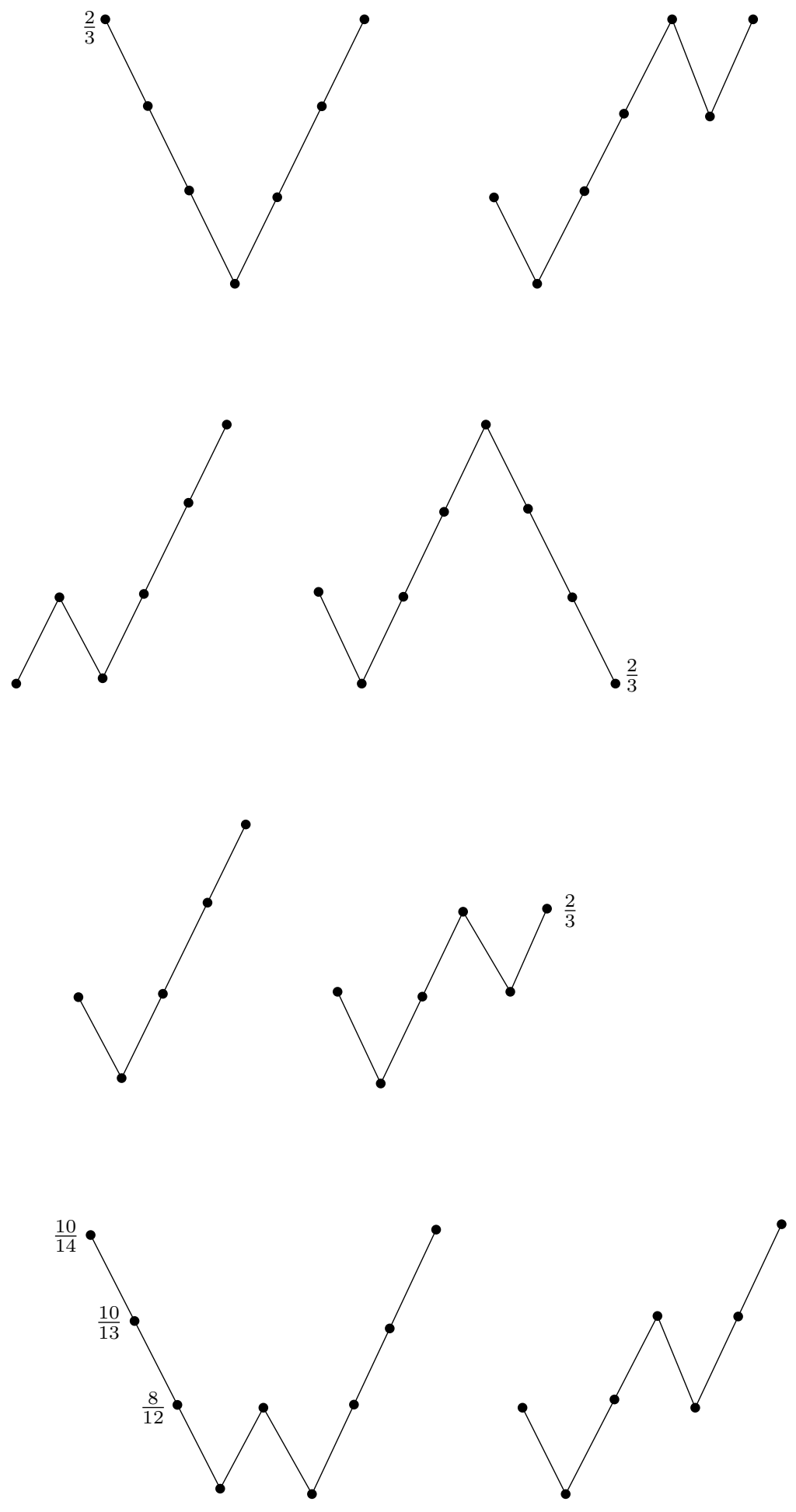

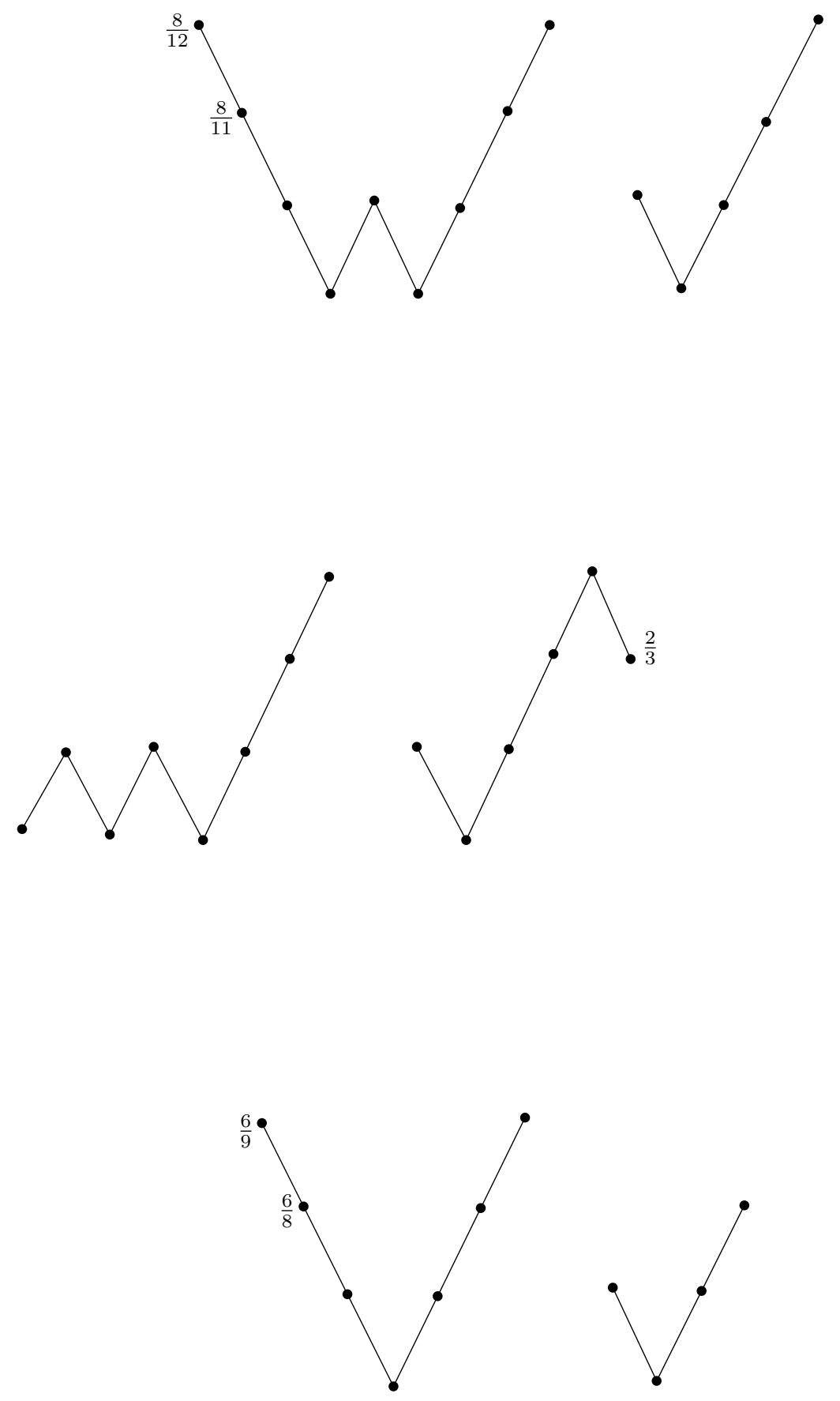


\subsection{Open problems}

Our results call the attention to the following conjecture which is a more appealing consequence of the Kynčl-Pach-Tóth conjecture.

Conjecture.[17] Every equicoloring of $2 n$ points in convex position admits a separated matching of size $\frac{4}{3} n+o(n)$.

The constructions presented in this chapter suggest that even the $O(\sqrt{n})$ remainder term is feasible. At the same time they show that the order of magnitude claimed above is the best possible.

It would be an interesting result to settle it in the affarmative. That would also prove the conjecture on alternating paths. 


\section{Chapter 3}

\section{Hamiltonian Alternating Paths on Bicolored Double-Chains}

\subsection{Introduction}

In this chapter we find arbitrarily large "universal" sets for which any equitable 2-coloring admits a noncrossing, alternating Hamiltonian path. We prove the "universality" for so-called double-chains with each chain containing at least one fifth of all the points. Double-chains were first considered in [12. In the previous chapters we investigated only point sets with an even number of points. Here we will allow that the sizes of the color classes differ by at most one.

A convex or a concave chain is a finite set of points in the plane lying on the graph of a strictly convex or a strictly concave function, respectively. A double-chain $\left(C_{1}, C_{2}\right)$ consists of a convex chain $C_{1}$ and a concave chain $C_{2}$ such that each point of $C_{2}$ lies strictly below every line determined by $C_{1}$ and similarly, each point of $C_{1}$ lies strictly above every line determined by $C_{2}$ (see Fig. 3.1). Note that we allow different sizes of the chains $C_{1}$ and $C_{2}$. Let $\left(C_{1}, C_{2}\right)$ be a double-chain, and let $p_{1}, p_{2}, \ldots, p_{k} \in C_{1} \cup C_{2}$ be distinct

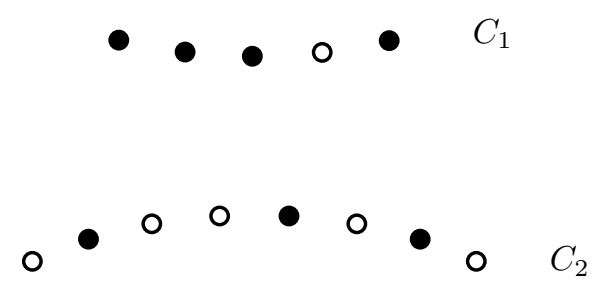

Figure 3.1: An equitably 2-colored double-chain $\left(C_{1}, C_{2}\right)$ 
points of $C_{1} \cup C_{2}$. The polygonal line $p_{1} p_{2} \ldots p_{k}$ consisting of the $k-1$ straight line segments $p_{1} p_{2}, p_{2} p_{3}, \ldots, p_{k-1} p_{k}$ is shortly called the path $p_{1} p_{2} \ldots p_{k}$. The path $p_{1} p_{2} \ldots p_{k}$ is noncrossing if any two non-consecutive segments in it are disjoint. The path $p_{1} p_{2} \ldots p_{k}$ is Hamiltonian (for the double-chain $\left(C_{1}, C_{2}\right)$ ) if it visits all the points of $C_{1} \cup C_{2}$ (that is, $k=\left|C_{1}\right|+\left|C_{2}\right|$ ).

Suppose that the points of a double-chain $\left(C_{1}, C_{2}\right)$ are colored by two colors. Then a path $p_{1} p_{2} \ldots p_{k}$ is alternating if the endpoints of each segment are colored by different colors. A path on $C_{1} \cup C_{2}$ is a good path if it is noncrossing, Hamiltonian and alternating.

An equitable 2-coloring of a double-chain $\left(C_{1}, C_{2}\right)$ is a coloring of $C_{1} \cup C_{2}$ by two colors such that the sizes of the color classes differ by at most one. We use red and blue as the colors in the colorings. Here is our main result:

Theorem 16. Let $\left(C_{1}, C_{2}\right)$ be a double-chain whose points are colored by an equitable 2-coloring, and let $\left|C_{i}\right| \geq 1 / 5\left(\left|C_{1}\right|+\left|C_{2}\right|\right)$ for $i=1,2$. Then $\left(C_{1}, C_{2}\right)$ has a good path. Moreover, a good path on $\left(C_{1}, C_{2}\right)$ can be found in linear time.

On the other hand, we show that double-chains with highly unbalanced sizes of chains do not admit a good path for some equitable 2-colorings:

Theorem 17. Let $\left(C_{1}, C_{2}\right)$ be a double-chain whose points are colored by an equitable 2-coloring, and let $C_{1}$ be periodic with the following period of length 16: 2 red, 4 blue, 6 red and 4 blue points. If $\left|C_{1}\right| \geq 28\left(\left|C_{2}\right|+1\right)$, then $\left(C_{1}, C_{2}\right)$ has no good path.

\subsection{Proof of Theorem 16}

The main idea of our proof is to cover the chains $C_{i}$ by a special type of pairwise noncrossing paths, so-called hedgehogs, and then to connect these hedgehogs into a good path by adding some edges between $C_{1}$ and $C_{2}$.

\subsubsection{Notation used in the proof}

For $i=1,2$, let $b_{i}$ be the number of red points of $C_{i}$ and let $w_{i}:=\left|C_{i}\right|-b_{i}$ denote the number of blue points of $C_{i}$.

Since the coloring is equitable, we may assume that $b_{1} \geq w_{1}$ and $w_{2} \geq b_{2}$. Then red is the major color of $C_{1}$ and the minor color of $C_{2}$, and blue is the major color of $C_{2}$ and the minor color of $C_{1}$. Points in the major color, that is, red points on $C_{1}$ and blue points on $C_{2}$, are called major points. Points in the minor color are called minor points. 


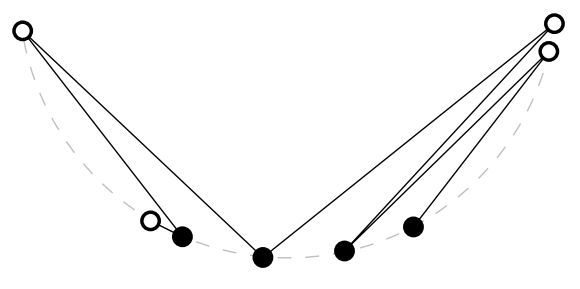

Figure 3.2: A hedgehog in $C_{1}$

Points on each $C_{i}$ are linearly ordered according to the $x$-coordinate. An interval of $C_{i}$ is a sequence of consecutive points of $C_{i}$. An inner point of an interval $I$ is any point of $I$ which is neither the leftmost nor the rightmost point of $I$.

A body $D$ is a non-empty interval of a chain $C_{i}(i=1,2)$ such that all inner points of $D$ are major. If the leftmost point of $D$ is minor, then we call it a head of $D$. Otherwise $D$ has no head. If the rightmost point of $D$ is minor, then we call it a tail of $D$. Otherwise $D$ has no tail. If a body consists of just one minor point, this point is both the head and the tail.

Bodies are of the following four types. A 00-body is a body with no head and no tail. A 11-body is a body with both head and tail. The bodies of remaining two types have exactly one endpoint major and the other one minor. We will call the body a 10-body or a 01-body if the minor endpoint is a head or a tail, respectively.

Let $D$ be a body on $C_{i}$. A hedgehog (built on the body $D \subseteq C_{i}$ ) is a noncrossing alternating path $H$ with vertices in $C_{i}$ satisfying the following three conditions: (1) $H$ contains all points of $D$, (2) $H$ contains no major points outside of $D,(3)$ the endpoints of $H$ are the first and the last point of $D$. A hedgehog built on an $\alpha \beta$-body is an $\alpha \beta$-hedgehog $(\alpha, \beta=0,1)$. If a hedgehog $H$ is built on a body $D$, then $D$ is the body of $H$ and the points of $H$ that do not lie in $D$ are spines. Note that each spine is a minor point. All possible types of hedgehogs can be seen on Fig. 3.3 (for better lucidity, we will draw hedgehogs with bodies on a horizontal line and spines indicated only by a "peak" from now on).

On each $C_{i}$, maximal intervals containing only major points are called runs. Clearly, runs form a partition of major points. For $i=1,2$, let $r_{i}$ denote the number of runs in $C_{i}$. 


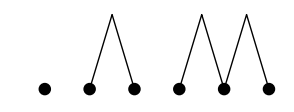

00-hedgehogs

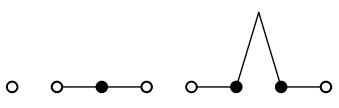

11-hedgehogs

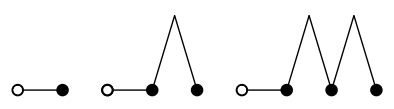

10-hedgehogs

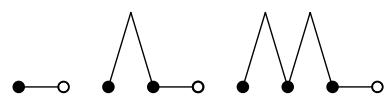

01-hedgehogs

Figure 3.3: Types of hedgehogs (sketch)

\subsubsection{Proof in the even case}

Throughout this subsection, $\left(C_{1}, C_{2}\right)$ denotes a double-chain with $\left|C_{1}\right|+\left|C_{2}\right|$ even. Since the coloring is equitable, we have $b_{1}+b_{2}=w_{1}+w_{2}$. Set

$$
\Delta:=b_{1}-w_{1}=w_{2}-b_{2} .
$$

First we give a lemma characterizing collections of bodies on a chain $C_{i}$ that are bodies of some pairwise noncrossing hedgehogs covering the whole chain $C_{i}$.

Lemma 18. Let $i \in\{1,2\}$. Let all major points of $C_{i}$ be covered by a set $\mathcal{D}$ of pairwise disjoint bodies. Then the bodies of $\mathcal{D}$ are the bodies of some pairwise noncrossing hedgehogs covering the whole $C_{i}$ if and only if $\Delta=d_{00}-d_{11}$, where $d_{\alpha \alpha}$ is the number of $\alpha \alpha$-bodies in $\mathcal{D}$.

Proof. An $\alpha \beta$-hedgehog containing $t$ major points contains $(t-1)+\alpha+\beta$ minor points. It follows that the equality $\Delta=d_{00}-d_{11}$ is necessary for the existence of a covering of $C_{i}$ by disjoint hedgehogs built on the bodies of $\mathcal{D}$.

Suppose now that $\Delta=d_{00}-d_{11}$. Let $F$ be the set of minor points on $C_{i}$ that lie in no body of $\mathcal{D}$, and let $M$ be the set of the mid-points of straight line segments connecting pairs of consecutive major points lying in the same body. It is easily checked that $|F|=|M|$. Clearly $F \cup M$ is a convex or a concave chain. Now it is easy to prove that there is a noncrossing perfect matching formed by $|F|=|M|$ straight line segments between $F$ and $M$ (for the proof, take any segment connecting a point of $F$ with a neighboring point of $M$, remove the two points, and continue by induction); see Fig. 3.4.

If $f \in F$ is connected to a point $m \in M$ in the matching, then $f$ will be a spine with edges going from it to those two major points that determined $m$. Obviously, these spines and edges define noncrossing hedgehogs with bodies in $\mathcal{D}$ and with all the required properties. 


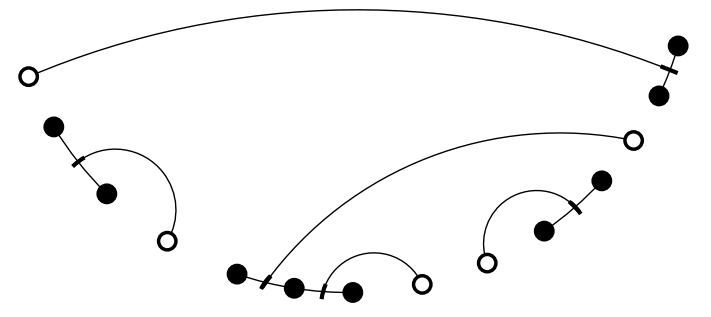

Figure 3.4: A noncrossing matching of minor points and midpoints (in $C_{1}$ )

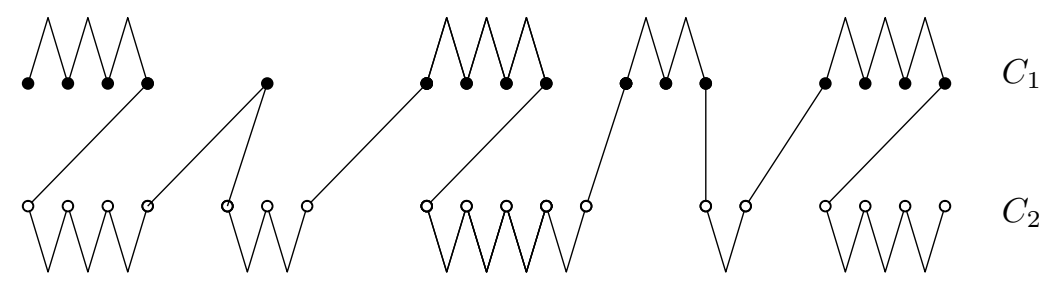

Figure 3.5: 00-hedgehogs connected to a good path

The following three lemmas and their proofs show how to construct a good path in some special cases.

Lemma 19. If $\Delta \geq \max \left\{r_{1}, r_{2}\right\}$, then $\left(C_{1}, C_{2}\right)$ has a good path.

Proof. Let $i \in\{1,2\}$. Since $r_{i} \leq \Delta \leq \max \left\{b_{i}, w_{i}\right\}$, the runs in $C_{i}$ may be partitioned into $\Delta$ 00-bodies. By Lemma [18, these 00-bodies may be extended to pairwise noncrossing hedgehogs covering $C_{i}$. This gives us $2 \Delta$ hedgehogs on the double-chain. They may be connected into a good path by $2 \Delta-1$ edges between the chains in the way shown in Fig. 3.5.

Lemma 20. If $r_{1}=r_{2}$, then $\left(C_{1}, C_{2}\right)$ has a good path.

Proof. Set $r:=r_{1}=r_{2}$. If $r \leq \Delta$ then we may apply Lemma 19, Thus, let $r>\Delta$.

Suppose first that $\Delta \geq 1$. We cover each run on each $C_{i}$ by a single body whose type is as follows. On $C_{1}$ we take $\Delta$ 00-bodies followed by $(r-\Delta)$ 10-bodies. On $C_{2}$ we take (from left to right) $(\Delta-1)$ 00-bodies, $(r-\Delta)$ 01-bodies, and one 00-body. By Lemma 18, the $r$ bodies on each $C_{i}$ can be extended to hedgehogs covering $C_{i}$. Altogether we obtain $2 r$ hedgehogs. They can be connected to a good path by $2 r-1$ edges between $C_{1}$ and $C_{2}$ (see Fig. 3.6).

Suppose now that $\Delta=0$. We add one auxiliary major point on each $C_{i}$ as follows. On $C_{1}$, the auxiliary point extends the leftmost run on the left. 


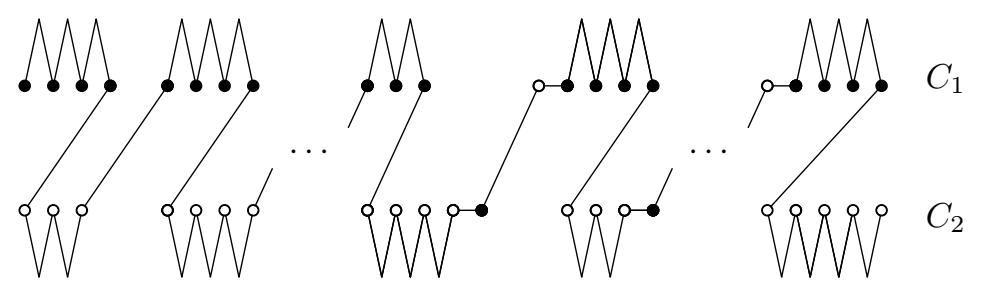

Figure 3.6: A good path in the case $r_{1}=r_{2}>\Delta \geq 1$

On $C_{2}$, the auxiliary point extends the rightmost run on the right. This does not change the number of runs and increases $\Delta$ to 1 . Thus, we may proceed as above. The good path obtained has the two auxiliary points on its ends. We may remove the auxiliary points from the path, obtaining a good path for $\left(C_{1}, C_{2}\right)$.

A singleton $s \in C_{i}$ is an inner point of $C_{i}(i=1,2)$ such that its two neighbors on $C_{i}$ are colored differently from $s$.

Lemma 21. Suppose that $C_{1}$ has no singletons and $C_{2}$ can be covered by $r_{1}-1$ pairwise disjoint hedgehogs. Then $\left(C_{1}, C_{2}\right)$ has a good path.

Proof. For simplicity of notation, set $r:=r_{1}$. We denote the $r-1$ hedgehogs on $C_{2}$ by $P_{1}, P_{2}, \ldots, P_{r-1}$ in the left-to-right order in which the bodies of these hedgehogs appear on $C_{2}$. For technical reasons, we enlarge the leftmost run of $C_{1}$ from the left by an auxiliary major point $\sigma$.

Our goal is to find $r$ hedgehogs $H_{1}, H_{2}, \ldots, H_{r}$ on $C_{1} \cup\{\sigma\}$ such that they may be connected with the hedgehogs $P_{1}, P_{2}, \ldots, P_{r-1}$ into a good path. For each $j=1, \ldots, r$, the body of the hedgehog $H_{j}$ will be denoted by $D_{j}$. For each $j=1, \ldots, r, D_{j}$ covers the $j$-th run of $C_{1} \cup\{\sigma\}$ (in the left-to-right order). We now finish the definition of the bodies $D_{j}$ by specifying for each $D_{j}$ if it has a head and/or a tail. The body $D_{1}$ is without head. For $j>1$, $D_{j}$ has a head if and only if $P_{j-1}$ has a tail. The last body $D_{r}$ is without tail and $D_{j}, j<r$, has a tail if and only if $P_{j}$ has a head.

It follows from Lemma 18 that we may add or remove some minor points on $C_{1} \cup\{\sigma\}$ so that $D_{1}, \ldots, D_{r}$ can then be extended to pairwise noncrossing hedgehogs $H_{1}, \ldots, H_{r}$ covering the "new" $C_{1}$. More precisely, there is a double-chain $\left(C_{1}^{\prime}, C_{2}\right)$ such that $D_{1}, \ldots, D_{r}$ can be extended to pairwise noncrossing hedgehogs $H_{1}, \ldots, H_{r}$ covering $C_{1}^{\prime}$, where either $C_{1}^{\prime}=C_{1} \cup\{\sigma\}$ or $C_{1}^{\prime}$ is obtained from $C_{1} \cup\{\sigma\}$ by adding some minor (blue) points on the left of $C_{1} \cup\{\sigma\}$ (say) or $C_{1}^{\prime}$ is obtained from $C_{1} \cup\{\sigma\}$ by removal of some minor (blue) points lying in none of the bodies $D_{1}, \ldots, D_{r}$. Then the concatenation 


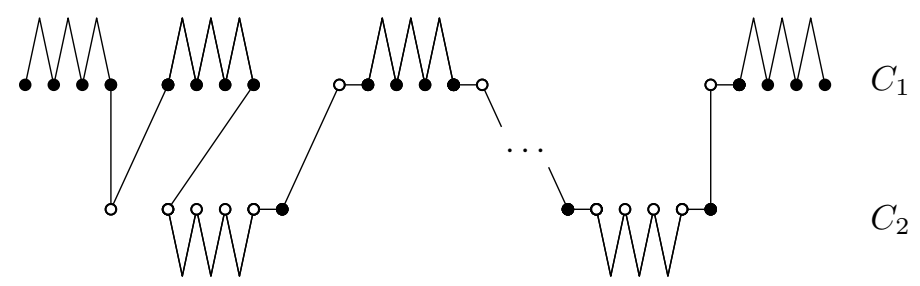

Figure 3.7: A good path in the case of no singletons on $C_{1}$

$H_{1} P_{1} H_{2} P_{2} \cdots H_{r-1} P_{r-1} H_{r}$ shown in Fig. 3.7 gives a good path on $\left(C_{1}^{\prime}, C_{2}\right)$. This good path starts with the point $\sigma$. Removal of $\sigma$ from it gives a good path $P$ for the double-chain $\left(C_{1}^{\prime} \backslash\{\sigma\}, C_{2}\right)$. The endpoints of $P$ have different colors. Thus, $P$ covers the same number of red and blue points. red points on $P$ are the $\left(\left|C_{1}\right|+\left|C_{2}\right|\right) / 2$ red points of $\left(C_{1}, C_{2}\right)$. Thus, $P$ covers exactly $\left|C_{1}\right|+\left|C_{2}\right|$ points. It follows that $\left|C_{1}^{\prime} \backslash\{\sigma\}\right|=\left|C_{1}\right|$ and thus $C_{1}^{\prime} \backslash\{\sigma\}=C_{1}$. The path $P$ is a good path on the double-chain $\left(C_{1}, C_{2}\right)$.

The following lemma will be used to find a covering needed in Lemma 21.

Lemma 22. Suppose that $\left|C_{i}\right| \geq k, r_{i} \leq k$ and $\Delta \leq k$ for some $i \in\{1,2\}$ and for some integer $k$. Then $C_{i}$ can be covered by $k$ pairwise disjoint hedgehogs.

Proof. The idea of the proof is to start with the set $\mathcal{D}$ of $\left|C_{i}\right|$ bodies, each of them being a single point, and then gradually decrease the number of bodies in $\mathcal{D}$ by joining some of the bodies together. We see that $\Delta=d_{00}-d_{11}$, where $d_{\alpha \alpha}$ is the number of $\alpha \alpha$-bodies in $\mathcal{D}$. If we join two neighboring 00 -bodies to one 00 -body and withdraw a single-point 11-body from $\mathcal{D}$ (to let the minor point become a spine) at the same time, the difference between the number of 00 -bodies and the number of 11-bodies remains the same and $|\mathcal{D}|$ decreases by two. We can reduce $|\mathcal{D}|$ by one while preserving the difference $d_{00}-d_{11}$ by joining a 00-body with a neighboring single-point 11-body into a 01- or a 10-body. Similarly we can join a 01- or a 10-body with a neighboring (from the proper side) single-point 11-body into a new 11-body to decrease $|\mathcal{D}|$ by one as well. When we are joining two 00-bodies, we choose the single-point 11-body to remove in such a way to keep as many single-point 11-bodies adjacent to 00-bodies as possible. This guarantees that we can use up to $r_{i}$ of them for heads and tails.

We start with joining neighboring 00-bodies and we do this as long as $|\mathcal{D}|>k+1$ and $d_{00}>r_{i}$. Note that by the assumption $\Delta \leq k$, we will have enough single-point 11-bodies to do that. When we end, one of the following conditions holds: $|\mathcal{D}|=k,|\mathcal{D}|=k+1$ or $d_{00}=r_{i}$. In the first 
case we are done. If $|\mathcal{D}|=k+1$, we just add one head or one tail (we can do this since $d_{00}+d_{11}=|\mathcal{D}|=k+1 \geq d_{00}-d_{11}+1$, which implies $\left.d_{11}>0\right)$ ). If $d_{00}=r_{i}$, then each run is covered by just one 00-body. We need to add $|\mathcal{D}|-k$ heads and tails. We have enough single-point 11-bodies to do that since $d_{11}=|\mathcal{D}|-d_{00}=|\mathcal{D}|-r_{i} \geq|\mathcal{D}|-k$. On the other hand, $r_{i}-d_{11}=\Delta \geq 0$, so the number of heads and tails needed is at most $r_{i}$. Therefore, all the single-point 11-bodies are adjacent to 00-bodies and we can use them to form heads and tails.

In all cases we get a set $\mathcal{D}$ of $k$ bodies. Now we can apply Lemma 18 to obtain $k$ pairwise disjoint hedgehogs covering $C_{i}$.

By a contraction we mean removing a singleton with both its neighbors and putting a point of the color of its neighbors in its place instead. It is easy to verify that if there is a good path in the new double-chain obtained by this contraction, it can be expanded to a good path in the original double-chain.

Now we can prove our main theorem in the even case.

Proof. Without loss of generality we may assume that $r_{1} \geq r_{2}$. In the case $r_{1}=r_{2}$, we get a good path by Lemma 20. In the case $\Delta \geq r_{1}$, we get a good path by Lemma 19. Therefore, the only case left is $r_{1}>r_{2}, r_{1}>\Delta$.

If there is a singleton on $C_{1}$, we make a contraction of it. By this we decrease $r_{1}$ by one and both $r_{2}$ and $\Delta$ remain unchanged. If now $r_{1}=r_{2}$ or $r_{1}=\Delta$, we again get a good path, otherwise we keep making contractions until one of the previous cases appears or there are no more singletons to contract.

If there is no more singleton to contract on $C_{1}$ and still $r_{1}>r_{2}$ and $r_{1}>\Delta$, we try to cover $C_{2}$ by $r_{1}-1$ pairwise disjoint paths. Before the contractions, $\left|C_{2}\right| \geq\left|C_{1}\right| / 4$ did hold and by the contractions we could just decrease $\left|C_{1}\right|$, therefore it still holds.

All the maximal intervals on the chain $C_{1}$ (with possible exception of the first and the last one) have now length at least two, which implies that $r_{1} \leq\left|C_{1}\right| / 4+1$. Hence $\left|C_{2}\right| \geq\left|C_{1}\right| / 4 \geq r_{1}-1$, so we can create $r_{1}-1$ pairwise disjoint hedgehogs covering $C_{2}$ using Lemma 22. Then we apply Lemma 21 and expand the good path obtained by Lemma 21 to a good path on the original double-chain.

There is a straightforward linear-time algorithm for finding a good path on $\left(C_{1}, C_{2}\right)$ based on the above proof. 


\subsubsection{Proof in the odd case}

In this section we prove Theorem 16 for the case when $\left|C_{1}\right|+\left|C_{2}\right|$ is odd. We set $\Delta=w_{2}-b_{2}$ and proceed similarly as in the even case. On several places in the proof we will add one auxiliary point $\omega$ to get the even case (its color will be chosen to equalize the numbers of red and blue points). We will be able to apply one of the Lemmas 1921 to obtain a good path. The point $\omega$ will be at some end of the good path and by removing $\omega$ we obtain a good path for $\left(C_{1}, C_{2}\right)$.

Without loss of generality we may assume that $r_{1} \geq r_{2}$. In the case $r_{1}=r_{2}$, we add an auxiliary major point $\omega$, which is placed either as the left neighbor of the leftmost major point on $C_{1}$ or as the right neighbor of the rightmost major point on $C_{2}$. Then we get a good path by Lemma 20 and the removal of $\omega$ gives us a good path for $\left(C_{1}, C_{2}\right)$.

In the case $\Delta \geq r_{1}$, we add an auxiliary point $\omega$ to the same place and we get a good path by Lemma 19. Again, the removal of $\omega$ gives us a good path for $\left(C_{1}, C_{2}\right)$.

Now, the only case left is $r_{1}>r_{2}, r_{1}>\Delta$. If there are any singletons on $C_{1}$, we make the contractions exactly the same way as in the proof of the even case. If Lemma 19 or 20 needs to be applied, we again add an auxiliary point $\omega$ and proceed as above.

If there is no more singleton to contract on $C_{1}$ and still $r_{1}>r_{2}$ and $r_{1}>\Delta$, we have $\left|C_{2}\right| \geq\left|C_{1}\right| / 4 \geq r_{1}-1$ as in the proof of the even case and we can use Lemma 22 to get $r_{1}-1$ pairwise disjoint hedgehogs covering $C_{2}$. Now we need to consider two cases: (1) If $b_{1}+b_{2}>w_{1}+w_{2}$, then we find a good path for $\left(C_{1}, C_{2}\right)$ in the same way as in the proof of Lemma 21, except we do not add the auxiliary point $\sigma$. (2) If $b_{1}+b_{2}<w_{1}+w_{2}$, we add an auxiliary point $\omega$ as the right neighbor of the rightmost major point on $C_{1}$. The number $r_{1}$ didn't change so Lemma 21 gives us a good path. Again, the removal of $\omega$ gives us a good path for $\left(C_{1}, C_{2}\right)$.

There is a straightforward linear-time algorithm for finding a good path on $\left(C_{1}, C_{2}\right)$ based on the above proof.

\subsection{Unbalanced double-chains with no good path}

In this section we prove Theorem 17. Let $\left(C_{1}, C_{2}\right)$ be a double-chain whose points are colored by an equitable 2 -coloring, and let $C_{1}$ be periodic with the following period: 2 red, 4 blue, 6 red and 4 blue points. Let $\left|C_{1}\right| \geq$ $28\left(\left|C_{2}\right|+1\right)$. We want to show that $\left(C_{1}, C_{2}\right)$ has no good path. 
Suppose on the contrary that $\left(C_{1}, C_{2}\right)$ has a good path. Let $P_{1}, P_{2}, \ldots, P_{t}$ denote the maximal subpaths of the good path containing only points of $C_{1}$. Since between every two consecutive paths $P_{i}, P_{j}$ in the good path there is at least one point of $C_{2}$, we have $t \leq\left|C_{2}\right|+1$. In the following we think of $C_{1}$ as of a cyclic sequence of points on the circle. Note that we get more intervals in this way. Theorem [17 now directly follows from the following theorem.

Theorem 23. Let $C_{1}$ be a set of points on a circle periodically 2-colored with the following period of length 16: 2 red, 4 blue, 6 red and 4 blue points. Suppose that all points of $C_{1}$ are covered by a set of $t$ noncrossing alternating and pairwise disjoint paths $P_{1}, P_{2}, \ldots, P_{t}$. Then $t>\left|C_{1}\right| / 28$.

Proof. Each maximal interval spanned by a path $P_{i}$ on the circle is called a base. Let $b\left(P_{i}\right)$ denote the number of bases of $P_{i}$. A path with one base only is called a leaf. We consider the following special types of edges in the paths. Long edges connect points that belong to different bases. Short edges connect consecutive points on $C_{1}$. Note that short edges cannot be adjacent to each other. A maximal subpath of a path $P_{i}$ spanning two subintervals of two different bases and consisting of long edges only is called a zig-zag. A path is separated if all of its edges can be crossed by a line. Note that each zig-zag is a separated path. A maximal separated subpath of $P_{i}$ that contains an endpoint of $P_{i}$ and spans one interval only is a rainbow. We find all the zig-zags and rainbows in each $P_{i}, i=1,2, \ldots, t$. Note that two zig-zags, or a zig-zag and a rainbow, are either disjoint or share an endpoint. A branch is a maximal subpath of $P_{i}$ that spans two intervals and is induced by a union of zig-zags.

For each path $P_{i}$ that is not a leaf construct the following graph $G_{i}$. The vertices of $G_{i}$ are the bases of $P_{i}$. We add an edge between two vertices for each branch that connects the corresponding bases. If $G_{i}$ has a cycle (including the case of a "2-cycle"), then one of the corresponding branches consists of a single edge that lies on the convex hull of $P_{i}$. We delete such an edge from $P_{i}$ and don't call it a branch anymore. By deleting a corresponding edge from each cycle of $G_{i}$ we obtain a graph $G_{i}^{\prime}$, which is a spanning tree of $G_{i}$. The branch graph $G^{\prime}$ is a union of all graphs $G_{i}^{\prime}$.

Let $\mathcal{L}$ denote the set of leaves and $\mathcal{B}$ the set of branches. Let $\mathcal{P}=$ $\left\{P_{1}, P_{2}, \ldots, P_{t}\right\}$.

Observation 24. The branch graph $G^{\prime}$ is a forest with components $G_{i}^{\prime}$. Therefore,

$$
|\mathcal{B}|=\sum_{i, P_{i} \notin \mathcal{L}}\left(b\left(P_{i}\right)-1\right)
$$


The branches and rainbows in $P_{i}$ do not necessarily cover all the points of $P_{i}$. Each point that is not covered is adjacent to a deleted long edge and to a short edge that connects this point to a branch or a rainbow. It follows that between two consecutive branches (and between a rainbow and the nearest branch) there are at most two uncovered points, that are endpoints of a common deleted edge. By an easy case analysis it can be shown that this upper bound can be achieved only if one of the nearest branches consists of a single zig-zag.

In the rest of the chapter, a run will be a maximal monochromatic interval of any color. In the following we will count the runs that are spanned by the paths $P_{i}$. The weight of a path $P, w(P)$, is the number of runs spanned by $P$. If $P$ spans a whole run, it adds one unit to $w(P)$. If $P$ partially spans a run, it adds half a unit to $w(P)$.

Observation 25. The weight of a zig-zag or a rainbow is at most 1.5. A branch consists of at most two zig-zags, hence it weights at most three units.

Lemma 26. A path $P_{i}$ that is not a leaf weights at most $3.5 k+3.5$ units where $k$ is the number of branches in $P_{i}$.

Proof. According to the above discussion, for each pair of uncovered points that are adjacent on $P_{i}$ we can join one of them to the adjacent branch consisting of a single zig-zag. To each such branch we join at most two uncovered points, hence its weight increases by at most one unit to at most 2.5 units. The number of the remaining uncovered points is at most $k+1$. Therefore, $w\left(P_{i}\right) \leq 3 k+3+0.5 \cdot(k+1)=3.5 k+3.5$.

Lemma 27. A leaf weights at most 3.5 units.

Proof. Let $L$ be a leaf spanning at least two points. Consider the interval spanned by $L$. Cut this interval out of $C_{1}$ and glue its endpoints together to form a circle. Take a line $l$ that crosses the first and the last edge of $L$. Note that the line $l$ doesn't separate any of the runs. Exactly one of the arcs determined by $l$ contains the gluing point $\gamma$.

Each of the ending edges of $L$ belongs to a rainbow, all of whose edges cross $l$. It follows that if $L$ has only one rainbow, then this rainbow covers the whole leaf $L$ and $w(L) \leq 1.5$. Otherwise $L$ has exactly two rainbows, $R_{1}$ and $R_{2}$. We show that $R_{1}$ and $R_{2}$ cover all edges of $L$ that cross the line $l$. Suppose there is an edge $s$ in $L$ that crosses $l$ and does not belong to any of the rainbows $R_{1}, R_{2}$. Then one of these rainbows, say $R_{1}$, is separated from $\gamma$ by $s$. Then the edge of $L$ that is the second nearest to $R_{1}$ also has the same property as the edge $s$. This would imply that $R_{1}$ spans two whole runs, a contradiction. It follows that all the edges of $L$ that are not covered by the 
rainbows are consecutive and connect adjacent points on the circle. There are at most three such edges; at most one connecting the points adjacent to $\gamma$, the rest of them being short on $C_{1}$. But this upper bound of three cannot be achieved since it would force both rainbows to span two whole runs. Therefore, there are at most two edges and hence at most one point in $L$ uncovered by the rainbows. The lemma follows.

Lemma 28. $|\mathcal{L}| \geq \sum_{i, P_{i} \notin \mathcal{L}}\left(b\left(P_{i}\right)-2\right)+2$.

Proof. The number of runs in $C_{1}$ is at least 4. By Lemma 27, if all the paths $P_{i}$ are leaves, then at least 2 of them are needed to cover $C_{1}$ and the lemma follows.

If not all the paths are leaves, we order the paths so that all the leaves come at the end of the ordering. The path $P_{1}$ spans $b\left(P_{1}\right)$ bases. Shrink these bases to points. These points divide the circle into $b\left(P_{1}\right)$ arcs each of which contains at least one leaf. If $P_{2}$ is not a leaf then continue. The path $P_{2}$ spans $b\left(P_{2}\right)$ intervals on one of the previous arcs. Shrink them to points. These points divide the arc into $b\left(P_{2}\right)+1$ subarcs. At least $b\left(P_{2}\right)-1$ of them contain leaves. This increased the number of leaves by at least $b\left(P_{2}\right)-2$. The case of $P_{i}, i>2$, is similar to $P_{2}$. The lemma follows by induction.

Corollary 29. $|\mathcal{B}| \leq|\mathcal{P}|-2$.

Proof. Combining Lemma 28 and Observation 24 we get the following:

$$
|\mathcal{B}|=\sum_{i, P_{i} \notin \mathcal{L}}\left(b\left(P_{i}\right)-1\right)=\sum_{i, P_{i} \notin \mathcal{L}}\left(b\left(P_{i}\right)-2\right)+|\mathcal{P}|-|\mathcal{L}|+2-2 \leq|\mathcal{P}|-2 .
$$

Now we are in position to finish the proof of Theorem 23. If the whole $C_{1}$ is covered by the paths $P_{i}$, then $\sum_{i=1}^{t} w\left(P_{i}\right) \geq\left|C_{1}\right| / 4$. Therefore,

$$
\left|C_{1}\right| \leq 4 \cdot(3.5|\mathcal{B}|+3.5(|\mathcal{P}|-|\mathcal{L}|)+3.5|\mathcal{L}|)<4 \cdot 7|\mathcal{P}|=28|\mathcal{P}|
$$




\subsection{Open problems}

Our result on the double-chain suggests that the convex position of points might be an extremal case regarding the length of the longest noncrossing, alternating path. Although it is not known what role convexity plays in the problem. In the general case more basic questions arise. One of the goals would be to settle the following problem. It is still open in general position if the trivial lower bound of $n$ points could be improved by more than a constant (see also the book [5]).

Problem. Does an equitably colored point set always admit a noncrossing, alternating path of $n+f(n)$ points where $f(n)$ is unbounded?

We may investigate other interesting special positions of our point set. Instead of the double-chain we could consider the point set to be on two convex chains.

Problem. How long is the longest noncrossing, alternating path in an equitably colored point set placed on two convex chains? 


\section{Chapter 4}

\section{Solution of Peter Winkler's Pizza Problem}

\subsection{Introduction}

Peter Winkler posed the following problem at the conference Building Bridges, honouring the 60th birthday of László Lovász, in Budapest in 2008. Bob and Alice are sharing a pizza. Bob cuts the pizza into slices of not necessarily equal size. Afterwards they take turns alternately to divide it among themselves. One slice is taken in each turn. In the first turn Alice takes any slice. In the forthcoming turns one may take a slice if it is adjacent to some previously taken slice. This is called the Polite Pizza Protocol. How much of the pizza can Alice gain?

The original puzzle, that is determining whether Bob can get more than half of the pizza, was devised by Dan Brown in 1996. Bob can easily ensure for himself one half of the pizza. For example, he may cut the pizza into an even number of slices of equal size. Then Bob always obtains exactly one half. Peter Winkler found out that Bob can actually get 5/9 of the pizza if he cuts the pizza properly - see Theorems 33 and 34 for such cuttings. He conjectured that Alice can obtain 4/9 of the pizza for any cutting. The main aim of this chapter is to show a strategy of Alice proving this conjecture.

The pizza after Bob's cutting may be represented by a circular sequence $P=p_{0} p_{1} \ldots p_{n-1}$ and by the sizes $\left|p_{i}\right| \geq 0$ (for $i=0,1, \ldots, n-1$ ); for simplicity of notation, throughout the chapter we do not separate the elements of (circular) sequences by commas. The size of $P$ is defined by $|P|:=\sum_{i=0}^{n-1}\left|p_{i}\right|$. Throughout the chapter the indices are counted modulo $n$.

For $1<j \leq n$, if one of the players chooses a slice $p_{i}$ in the $(j-1)$-st turn and the other player chooses $p_{i-1}$ or $p_{i+1}$ in the $j$-th turn, then the $j$-th 
turn is called a shift, otherwise it is called a jump. Except for the first and the last turn, there are two choices in each turn and exactly one of them is a shift and the other one is a jump. The last turn is always a shift.

If some strategy of a player allows the player to make at most $j$ jumps, then we call it a j-jump strategy. We remark that given a circular sequence $P$ of length $n$, Alice has exactly $n$ zero-jump strategies on $P$, determined by Alice's first turn.

Let $\Sigma$ be a particular strategy of one of the players. We say that $\Sigma$ is a strategy with gain $g$ if it guarantees the player a subset of slices with the sum of sizes at least $g$. Note that according to this definition, if $\Sigma$ is a strategy with gain $g$ then it is also a strategy with gain $g^{\prime}$ for any $g^{\prime} \leq g$.

If the number of slices is even, Alice has the following zero-jump strategy with gain $|P| / 2$. She partitions the slices of the pizza into two classes, even and odd, according to their parity in $P$. In the first turn Alice takes a slice from the class with the sum of slice sizes at least $|P| / 2$. In all her forthcoming turns she makes shifts, thus forcing Bob to eat from the other class in each of his turns.

Here is our main result.

Theorem 30. For any $P$, Alice has a two-jump strategy with gain $4|P| / 9$.

More generally, we determine Alice's guaranteed gain for any given number of slices.

Theorem 31. For $n \geq 1$, let $g(n)$ be the maximum $g \in[0,1]$ such that for any cutting of the pizza into $n$ slices, Alice has a strategy with gain $g|P|$. Then

$$
g(n)=\left\{\begin{array}{cl}
1 & \text { if } n=1 \\
4 / 9 & \text { if } n \in\{15,17,19, \ldots\} \\
1 / 2 & \text { otherwise }
\end{array}\right.
$$

Moreover, Alice has a zero-jump strategy with gain $g(n)|P|$ when $n$ is even or $n \leq 7$, she has a one-jump strategy with gain $g(n)|P|$ for $n \in\{9,11,13\}$, and she has a two-jump strategy with gain $g(n)|P|$ for $n \in\{15,17,19, \ldots\}$.

If we make a restriction on the number of Alice's jumps we get the following results.

Theorem 32. (a) Alice has a zero-jump strategy with gain $|P| / 3$ and the constant $1 / 3$ is the best possible.

(b) Alice has a one-jump strategy with gain $7|P| / 16$ and the constant $7 / 16$ is the best possible.

Due to Theorem 31, the following theorem describes all minimal cuttings for which Bob has a strategy with gain $5|P| / 9$. 
Theorem 33. For any $\omega \in[0,1]$, Bob has a one-jump strategy with gain $5|P| / 9$ if he cuts the pizza into 15 slices as follows: $P_{\omega}=0010100(1+$ $\omega) 0(2-\omega) 00202$. These cuttings describe, up to scaling, rotating and flipping the pizza upside-down, all the pizza cuttings into 15 slices for which Bob has a strategy with gain $5|P| / 9$.

For $\omega=0$ or $\omega=1$, the cutting in Theorem 33 has slices of only three different sizes $0,1,2$. If all the slices have the same size, then Alice always gets at least half of the pizza. But two different slice sizes are already enough to obtain a cutting with which Bob gets $5 / 9$ of the pizza.

Theorem 34. Up to scaling, rotating and flipping the pizza upside-down, there is a unique pizza cutting into 21 slices of at most two different sizes for which Bob has a strategy with gain $5|P| / 9$. The cutting is 001010010101001010101.

In subsection 4.7 .1 we describe a linear-time algorithm for finding Alice's two-jump strategy with gain $g(n)|P|$ guaranteed by Theorem 31 ,

Theorem 35. There is an algorithm that, given a cutting of the pizza with $n$ slices, performs a precomputation in time $O(n)$. Then, during the game, the algorithm decides each of Alice's turns in time $O(1)$ in such a way that Alice makes at most two jumps and her gain is at least $g(n)|P|$.

There is also a straightforward quadratic-time dynamic algorithm finding optimal strategies for each of the two players.

Claim 36. There is an algorithm that, given a cutting of the pizza with $n$ slices, computes an optimal strategy for each of the two players in time $O\left(n^{2}\right)$. The algorithm stores an optimal turn of the player on turn for all the $n^{2}-n+2$ possible positions of the game.

We remark that, unlike in Theorem 30 , the number of Alice's jumps in her optimal strategy cannot be bounded by a constant. In fact, it can be as large as $\lfloor n / 2\rfloor-1$ for $n \geq 2$ (see Observation 57 in subsection 4.7.2). A similar statement holds for the number of Bob's jumps in his optimal strategy.

The following question is still open.

Problem 1. Is there an algorithm that uses o( $\left.n^{2}\right)$ time for some precomputations and then computes each optimal turn in constant time?

We remark that we even don't know if Alice's optimal first turn can be computed in time $o\left(n^{2}\right)$.

Independently of us and approximately at the same time, K. Knauer, P. Micek and T. Ueckerdt [21] also proved Theorem 30 and some related results.

The chapter is organized as follows. Theorem 30 is proved in subsection 4.2. Section 4.3 contains examples of cuttings showing that the constant 

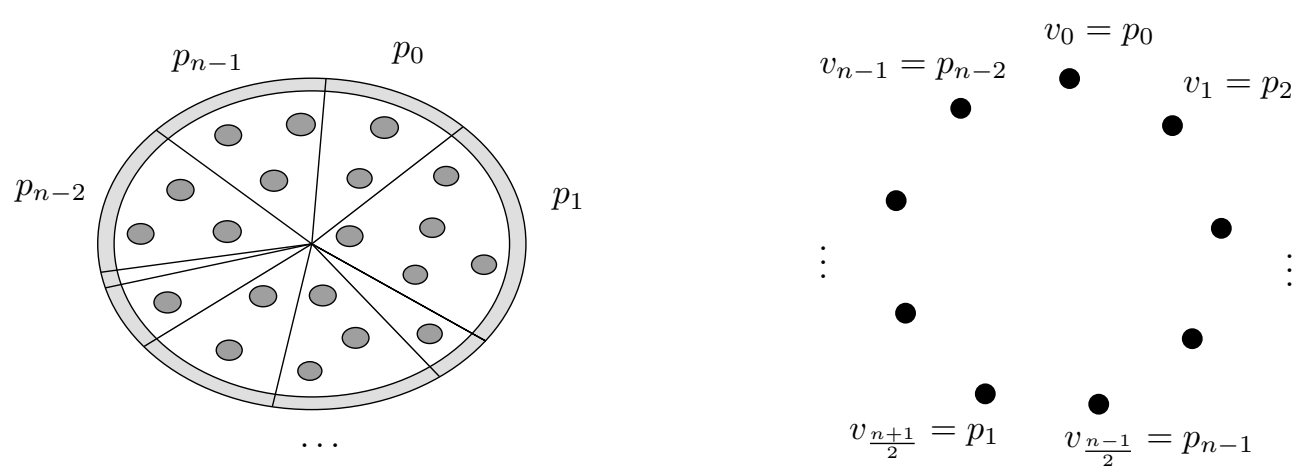

Figure 4.1: A cutting of a pizza and the corresponding characteristic cycle.

4/9 in Theorem 30 cannot be improved. Section 4.4 is devoted to the proof of Theorem 31. Theorems 33 and 34 are proved in Section 4.5. Section 4.6 contains the proof of Theorem [32. The algorithms from Theorem 35 and Claim 36 are described in Section 4.7.1 and Section 4.7.2, respectively.

In a follow-up paper [8] we discuss generalizations of the Pizza Problem.

\subsection{The lower bound}

When the number of slices is even, Alice can always gain at least $|P| / 2$. Here we prove the lower bound on her gain when $n \geq 3$ is odd.

\subsubsection{Preliminaries}

If the number of slices is odd, instead of the circular sequence $P=p_{0} p_{1} \ldots p_{n-1}$ we will be working with the related circular sequence $V=v_{0} v_{1} \ldots v_{n-1}=$ $p_{0} p_{2} \ldots p_{n-1} p_{1} p_{3} \ldots p_{n-2}$ that we call the characteristic cycle (see Figure 4.1). The size of the characteristic cycle is denoted by $|V|$. Clearly $|V|=|P|$.

An $\operatorname{arc}$ is a sequence of at most $n-1$ consecutive elements of $V$. If we talk about the first or the last element of an arc, we always consider it with respect to the linear order on the arc inherited from the characteristic cycle $V$. For an $\operatorname{arc} X=v_{i} v_{i+1} \ldots v_{i+l-1}$, its length is $l(X):=l$ and its size is $|X|:=\sum_{j=i}^{i+l-1}\left|v_{j}\right|$. An arc of length $(n+1) / 2$ is called a half-circle. Figure 4.2 shows an example of a game on $V$. The slice taken in the $i$-th turn is labeled by the initial letter of the player with $i$ in the subscript.

At any time during a game, a player may decide to make only shifts further on. The player will take one or two arcs of the characteristic cycle afterwards. An example of such a game when Alice decided to make no more 


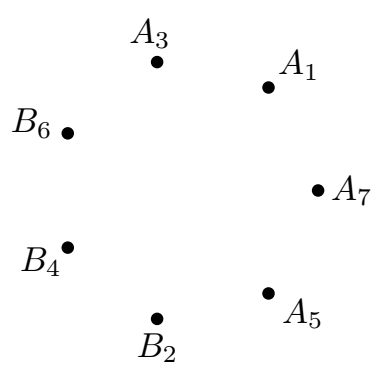

Figure 4.2: A game illustrated on the characteristic cycle $V$ (the turns are $\left.A_{1}, B_{2}, A_{3}, \ldots\right)$. The turns $B_{4}$ and $A_{5}$ are jumps and all the other turns (except $A_{1}$ ) are shifts.

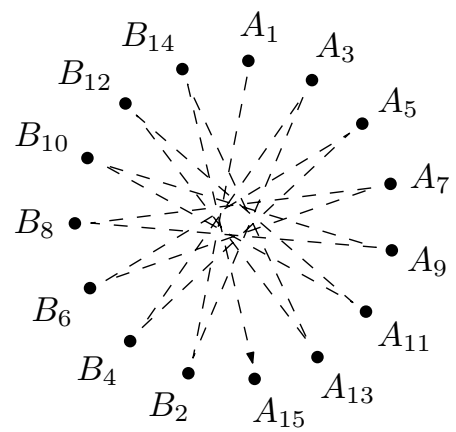

Figure 4.3: An example of a game where both players used a zero-jump strategy. 

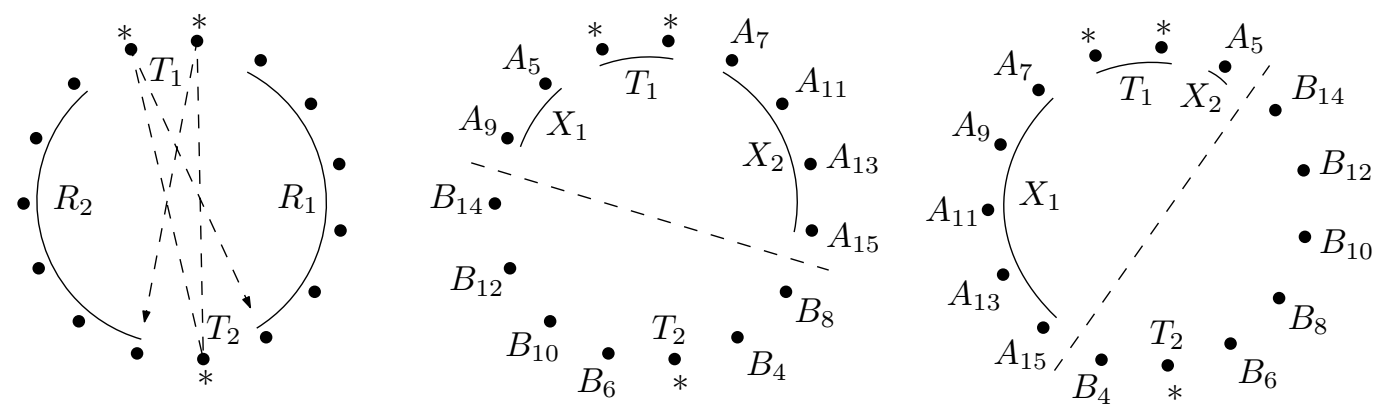

Figure 4.4: Situation before Bob's turn with the two possible options marked by arrows (left) and two of the possible ends of the game where Alice made no more jumps (middle and right).

jumps is depicted on Figure 4.4 (slices taken before the decision point are labeled with $*$, and selected pairs of slices neighboring in the original pizza are connected by dashed segments). The slices she took after the decision point are forming two arcs that are separated in between by some arc of previously taken slices.

Observation 37. Consider a position after Alice's turn $A_{j}, j \neq 1, n$. We have $V=T_{1} R_{1} T_{2} R_{2}$, where $\ell\left(T_{1}\right)=\ell\left(T_{2}\right)+1=(j+1) / 2, \ell\left(R_{1}\right)=\ell\left(R_{2}\right), T_{1}$ and $T_{2}$ are two arcs of already taken slices, and $R_{1}$ and $R_{2}$ are two arcs containing the remaining slices. Suppose that all the remaining turns of Alice $\left(A_{j+2}, A_{j+4}, \ldots, A_{n}\right)$ are shifts. Then, regardless of Bob's remaining turns $B_{j+1}, \ldots, B_{n-1}$, the slices taken by Alice in the turns $A_{j+2}, A_{j+4}, \ldots, A_{n}$ necessarily form two arcs $X_{1}$ and $X_{2}$ such that $X_{1} T_{1} X_{2}$ is a half-circle of $V$.

In addition, for any half-circle $Y_{1} T_{1} Y_{2}$, Bob can choose his turns $B_{j+2}, \ldots$, $B_{n-1}$ so that $X_{1}=Y_{1}$ and $X_{2}=Y_{2}$.

Proof. We will show by induction that before any Bob's turn $B_{j+2 k+1}$, the slices taken by him in turns $B_{j+1}, \ldots, B_{j+2 k-1}$ form two $\operatorname{arcs} Z_{1}$ and $Z_{2}$ such that $Z=Z_{1} T_{2} Z_{2}$ is an arc and his two possible moves are on the two neighbors of $Z$. This is true for $B_{j+1}$ and by induction if this is true before $B_{j+2 k+1}$, then Bob takes for $B_{j+2 k+1}$ one of the two neighbors of $Z$ and $Z^{\prime}:=Z \cup B_{j+2 k+1}$ is an arc. After Alice's shift, Bob's shift would be a neighbor of $B_{j+2 k+1}$, thus a neighbor of $Z^{\prime}$. Bob's jump would be the neighbor of $Z$ different from $B_{j+2 k+1}$, thus a neighbor of $Z^{\prime}$.

For any given half-circle $Y_{1} T_{1} Y_{2}$ and before any of Bob's turns $B_{j+1}, \ldots$, $B_{n-1}$, the two slices available for Bob are neighbors of an arc of length at most $(n-3) / 2$ which is not a subarc of $Y_{1} T_{1} Y_{2}$. Thus one of the two slices available 

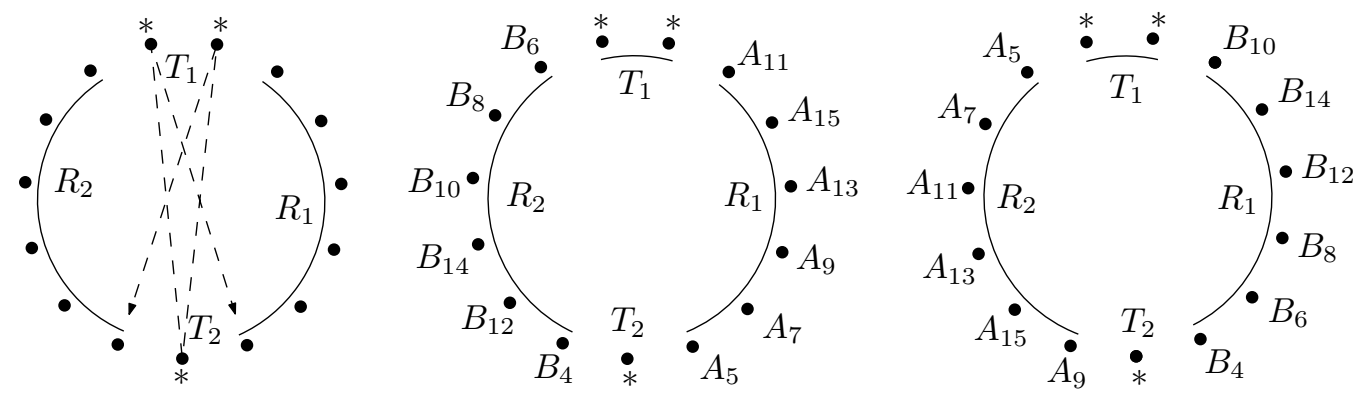

Figure 4.5: Two possible choices of Bob's next turn (left) and the two possible ends of the game where Bob made no more jumps (middle and right).

for him is not in $Y_{1} T_{1} Y_{2}$ and Bob can choose his turns $B_{j+1}, \ldots, B_{n-1}$ so that $X_{1}=Y_{1}$ and $X_{2}=Y_{2}$.

If Bob decides to make only shifts for the rest of the game, he takes one arc afterwards. Namely, if there are two arcs of already taken slices in $V$ at his decision point, then the arc that will be taken by Bob is neighboring these two arcs at both of its ends (see Figure 4.5).

Observation 38. Consider a position after Alice's turn $A_{j}, j \neq 1, n$. We have $V=T_{1} R_{1} T_{2} R_{2}$, where $\ell\left(T_{1}\right)=\ell\left(T_{2}\right)+1=(j+1) / 2, \ell\left(R_{1}\right)=\ell\left(R_{2}\right)$, $T_{1}$ and $T_{2}$ are two arcs of already taken slices, and $R_{1}$ and $R_{2}$ are two arcs containing the remaining slices. Bob's turn $B_{j+1}$ may be on the last slice of $R_{1}$ or on the first slice of $R_{2}$. If $B_{j+1}$ is on the last slice of $R_{1}$ and all the remaining turns of Bob are shifts then, regardless of Alice's remaining turns, Bob will take $R_{1}$ and Alice will take $R_{2}$ in this phase of the game. Similarly, if $B_{j+1}$ is on the first slice of $R_{2}$ and all the remaining turns of Bob are shifts then, regardless of Alice's remaining turns, Bob will take $R_{2}$ and Alice will take $R_{1}$ in this phase of the game.

Proof. Similarly to the proof of Observation 37, it is easy to prove by induction that if Bob played $B_{j+1}$ on $R_{1}$, then before each Alice's turn, the two slices available for her are from $R_{2}$.

\subsubsection{Minimal triples}

For each $v$ in $V$ the potential of $v$ is the minimum of the sizes of half-circles covering $v$. The maximum of the potentials in $V$ is the potential of $V$, which we further denote by $p(V)$. It is an immediate conclusion that Alice has a strategy with gain $p(V)$ because by choosing an element with potential 
equal to $p(V)$ and making only shifts afterwards Alice obtains at least $p(V)$. Therefore we may assume that $p(V)<|V| / 2$.

A covering triple of half-circles is a triple of half-circles such that each element of $V$ appears in at least one of the three half-circles. We allow two half-cirles to be equal in the covering triple. A covering triple is minimal if it contains a half-circle of minimum size (among all $n$ half-circles), all halfcircles forming the triple have size at most $p(V)$ and none of them may be replaced in the triple by a half-circle of strictly smaller size.

Claim 39. Each half-circle of minimum size lies in at least one minimal triple.

Proof. Take a half-circle $H_{1}$ of minimum size. Consider $v_{k}$ and $v_{k+(n-3) / 2}$ the two uncovered elements neighboring $H_{1}$ on $V$. Let $H_{2}$ be the half-circle of size at most $p(V)$ that covers $v_{k}$ and as many elements of $V$ not covered by $H_{1}$ as possible. We define $H_{3}$ in the same way for $v_{k+(n-3) / 2}$. The above triple of half-circles covers $V$. If it is not the case, then take an uncovered element $v$. Consider a half-circle $H$ that has minimal size among half-circles covering $v$. At least one of $v_{k}$ and $v_{k+(n-3) / 2}$ is covered by $H$. This contradicts the choice of $\mathrm{H}_{2}$ or $\mathrm{H}_{3}$. So we get that the given triple of half-circles forms a covering triple. Now while any of the half-circles can be replaced in the triple by a half-circle of strictly smaller size, we replace it. Obviously $H_{1}$ won't be replaced as it is a half-circle of minimum size. Consequently the triple we get is a minimal triple.

Observation 40. If the size of a half-circle in a minimal triple is $z$ then Alice has a zero-jump strategy with gain z.

Proof. As in a minimal triple all half-circles are of size at most $p(V)$ and Alice has a zero-jump strategy with gain $p(V)$, the statement of the observation follows.

Claim 41. Let $p(V)<|V| / 2$. Then any minimal triple contains three pairwise different half-circles, and thus there is a partition of $V$ into six arcs $A, B, C, D, E, F$ such that the half-circles in the minimal triple are $A B C$, $C D E$ and $E F A$ (see Figure 4.6). The lengths of the arcs satisfy $l(A)=$ $l(D)+1 \geq 2, l(C)=l(F)+1 \geq 2$ and $l(E)=l(B)+1 \geq 2$.

Proof. If two of the three half-circles in a minimal triple are equal then $V$ can be covered by two half-circles of the triple. Since each half-circle in the triple has size at most $p(V)$, the total size of the pizza is at most $2 p(V)<|V|$, a contradiction. If at least one of $B, D, F$ has length 0 , we argue exactly in the same way. 


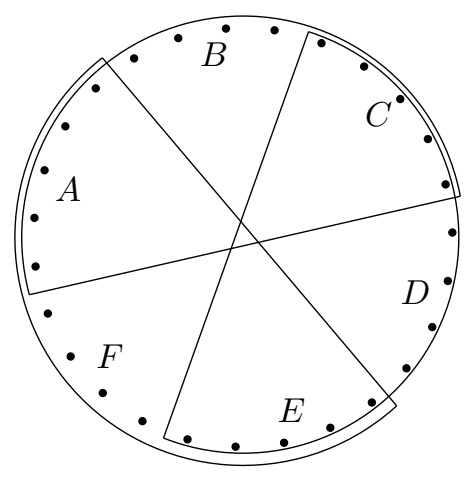

Figure 4.6: The partitioning of the characteristic cycle given by the covering half-circles.

We have $l(A B C)+l(E F A)=n+1=l(A)+\cdots+l(F)+1$, therefore $l(A)=l(D)+1 \geq 2$. The other two equalities are analogous.

\subsubsection{An auxiliary one-jump strategy}

Throughout this subsection we assume that $p(V)<|V| / 2$. We fix any minimal triple $T$ of half-circles. By Claim 41, it yields a partition of $V$ into six $\operatorname{arcs} A, B, C, D, E, F$ such that the half-circles in the triple are $A B C, C D E$, $E F A$ (see Figure 4.6). We further use the notation $a:=|A|, b:=|B|$, and so on.

We define a median slice of an $\operatorname{arc} X=v_{i} v_{i+1} \ldots v_{i+l}$ to be a slice $v_{k} \in X$ such that $\sum_{j=i}^{k-1}\left|v_{j}\right| \leq|X| / 2$ and $\sum_{j=k+1}^{i+l}\left|v_{j}\right| \leq|X| / 2$. Observe that any arc of positive length has at least one median slice.

Claim 42. Alice has a one-jump strategy for $V$ with gain $b / 2+\min \{c+$ $d, f+a\}$ if $p(V)<|V| / 2$.

Proof. By Claim 41 we have that $l(B)>0$. In the first turn Alice takes a median slice $v_{k}$ of $B$. Consequently Bob is forced to start in $E$. He may take the element $v_{k+(n-1) / 2}$ or $v_{k+(n+1) / 2}$. Alice makes only shifts while the shift implies taking an element of $B$. In the meantime Bob necessarily takes elements from $E$. In the turn, when Alice's shift would imply taking an element outside of $B$, Alice makes a jump instead. In that moment some initial arc $E_{0}$ of $E$ starting from the boundary of $E$ is already taken. Let $E_{1}$ be the remaining part (subarc) of $E$. Alice takes the available element of $E_{1}$. Note, that such an element exists since in the sequence $P$, all the neighbors of the slices of $B$ are in $E$, (see Figure 4.7). The half-circle $X_{1} E_{0} X_{2}$ can replace either $C D E$ or $E F A$ in the fixed minimal triple. Thus due to the 

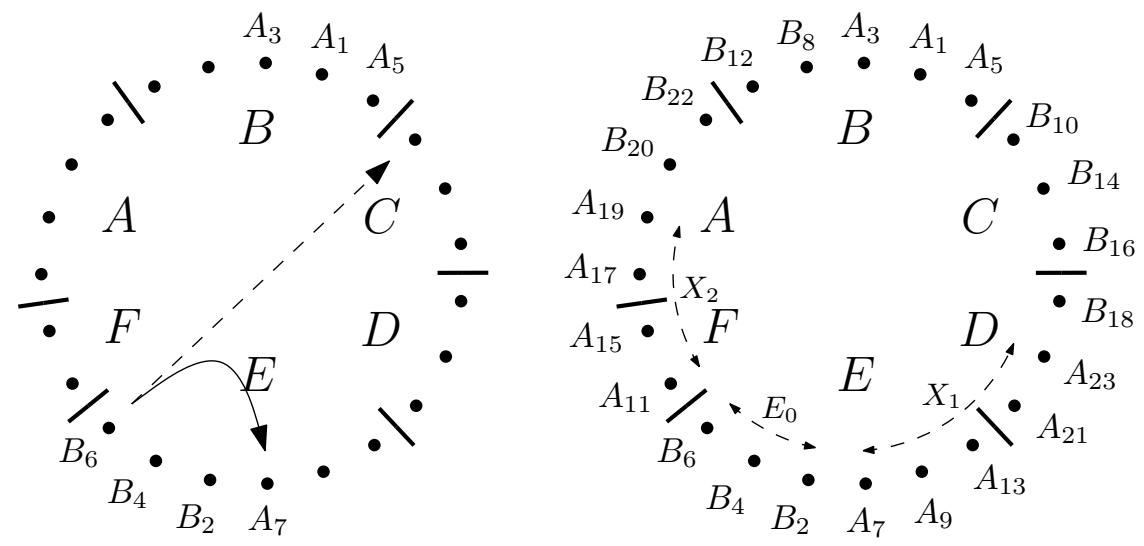

Figure 4.7: One-jump strategy: Alice chooses a jump rather than a shift (left) and makes no more jumps afterwards (right).

minimality of the triple, the size of $X_{1} X_{2}$ is always at least the size of either $C D$ or $F A$. As Alice obtained at least the half of $B$ before the jump, in the end she gains at least $b / 2+\min \{c+d, f+a\}$.

Corollary 43. Alice has a one-jump strategy for $V$ with gain $(a+b+c) / 4+$ $(d+e+f) / 2$ if $p(V)<|V| / 2$.

Proof. By Claim 42 Alice has a strategy with gain $b / 2+\min \{c+d, f+a\}$. Without loss of generality we may assume this sum is $g_{1}:=b / 2+c+d$. Alice also has a strategy with gain $g_{2}:=e+f+a$ by Observation 40. Combining the two results Alice has a gain $\max \left\{g_{1}, g_{2}\right\} \geq g_{1} / 2+g_{2} / 2=$ $(a+c+d+e+f) / 2+b / 4 \geq(a+b+c) / 4+(d+e+f) / 2$.

\subsubsection{A two-jump strategy}

Throughout this subsection we assume that $p(V)<|V| / 2$ and that $V$ is partitioned into six $\operatorname{arcs} A, \ldots, F$ in the same way as in the previous subsection.

In this subsection we describe a strategy satisfying the following claim.

Claim 44. Alice has a two-jump strategy for $V$ with gain $b / 2+e / 4+\min \{c+$ $d, f+a\}$ if $p(V)<|V| / 2$. 


\subsubsection{Two phases of the game}

Let $B=v_{i} v_{i+1} \ldots v_{i+\Delta}$. Then $E=v_{j} v_{j+1} \ldots v_{j+\Delta+1}$, where $j=i+(n-1) / 2$. Consider the circular sequence $V^{\prime}=v_{i} v_{i+1} \ldots v_{i+\Delta} v_{j} v_{j+1} \ldots v_{j+\Delta+1}$ obtained by concatenating the $\operatorname{arcs} B$ and $E$.

Let $H$ be a half-circle of $V^{\prime}$ containing $v_{j}$. Then its size is not smaller than the size of $E$, since otherwise the half-circle $C D E$ of $V$ could be replaced in the minimal triple $T$ by a half-circle of smaller size - namely by the half-circle formed by the slices contained in $C D$ and in $H$.

Similarly, if $H$ is a half-circle of $V^{\prime}$ containing $v_{j+\Delta+1}$, then its size is also not smaller than the size of $E$. Since each half-circle of $V^{\prime}$ contains $v_{j}$ or $v_{j+\Delta+1}$, it follows that $E$ is a half-circle of $V^{\prime}$ of minimum size.

If $p\left(V^{\prime}\right) \geq\left|V^{\prime}\right| / 2$ then Alice has a zero-jump strategy $\Sigma$ for $V^{\prime}$ with gain $p\left(V^{\prime}\right) \geq\left|V^{\prime}\right| / 2 \geq b / 2+e / 4$. Otherwise, by Corollary 43 (applied on $\left.V^{\prime}\right)$, Alice has a one-jump strategy $\Sigma$ for $V^{\prime}$ with gain $b / 2+e / 4$ (we use the fact that $E$ is a half-circle of $V^{\prime}$ of minimum size, and therefore it is contained in a minimal triple yielding a partition of $V^{\prime}$ into six $\operatorname{arcs} A^{\prime}, B^{\prime}, \ldots, F^{\prime}$ such that $E=A^{\prime} B^{\prime} C^{\prime}$ and $\left.B=D^{\prime} E^{\prime} F^{\prime}\right)$.

Briefly speaking, Alice's strategy on $V$ follows the strategy $\Sigma$ as long as it is possible, then Alice makes one jump and after that she makes only shifts till the end of the game.

In the rest of this subsection (subsection 4.2.4), we consider a game $G$ on $V$. We divide the turns of $G$ into two phases. The first phase of $G$ is the phase when Alice follows the strategy $\Sigma$ and it ends with Bob's turn. Alice's first turn that does not follow (and actually cannot follow) the strategy $\Sigma$ is the first turn of the second phase of $G$. It is always a jump and all the other turns of Alice in the second phase are shifts.

We now describe Alice's strategy in each of the two phases of $G$ in detail.

\subsubsection{Alice's strategy in the first phase}

As mentioned above, Alice has a one-jump strategy $\Sigma$ for $V^{\prime}$ with gain $b / 2+$ $e / 4$. We now distinguish two cases.

Case 1: The strategy $\Sigma$ is a zero-jump strategy. Let the first turn in the zero-jump strategy $\Sigma$ be on a slice $q \in V^{\prime}$. The first turn could be also on any other point of $V^{\prime}$ with the same or larger potential. Observe that the potentials of the slices in $V^{\prime}$ are $e$ on $E$ and at least $e$ on $B$. Therefore we may assume that $q$ lies in $B$.

In the game $G$, Alice makes her first turn also on $q$. In the second turn Bob can choose between two slices in $E$. In the subsequent turns Alice makes shifts as long as Bob's previous turn was neither on the first nor on the last 

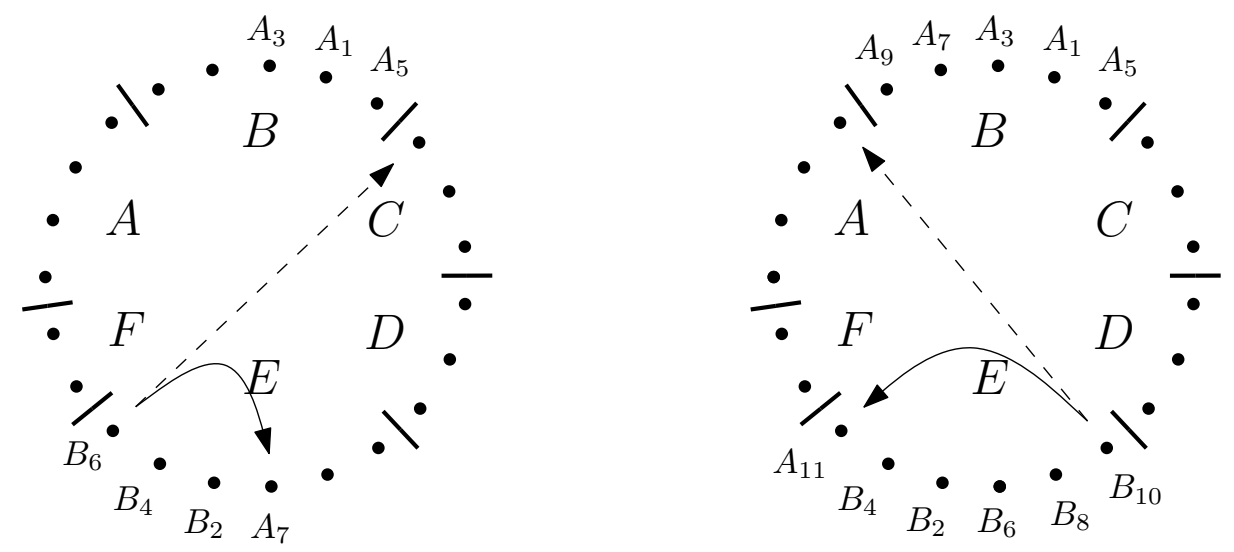

Figure 4.8: Case 1: After the end of first phase, Alice chooses a jump rather than a shift (two examples shown).

slice of $E$. Consider all slices taken by Bob up to any fixed moment during the first phase of the game $G$. They always form a subarc of $E$ (and the slices taken by Alice form a subarc of $B$ ). The first turn in which Bob takes the first or the last slice of $E$ is the last turn of the first phase. Note that after that Alice's shift would be either on the last slice of $A$ or on the first slice of $C$ (see Figure 4.8). But Alice makes a jump and this jump is the first turn of the second phase. Note that this jump is in $E$ (see Figure 4.8).

Case 2: The strategy $\Sigma$ is not a zero-jump strategy. Following the proof of Corollary 43, we may suppose that $\Sigma$ is the strategy that we describe below.

By Claim 39, the half-circle $E$ of minimum size is contained in some minimal triple $T^{\prime}$ of half-circles of $V^{\prime}$. The triple $T^{\prime}$ determines a partition of $V^{\prime}$ into six arcs $A^{\prime}, B^{\prime}, \ldots, F^{\prime}$ in the same way as $T$ determined a partition of $V$ into $A, B, \ldots, F$. We may suppose that $E=A^{\prime} B^{\prime} C^{\prime}$ and $B=D^{\prime} E^{\prime} F^{\prime}$.

We may suppose that the size of $B^{\prime}$ is positive, since otherwise one of the half-circles $C^{\prime} D^{\prime} E^{\prime}$ and $E^{\prime} F^{\prime} A^{\prime}$ has size at least $b / 2+e / 2$ and thus Alice has a zero-jump strategy for $V^{\prime}$ with gain $b / 2+e / 2$, allowing us to use the above Case 1.

In the first turn Alice takes a median slice of $B^{\prime}$. Then in the second turn Bob can choose between two slices of $E^{\prime}$. In the subsequent turns Alice makes shifts as long as Bob's previous turn was neither on the first nor on the last slice of $E^{\prime}$. In each moment in this part of the game Bob's turns form a subarc of $E^{\prime}$. At the first instance when Bob takes the first or the last slice of $E^{\prime}$, Alice makes a jump, which is always in $E^{\prime}$ (see Figure 4.9). Note that so far the game was an analogue of the first phase in Case 1 , with $B^{\prime}$ and $E^{\prime}$ in place of $B$ and $E$, respectively. After her first jump Alice makes shifts as 


\section{$B$}

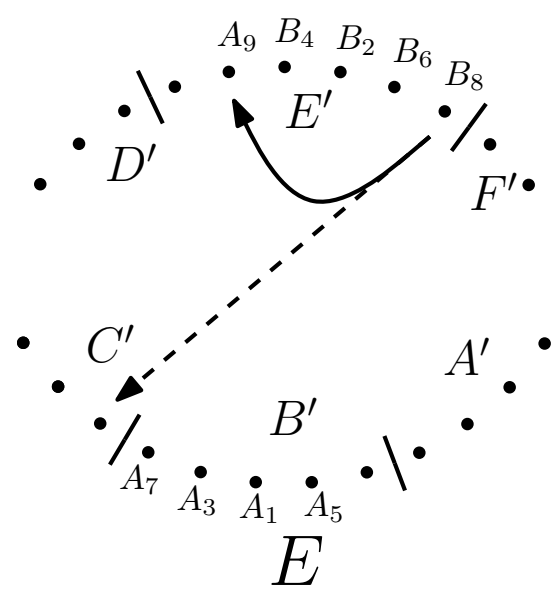

$B$

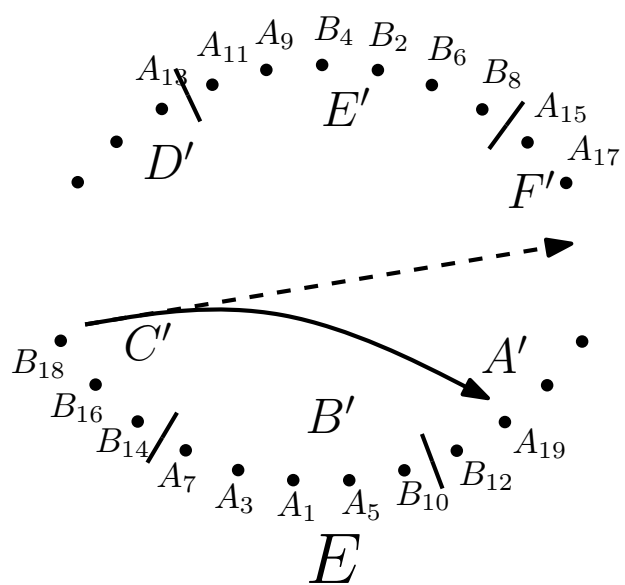

Figure 4.9: Case 2: During the first phase, Alice makes a jump rather than a shift (left) and then she makes an other jump after the end of the first phase (right).

long as Bob's previous turn was neither on the first nor on the last slice of $E$. Note that Bob's turns in this part of the game are in $E$ (see Figure 4.9). At the first instance when Bob takes the first or the last slice of $E$, Alice makes a jump, which is already the first turn of the second phase. This jump is necessarily in $E$ (see Figure 4.9).

\subsubsection{Alice's strategy in the second phase}

Alice's strategy in the second phase is very simple. Above we describe the first phase and also the first turn of the second phase, which is always a jump done by Alice. In the rest of the second phase Alice makes only shifts.

\subsubsection{Analysis of Alice's gain}

Since the first phase of $G$ ends by Bob's turn on the first or on the last slice of $E$, we may suppose without loss of generality that it ends with Bob's turn on $v_{j}$. Then the part of $V$ removed in the first phase of $G$ is a union of some initial subarc $B_{0}$ of $B$ and some initial subarc $E_{0}$ of $E$. Let $E_{1}$ be the arc formed by the slices of $E$ not taken in the first phase of $G$, thus $E=E_{0} E_{1}$, and let $e_{1}:=\left|E_{1}\right|$. In her jump at the beginning of the second phase of $G$, Alice takes the first slice of $E_{1}$.

By Observation [37, all the slices taken by Alice in the second phase of 
$G$ form two $\operatorname{arcs} X_{1}$ and $X_{2}$ such that $X_{1} E_{0} X_{2}$ is a half-circle of $V$ (see Figure 4.7). Since none of the half-circles $C D E$ and $E F A$ can be replaced in the triple $T$ by a half-circle of a strictly smaller size, the sum $\left|X_{1}\right|+\left|X_{2}\right|$ achieves its minimum either for $X_{1}=C D$ and $X_{2}=E_{1}$, or for $l\left(X_{1}\right)=0$ and $X_{2}=E_{1} F A$. Thus, the portion collected by Alice in the second phase of $G$ is at least $e_{1}+\min \{c+d, f+a\}$.

Now, consider an auxiliary game $G^{\prime}$ on $V^{\prime}$ consisting of two phases defined as follows. The turns in the first phase of $G^{\prime}$ are exactly the same as the turns in the first phase of $G$ (this is a correct definition, as all turns in the first phase of $G$ are in $B \cup E$ and the first or the last slice of $E$ is taken only at the very end of the first phase). In the second phase of $G^{\prime}$, both Alice and Bob make only shifts.

We claim that Alice actually follows the one-jump strategy $\Sigma$ in the whole game $G^{\prime}$. This is obvious in the first phase of $G^{\prime}$. Further, if $\Sigma$ is a zero-jump strategy then Alice clearly follows $\Sigma$ also in the second phase of the game $G^{\prime}$. Otherwise Alice makes her only jump in the first phase of the game (see Case 2 in Paragraph 4.2.6) and thus again she follows $\Sigma$ also in the second phase of $G^{\prime}$.

By Observation [38, Alice collects exactly the slices of $E_{1}$ in the second phase of $G^{\prime}$. Thus, if $g$ denotes the portion collected by Alice in the first phase of $G^{\prime}$ then $g+e_{1}$ is her portion in the whole game $G^{\prime}$. Since the strategy $\Sigma$ guarantees gain $b / 2+e / 4$ to Alice, we get $g+e_{1} \geq b / 2+e / 4$.

Alice's portion in the whole game $G$ is at least $g+\left(e_{1}+\min \{c+d, f+a\}\right) \geq$ $b / 2+e / 4+\min \{c+d, f+a\}$, which completes the proof of Claim 44.

\subsubsection{Proof of the lower bound}

Proof of Theorem 30. If the number of slices is even then Alice has a zerojump strategy with gain $|P| / 2$.

We further suppose that the number of slices is odd. We consider the characteristic circle $V$. If $p(V) \geq|V| / 2$ then Alice has a zero-jump strategy with gain $|V| / 2=|P| / 2$.

Suppose now that $p(V)<|V| / 2$. Then $V$ may be partitioned into six $\operatorname{arcs} A, \ldots, F$ as in Claim 41, Without loss of generality, we may assume that $a+b+c \leq c+d+e \leq e+f+a$. Thus, $a+b \leq d+e$ and $c+d \leq f+a$. By Observation 40, Alice has a zero-jump strategy with gain

$$
g_{1}:=e+f+a .
$$

By Claim 44, Alice has a two-jump strategy with gain

$$
g_{2}:=b / 2+e / 4+\min \{c+d, f+a\}=b / 2+e / 4+c+d .
$$


By an analogue of Claim 44, Alice also has a two-jump strategy with gain

$$
g_{3}:=f / 2+c / 4+\min \{a+b, d+e\}=f / 2+c / 4+a+b .
$$

One of the three strategies gives gain

$$
\begin{gathered}
\max \left\{g_{1}, g_{2}, g_{3}\right\} \geq\left(3 g_{1}+4 g_{2}+2 g_{3}\right) / 9 \\
=(5 a+4 b+9 c / 2+4 d+4 e+4 f) / 9=(4|P|+a+c / 2) / 9 \geq 4|P| / 9 .
\end{gathered}
$$

\subsection{The upper bound}

In this section we show a strategy for Bob that guarantees him 5/9 of the pizza. Then Bob has to cut the pizza into an odd number of slices, since otherwise Alice has a strategy with gain $|P| / 2$, as was observed in the introduction. Before each turn of Bob, the number of the remaining slices is even. The sequence of all the remaining slices can be then written as

$$
p_{i} p_{i+1} p_{i+2} \ldots p_{i+2 j-1} \text {. }
$$

Let $K:=p_{i} p_{i+2} \ldots p_{i+2 j-2}$ and $L:=p_{i+1} p_{i+3} \ldots p_{i+2 j-1}$ be the sequences of slices on odd and even positions respectively.

We use the following reformulation of Observation 38:

Observation 45. Before any of his turns, Bob has a strategy that guarantees him $\max \{|K|,|L|\}$ in addition to what he already has. In the strategy Bob makes only shifts, except possibly for the first turn.

Proof. We prove that Bob can get all slices from $L$. A similar proof shows that he can get all slices from $K$. In his first turn, Bob takes $p_{i+2 j-1} \in L$. In each other turn, Bob makes shifts. Then before each of Alice's turns, the two slices available for her are from $K$.

Claim 46. Bob has a one-jump strategy with gain $5|P| / 9$ if he cuts the pizza into 15 slices in the following way: 002020030300404.

Proof. The size of the pizza is 18 , which means that Bob wants to get slices with sum of sizes at least 10 .

We consider all possible first moves of Alice: 
1. Alice takes a zero slice located between two nonzero slices. The sizes of the slices remaining after her turn are

$$
\underline{a} 0 \underline{0} b \underline{0} b \underline{0} 0 \underline{c} \underline{c} 0 \underline{c} 0 \underline{0} a,
$$

where the elements of $K$ are underlined and $a, b$ and $c$ are in one of the six possible bijections with 2,3 and 4 . Then $|K|=2 c+a$ and $|L|=2 b+a$ and by a case analysis of the possible values of $a, b$ and $c$, Bob gets $\max \{|K|,|L|\} \geq 10$.

2. Alice takes a zero slice located between a zero slice and a nonzero slice. This leads to

$$
\underline{a} 0 \underline{a} 0 \underline{0} \underline{b} \underline{0} b \underline{0} 0 \underline{c} \underline{0} \underline{c} 0
$$

and Bob gets $\max \{|K|,|L|\}=\max \{2 a+2 c, 2 b\}=2 a+2 c \geq 10$.

3. Alice takes a nonzero slice. The situation is then

$$
\underline{0} a \underline{0} \underline{0} \underline{b} 0 \underline{b} 0 \underline{0} \underline{0} c \underline{0} c \underline{0} 0 \text {. }
$$

Bob now takes the rightmost slice and then makes shifts until he either takes $a$ or the two slices $c$. This leads to three possible cases:
(a) $\underline{0} \underline{0} \underline{b} 0 \underline{b} 0 \underline{0} \underline{0} c \underline{0} c \underline{0}$,
(b) $\underline{0} 0 \underline{b} 0 \underline{b} 0 \underline{0} c \underline{0}$,
(c) $\underline{0} a \underline{0} \underline{0} \underline{b} 0 \underline{b} 0 \underline{0}$.

After Alice takes one of the available zero slices, we use Observation 45 to show that the gain of Bob in these three cases is

(a) $a+\max \{|K|,|L|\}=a+\max \{2 b, 2 c\}$,

(b) $a+c+\max \{|K|,|L|\}=a+c+\max \{2 b, c\}=a+c+2 b$,

(c) $2 c+\max \{|K|,|L|\}=2 c+\max \{2 b, a\}=2 c+2 b$.

In any of the three cases and for any bijective assignment of the values 2, 3 and 4 to $a, b$ and $c$, Bob gets slices of total size at least 10 .

Corollary 47. For any $\omega \in[0,1]$, Bob has a one-jump strategy with gain $5|P| / 9$ if he cuts the pizza into 15 slices as follows: $P_{\omega}=0010100(1+\omega) 0(2-$ $\omega) 00202$. 
Proof. The claim holds for $\omega=1 / 2$, since $P_{1 / 2}$ is a scale-down of the pizza considered in Claim 46,

Clearly, if some slices of $P_{1 / 2}$ have total size at least 5 then also the corresponding slices of $P_{\omega}, \omega \in[0,1]$, have total size at least 5 . Therefore, Bob can ensure gain $5\left|P_{\omega}\right| / 9=5$ for $P_{\omega}, \omega \in[0,1]$, with the same strategy as for $P_{1 / 2}$.

In subsection 4.4 we show that Bob has no strategy with gain $5|P| / 9$ for pizza cuttings with fewer than 15 slices. Moreover, in subsection 4.5 we show that Corollary 47 describes essentially all cuttings into 15 slices that guarantee Bob $5 / 9$ of the pizza.

Claim 48. For any odd $n \geq 15$, Bob has a one-jump strategy with gain $5|P| / 9$ using some cutting of the pizza into $n$ slices.

Proof. For $n=15$ the claim follows from Claim 46, For larger $n$, we take the cutting $P$ from Claim 46 and add $n-15$ zero slices between some two consecutive zero slices in the sequence.

If Alice starts in one of the added slices, then the situation is similar to the case 2 of the proof of Claim 46. The only difference is that there might be additional zeros at the beginning and at the end of the sequence. But these zeros either do not change the values of $|K|$ and $|L|$ or swap the two values. Thus Bob can get $\max \{|K|,|L|\}=10$.

Otherwise Bob uses the strategy from the proof of Claim 46, In cases 1, 2, the even number of consecutive newly added zero slices does not change the value of $\max \{|K|,|L|\}$ and Bob can thus get slices of total size 10. In case 3 , Alice first takes the slice of size $a$. The even number of added zero slices does not change the fact that before she is able to take any other nonzero slice, Bob takes either the slice of size $a$ or the two slices of size $c$. After this, the value of $\max \{|K|,|L|\}$ is the same as in the proof of Claim 46.

For $\omega=0$ or $\omega=1$, the cutting used in Corollary 47 has slices of only three different sizes $0,1,2$. If all the slices have the same size, then Alice always gets at least half of the pizza. But two different slice sizes are already enough to obtain a cutting with which Bob gets $5 / 9$ of the pizza:

Claim 49. If Bob can make slices of only two different sizes, then he can gain 5/9 of the pizza by cutting the pizza into 21 slices of sizes 0 and 1 in the following way: 001010010101001010101.

Moreover for any odd $n \geq 21$, there is a cutting with $n$ slices of two different sizes of slices, for which Bob has a one-jump strategy with gain $5|P| / 9$. 
Proof. Let $n \geq 21$ and let the cutting be $(00)^{m} 1010101001010010101$ where $m \geq 1$. After Alice makes her first turn, there will be an even number of slices remaining and they can be partitioned into two classes based on their parity in the new sequence. If Alice takes a slice of size 0 in the first turn, necessarily one of the classes will contain more slices of size 1 than the other class. Bob's strategy will be to take the available element of the bigger class in each turn. Consequently Alice will be forced to take an element of the smaller class in each turn. If in the first turn Alice takes a slice of size 1 but the previous partitioning still gives two classes of different size, Bob uses the same strategy. Obviously Bob gains at least 5/9 of the pizza in these cases.

There are three slices of size 1 indicated by bold which if taken in the first turn result in a partitioning into two classes of equal size:

$(00)^{m} 1010101001010010101$.

The sequences below show the situation after the first turn, the vertical line indicates the place of the taken slice:

1. $(00)^{m} 1010 \mid \underline{0} 1001010010101$

2. $(00)^{m} 10101010010 \mid \underline{0} 010101$

3. $(00)^{m} 1010101001010 \underline{0} \mid 0101$

Bob takes the underlined slice of size 0 in his first turn. He will make shifts until he gets to one of the borders of the boxes indicated above, then he makes a jump in his next turn and afterwards only shifts till the end of the game.

Regardless of what turns Alice makes, depending on the case Bob will obtain at least one or two slices of size 1 before anybody reaches outside the given box. As he makes a jump in his next turn and later only shifts, he will get all slices of size 1 outside the box. Therefore in all cases his gain adds up to at least $5 / 9$ of the pizza.

The claim can also be checked for any fixed odd number $n \geq 21$ with a computer program based on the algorithm from subsection 4.7.2.

\subsection{Fixed number of slices}

Here we prove Theorem 31. The theorem is trivial for $n=1$ and easy for $n$ even as observed in the introduction. Further, the theorem for $n \in$ $\{15,17,19, \ldots\}$ follows from Theorem 30 and Claim 46. An upper bound $g(n) \leq 1 / 2$ for any $n \geq 2$ can be seen on the pizza $1100 \ldots 00$. It remains 
to show that Alice has a one-jump strategy with gain $1 / 2$ for any pizza $p_{1} p_{2} \ldots p_{n}$, where $n$ is odd and $3 \leq n \leq 13$.

Let $n$ be odd and let $3 \leq n \leq 13$. We partition the characteristic cycle $V=v_{1} v_{2} \ldots v_{n}$ into six $\operatorname{arcs} A, B, \ldots, E$ in the same way as in subsection 4.2 . We may suppose that each of the six arcs has a positive length, since otherwise Alice has a zero-jump strategy with gain $|P| / 2$ (by Claim41). Therefore, as $l(A)=l(D)+1, l(C)=l(F)+1$ and $l(E)=l(B)+1$, and $n \leq 13$, at least one of the $\operatorname{arcs} B, D, F$ has length at most 1 (and hence, exactly 1 ). Due to the symmetries, it therefore suffices to prove the following claim:

Claim 50. If $l(B)=1$ then Alice has a one-jump strategy with gain $1 / 2$.

Proof. First we describe a one-jump strategy with gain $b+\min \{c+d, f+a\}$. Alice's first turn in the strategy is on the only slice of $B$. Recall that $l(E)=$ $l(B)+1=2$. Bob can choose between the two slices of $E$ in the second turn. Alice takes the other slice of $E$ in the third turn of the game. In the rest of the game, Alice makes only shifts, thus collecting slices of some pair of $\operatorname{arcs} X_{1}$ and $X_{2}$ such that $X_{1} E X_{2}$ is a half-circle (see Figure 4.7). Since none of the half-circles $C D E$ and $E F A$ can be replaced in the triple $T$ by a half-circle of a strictly smaller size, the sum $\left|X_{1}\right|+\left|X_{2}\right|$ achieves its minimum either for $X_{1}=C D$ and $X_{2}=\emptyset$, or for $X_{1}=\emptyset$ and $X_{2}=F A$. Thus, the portion collected by Alice in the whole game is at least

$$
g_{1}:=b+\min \{c+d, f+a\} .
$$

By two applications of Observation 40, Alice also has a zero-jump strategy with gain

$$
g_{2}:=\max \{c+d+e, e+f+a\} .
$$

One of the two strategies is a one-jump strategy with gain

$$
\max \left\{g_{1}, g_{2}\right\} \geq\left(g_{1}+g_{2}\right) / 2=1 / 2 \text {. }
$$

\subsection{Cuttings into 15 and 21 slices}

Here we prove that Bob's cuttings described in subsection 4.3 include all pizza cuttings into 15 and into at most 21 slices where he gets his best possible gain. Theorem 31 implies the minimality of 15 slices as well.

Claim 51. Corollary 47 describes, up to scaling, rotating and flipping the pizza upside-down, all the pizza cuttings into 15 slices for which Bob has a strategy with gain $5|P| / 9$. 
Proof. Suppose Bob cuts the pizza into 15 slices so that Alice cannot gain more than $4|P| / 9$. It follows that $p(V) \leq 4 / 9<1 / 2$. By Claim 41, the characteristic cycle can be partitioned into non-empty arcs $A, B, C, D, E, F$ such that $A B C, C D E$ and $E F A$ form a minimal triple.

Following the proof of Theorem 30, we assume without loss of generality that $a+b+c \leq c+d+e \leq e+f+a$ and we consider the same three strategies with gains $g_{1}, g_{2}$ and $g_{3}$. Combining the assumption $g_{1}, g_{2}, g_{3} \leq 4|P| / 9$ with the inequalities $\left(3 g_{1}+4 g_{2}+2 g_{3}\right) / 9 \geq(4|P|+a+c / 2) / 9 \geq 4|P| / 9$ we get equalities everywhere. Consequently, $g_{1}=g_{2}=g_{3}=4|P| / 9$ and $a=c=0$. This, in particular, implies that $e+f=b / 2+e / 4+d=f / 2+b=4|P| / 9$.

Now we show that $e=0$. Applying Claim 50 three times, we get that $l(B)=l(D)=l(F)=2$ and $l(A)=l(C)=l(E)=3$. Particularly, the length of the circular sequence $V^{\prime}$ obtained by concatenating $\operatorname{arcs} B$ and $E$ is 5 . Hence, by Theorem 31, Alice has a strategy with gain $b / 2+e / 2$ on $V^{\prime}$. Following the proof of Claim 44 we get a two-jump strategy on $V$ with gain $b / 2+e / 2+c+d=g_{2}+e / 4=4|P| / 9+e / 4$. Therefore $e=0$.

It follows that $f=4|P| / 9, b=2|P| / 9$ and $d=3|P| / 9$. If one of the two slices in $B$ had size greater than $|P| / 9$, then by the proof of Claim 42 Alice would have a one-jump strategy with gain greater than $|P| / 9+c+d=4|P| / 9$. It follows that both slices in $B$ have size exactly $|P| / 9$. Similarly, using an analogue of Claim 42, we conclude that both slices in $F$ have size exactly $2|P| / 9$ and both slices in $D$ have size at most $2|P| / 9$.

Lemma 52. Let $P=p_{1} p_{2} \ldots p_{n}$ be a cutting of a pizza into an odd number of slices for which Bob has a strategy with gain $g \geq|P| / 2$. Let $x=$ $\min _{i \in\{1,2, \ldots, n\}}\left|p_{i}\right|$ and let $P^{\prime}=p_{1}^{\prime} p_{2}^{\prime} \ldots p_{n}^{\prime}$ be a cutting of a pizza with slices of sizes $\left|p_{i}^{\prime}\right|=\left|p_{i}\right|-x$. If $x>0$, then for the cutting $P^{\prime}$ Bob has a strategy with gain strictly greater than $g\left|P^{\prime}\right| /|P|$.

Proof. Let $\Sigma$ be Bob's strategy for the cutting $P$ with gain $g \geq|P| / 2$. For the cutting $P^{\prime}$, Bob uses the same strategy $\Sigma$. In this way he is guaranteed to get a subset $Q^{\prime} \subset P^{\prime}$ of $(n-1) / 2$ slices such that the corresponding subset $Q \subset P$ has size at least $g$. Therefore, Bob's gain is

$$
\sum_{p_{i}^{\prime} \in Q^{\prime}}\left|p_{i}^{\prime}\right|=\sum_{p_{i} \in Q}\left(\left|p_{i}\right|-x\right) \geq g-x(n-1) / 2
$$

Since $\left|P^{\prime}\right|=|P|-x n$, we have to show that $(g-x(n-1) / 2)|P|>$ $g(|P|-x n)$, which is equivalent to $x(n-1)|P| / 2<x n g$. The last inequality follows directly from the assumptions $g \geq|P| / 2$ and $x>0$. 
Claim 53. Corollary 49 describes, up to scaling, rotating and flipping the pizza upside-down, all the pizza cuttings into at most 21 slices of at most two different sizes for which Bob has a strategy with gain $5|P| / 9$.

Proof. Let $P$ be a cutting of the pizza into $n \leq 21$ slices of at most two different sizes for which Bob has a strategy with gain $5|P| / 9$. If $n$ is even, then Alice has a (zero-jump) strategy with gain $|P| / 2$. If all slices have positive size, then by Theorem 30 and Lemma [52, Bob has no strategy with gain $5|P| / 9$. Therefore $n$ is odd and at least one slice in $P$ has size 0 . So we can without loss of generality assume that each slice has size 0 or 1 .

Now we proceed exactly as in the proof of Claim 51, up to the point where we are showing that $e=0$. After we apply Claim 50 (three times), we only conclude that $l(B), l(D), l(F) \geq 2$ and consequently $l(A), l(C), l(E) \geq 3$. The length of the circular sequence $V^{\prime}$ obtained by concatenating $\operatorname{arcs} B$ and $E$ is then at most 11 . The rest of the argument that $e=0$ is exactly the same as in the proof of Claim [51. We also conclude that $f=4|P| / 9, d=3|P| / 9$ and $b=2|P| / 9$.

Since the numbers $f, d$ and $b$ are non-negative integers, their sum must be a positive multiple of 9 . Since $l(F)+l(D)+l(B) \leq 12$ and the size of each arc is bounded by its length, we have $|P|=9, f=4, d=3$ and $b=2$. Consequently, $l(F) \geq 4, l(D) \geq 3, l(B) \geq 2$ and $l(C) \geq 5, l(A) \geq$ $4, l(E) \geq 3$. Since $l(A)+\cdots+l(F) \leq 21$, none of these six inequalities may be strict. Therefore $A=0000, B=11, C=00000, D=111, E=000$ and $F=1111$.

\subsection{One-jump strategies}

The main aim of this section is to prove Theorem 32 .

The following corollary proves Theorem $\underline{32}$ (a).

Corollary 54. Alice has a zero-jump strategy for $V$ with gain $|V| / 3$. The constant $1 / 3$ is the best possible.

Proof. The gain $|V| / 3$ trivially follows from Observation 40,

Let $V=100100100$. For every element $v$ of $V$ there is a half-circle $C_{v}$ of size not greater than $|V| / 3$ covering it. So no matter which element $v$ Alice takes in the first turn, as Alice only makes shifts, Bob can play in such a way that Alice gets $C_{v}$.

In the rest of this subsection we prove Theorem 32 (b). 


\subsubsection{Lower bound}

In this subsection we show the strategy for Alice to gain at least $7 / 16$ of the pizza.

We can assume that the number of slices is odd and that $p(V)<|V| / 2$ (otherwise Alice has a strategy with gain $|P| / 2 \geq 7|P| / 16$ ).

We also fix a minimal triple of half-circles and a partition of $V$ into arcs $A, B, C, D, E$ and $F$ given by Claim 41 .

We can use the zero-jump strategy with gain equal to $p(V)$ and the onejump strategies from Claim 42 (and its analogues). It can be shown, however, that these strategies alone guarantee Alice only $3 / 7$ of the pizza.

To improve Alice's gain we introduce one more one-jump strategy.

Claim 55. Alice has a one-jump strategy with gain $3 b / 8+e / 2+\min \{c+$ $d, f+a\}$ if $p(V)<|V| / 2$.

Proof. If $3 b / 8-e / 2 \leq 0$, Alice starts by taking a slice from $E$ and then she makes shifts only. As observed in the proof of Claim 42, the potential of any slice in $E$ (and thus Alice's gain) is equal to $e+\min \{c+d, f+a\} \geq$ $3 b / 8+e / 2+\min \{c+d, f+a\}$.

For the rest of the proof we assume that $3 b / 8-e / 2>0$. The main idea of the Alice's strategy is to start with taking a slice somewhere in the arc $B$ and to jump at some appropriate moment before crossing the boundary of $B$.

Let $k=l(B)$. For $i=0,1, \ldots k$, let $B_{i}$ be the initial subarc of $B$ of length $i$. Symmetrically, let $B_{i}^{\prime}$ be the arc containing the last $i$ slices of $B$. Similarly we define $\operatorname{arcs} E_{i}$ and $E_{i}^{\prime}$ for $i=0,1, \ldots k+1$. For $i=0,1, \ldots k$, let $h(i)=\left|B_{i}\right|-\left|E_{i}\right|$ and $h^{\prime}(i)=\left|B_{i}^{\prime}\right|-\left|E_{i}^{\prime}\right|$.

The functions $h$ and $h^{\prime}$ can be used to measure the difference between Alice's and Bob's gain during the first phase (before Alice decides to jump). We call this difference an advantage of Alice. During the first phase, Alice takes a sub-arc of $B$ and Bob takes an equally long subarc of $E$. If Alice took $B_{j} \backslash B_{i}$ and Bob took $E_{j} \backslash E_{i}$ during the first phase, then Alice's advantage is $h(j)-h(i)$. The other possibility is that Bob took $E_{j+1} \backslash E_{i+1}$; equivalently, Alice took $B_{i^{\prime}}^{\prime} \backslash B_{j^{\prime}}^{\prime}$ and Bob took $E_{i^{\prime}} \backslash E_{j^{\prime}}$, where $i^{\prime}=k-i$ and $j^{\prime}=k-j$. In this case the advantage of Alice is $h^{\prime}\left(j^{\prime}\right)-h^{\prime}\left(i^{\prime}\right)$.

By the minimality of the triple that determined the $\operatorname{arcs} A, B, \ldots, F$, both functions $h$ and $h^{\prime}$ are non-negative.

Similarly as in the previous strategies, Bob's best choice after Alice's jump is to let Alice take the rest of the arc $E$ and one of the $\operatorname{arcs} C D$ or $F A$. It follows that if Alice's advantage is $g$, then her gain will be at least 
$g+e+\min \{c+d, f+a\}$. It only remains to show that Alice can always achieve an advantage greater than or equal to $3 b / 8-e / 2$.

Let $i$ be the largest index such that $h(i) \leq 3 b / 8-e / 2$. Symmetrically, Let $i^{\prime}$ be the largest index such that $h^{\prime}\left(i^{\prime}\right) \leq 3 b / 8-e / 2$. We distinguish two cases.

Case 1: $i+i^{\prime} \leq k$. Equivalently, $B_{i}$ and $B_{i^{\prime}}^{\prime}$ are disjoint. Observe that we actually have $i+i^{\prime} \leq k-1$. Alice starts by taking any of the slices from $B \backslash\left(B_{i} \cup B_{i^{\prime}}\right)$. She jumps as soon as Bob takes the first or the last slice from E.

During the first phase either Alice took $B_{j}$ and Bob took $E_{j}$ for some $j \geq i+1$, or Alice took $B_{j^{\prime}}^{\prime}$ and Bob took $E_{j^{\prime}}^{\prime}$ for some $j^{\prime} \geq i^{\prime}+1$. Alice's advantage is $g=h(j)>3 b / 8-e / 2$ in the first case and $g=h^{\prime}\left(j^{\prime}\right)>3 b / 8-e / 2$ in the second case.

Case 2: $i+i^{\prime}>k$. Divide the $\operatorname{arc} B$ into consecutive $\operatorname{arcs} B^{1}=B_{k-i^{\prime}}, B^{2}=$ $B_{i} \backslash B_{k-i^{\prime}}$ and $B^{3}=B_{k-i}^{\prime}$. Similarly the arc $E$ is divided into $E^{1}=E_{k-i^{\prime}+1}$, $E^{2}=E_{i} \backslash E_{k-i^{\prime}+1}$ and $E^{3}=E_{k-i+1}^{\prime}$.

Since $\left|E^{2}\right| \geq\left|E^{2}\right|-\left|B^{2}\right|=-\left(h(i)+h^{\prime}\left(i^{\prime}\right)-(b-e)\right) \geq b-e-2(3 b / 8-e / 2)=$ $b / 4$, we have $\min \left(\left|E^{1}\right|,\left|E^{3}\right|\right) \leq(e-b / 4) / 2$. We can without loss of generality assume that $\left|E^{1}\right| \leq\left|E^{3}\right|$, hence $\left|E^{1}\right| \leq(e-b / 4) / 2$. Note that the arc $B^{1}$ (and hence $E^{1}$ ) is non-empty, as $\left|B^{1}\right| \geq\left|B^{1}\right|-\left|E^{1}\right|=b-e-\left(\left|B_{i^{\prime}}^{\prime}\right|-\left|E_{i^{\prime}}^{\prime}\right|\right)=$ $b-e-h^{\prime}\left(i^{\prime}\right) \geq 5 b / 8-e / 2>b / 4>0$.

Alice now plays as in the proof of Claim 42, where $B$ is replaced by $B^{1}$ and $E$ is replaced by $E^{1}$. That is, she starts with taking the median slice of $B^{1}$ and jumps as soon as Bob takes the first or the last slice of $E^{1}$. In this way she gets an advantage

$g \geq\left|B^{1}\right| / 2-\left|E^{1}\right|=\left(\left|B^{1}\right|-\left|E^{1}\right|\right) / 2-\left|E^{1}\right| / 2=\left(b-e-h^{\prime}\left(i^{\prime}\right)\right) / 2-\left|E^{1}\right| / 2 \geq$ $(5 b / 8-e / 2) / 2-(e-b / 4) / 4=3 b / 8-e / 2$.

Remark. By iterating the strategy from Claim 55 we obtain an infinite sequence $\Sigma_{1}, \Sigma_{2}, \ldots$ of one-jump strategies, where $\Sigma_{k+1}$ recursively uses $\Sigma_{k}$ in the same way as the strategy $\Sigma_{1}$ from Claim 55 used the strategy $\Sigma_{0}$ from Claim 42. These iterated strategies give better gain when the ratio $b / e$ tends to 1 . However, if the ratio $b / e$ is smaller than $5 / 3$, the strategies $\Sigma_{i}$ are beaten by the previous one-jump strategies that start outside the $\operatorname{arcs} B$ and E.

Proof of the lower bound in Theorem 32 (b). As in the proof of Theorem 30, we may without loss of generality assume that $a+b+c \leq c+d+e \leq e+f+a$.

By Observation 40, Alice has a zero-jump strategy with gain

$$
g_{1}:=e+f+a
$$




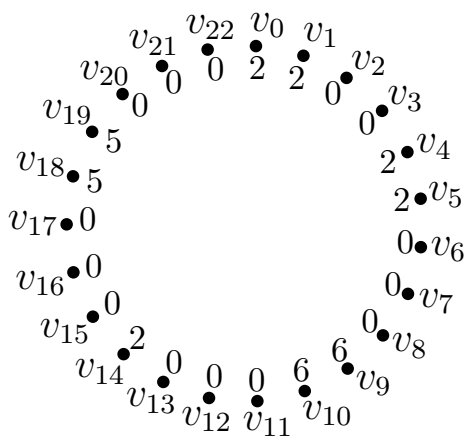

Figure 4.10: Characteristic cycle of the cutting used in Claim 56.

By Claim 44, Alice has a one-jump strategy with gain

$$
g_{2}:=b / 2+\min \{c+d, f+a\}=b / 2+c+d .
$$

By an analogue of Claim 44, Alice also has a one-jump strategy with gain

$$
g_{3}:=f / 2+\min \{a+b, d+e\}=f / 2+a+b .
$$

By Claim 55, Alice has a one-jump strategy with gain

$$
g_{4}:=3 b / 8+e / 2+\min \{c+d, f+a\}=3 b / 8+e / 2+c+d .
$$

One of these four strategies gives gain

$$
\begin{gathered}
\max \left\{g_{1}, g_{2}, g_{3}, g_{4}\right\} \geq\left(5 g_{1}+3 g_{2}+4 g_{3}+4 g_{4}\right) / 16= \\
=(9 a+7 b+7 c+7 d+7 e+7 f) / 16=(7|P|+2 a) / 16 \geq 7|P| / 16 .
\end{gathered}
$$

\subsubsection{Upper bound}

Claim 56. If Alice is allowed to make only one jump, then Bob has a strategy with gain $9|P| / 16$. This gain is achieved for the following cutting of the pizza into 23 slices: 20200200202006060050500.

Proof. The characteristic cycle $V$ is depicted on Figure 4.10, The size of the pizza is 32, which means that we need to show that Bob can get slices with the sum of the sizes at least 18 .

The potential of the cutting is 14, thus Alice has no zero-jump strategy with gain greater than 14 . 
It is easy to check that on the cutting sequence $P$, every zero slice has a neighboring nonzero slice and both neighbors of every nonzero slice are zero slices. If Alice starts by taking some zero slice, then Bob takes the nonzero slice. Alice can then jump, but since she cannot make any more jumps, she would get only at most the potential of $V$. If she does not jump, she takes a zero slice in her next turn and from Observation 38, Bob can take one of the two arcs. Since Bob already took a nonzero slice, the sum of the sizes of the two arcs is at most 30. If both the arcs have size 15, then both must contain a slice of size 5 because there are no other slices of odd size. But this is impossible because the two slices with size 5 are neighbors on the characteristic cycle. Thus one of the arcs has size at most 14 and if Bob chooses the other one, he gets 18 for the whole game.

Now we may assume that Alice starts by taking a nonzero slice. In his first turn, Bob takes a zero slice such that Alice cannot take a nonzero slice in the next turn. In the first phase, Bob makes shifts. The first phase ends after Alice's jump or if Bob's shift would allow Alice to take a nonzero slice in her next turn.

If Alice jumped in the first phase, she would get at most the slice from her first turn plus the potential of one of its two neighbors from the cutting sequence $P$. But it is easy to verify that this would mean a gain at most 14 for Alice. If Alice did not start in $v_{4}$ or in $v_{10}$ and did not jump, then it is easy to verify that after the first phase, one of the two Bob's zero-jump strategies from Observation 38 guarantees Bob gain 18 .

If Alice started in $v_{10}$ and the first phase did not end by Alice's jump, then Bob continues making shifts until either Alice jumps or his shift would allow Alice to take the $v_{18}$ slice in her next turn. This is the second phase. If Alice jumped during the second phase then Bob can make sure that she gets at most $\left|v_{10}\right|+\left|v_{14}\right|+\left|v_{4}\right|+\left|v_{5}\right|=12$, see Figure 4.11 (left)). If she did not jump until the end of the second phase, then from Observation 38, Bob can make sure that Alice gets at most $\left|v_{10}\right|+\left|v_{14}\right|+\left|v_{9}\right|=14$, see Figure 4.11 (right).

If Alice started in $v_{4}$ and the first phase did not end by Alice's jump, then Bob starts the second phase by making a jump and then only shifts. The second phase ends after Alice's jump or if Bob's shift would allow Alice to take $v_{9}$. If Alice jumped during the second phase then Bob can make sure that she gets at most $\left|v_{4}\right|+\left|v_{5}\right|+\left|v_{18}\right|+\left|v_{19}\right|=14$, see Figure 4.12 (left). Otherwise we use Observation 38 to show that Bob can make sure that Alice gets at most $\left|v_{4}\right|+\left|v_{5}\right|+\left|v_{0}\right|+\left|v_{1}\right|=8$, see Figure 4.12 (right). 


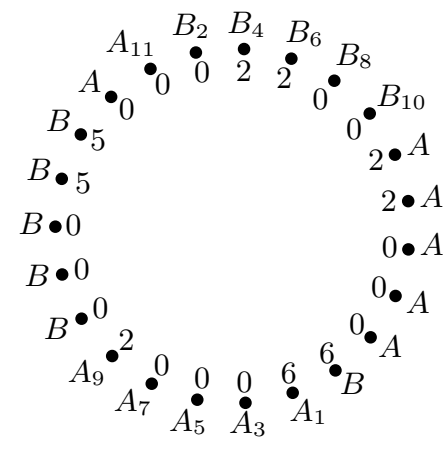

a)

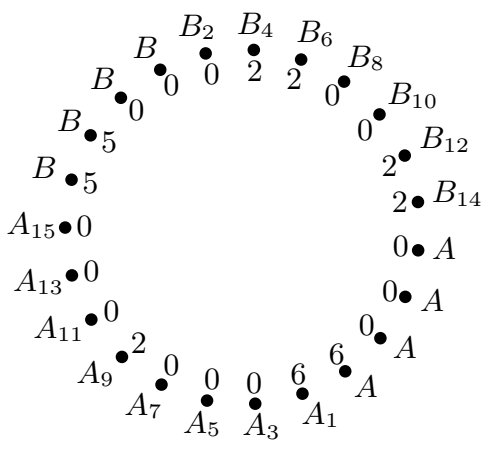

b)

Figure 4.11: Two examples of games starting in $v_{10}$ illustrating how Bob can prevent Alice from gaining more than 14.

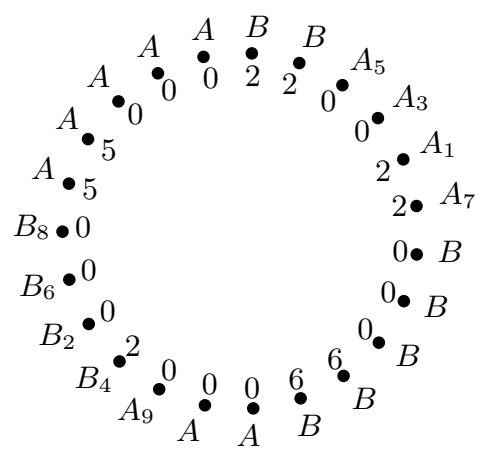

a)

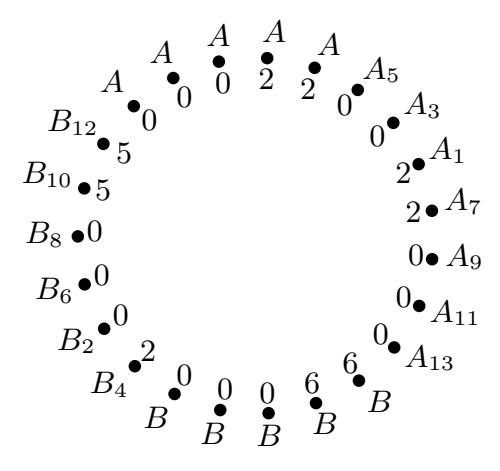

b)

Figure 4.12: Two examples of games starting in $v_{4}$ illustrating how Bob can prevent Alice from gaining more than 14 . 


\subsection{Algorithms}

\subsubsection{Linear algorithm}

In this subsection we describe an algorithm proving Theorem 35 ,

For a given cutting of the pizza with $n$ slices, the algorithm computes Alice's two-jump strategy with gain $4|P| / 9$ in time $O(n)$.

Without loss of generality we may assume that $|V|$ is a part of the input. The algorithm first computes consecutively the sizes of all $n$ half-circles and finds a half-circle of minimum size in the following way. Consider the characteristic cycle $V=v_{0} v_{1} \ldots v_{n-1}$. For $i=0$ to $n-1$ let $s_{i}$ be the variable in which the size of the half-circle with starting point $v_{i}$, continuing in clockwise direction, is stored. Let $s$ be the size of a currently minimal halfcircle $H$, and $v$ the starting point of $H$. In the initialization step, compute $s_{0}:=\sum_{j=0}^{(n-1) / 2}\left|v_{j}\right|$ and set $s:=s_{0}$ and $v:=v_{0}$. Then for $i=1,2, \ldots, n-1$, compute $s_{i}:=s_{i-1}-\left|v_{i-1}\right|+\left|v_{(n+2 i-1) / 2}\right|$. If $s_{i}<s$, then set $s:=s_{i}$ and $v:=v_{i}$. The above computations can be done in time $O(n)$.

After these precomputations we get a half-circle $H$ of minimum size that we fix. Let $v_{k}$ and $v_{k+(n-3) / 2}$ be the two uncovered elements neighboring $H$ on $V$. In the following the algorithm computes the potentials of the elements of the uncovered $\operatorname{arc} X=v_{k} \ldots v_{k+(n-3) / 2}$. Any half-circle covering an element $v_{i}$ of $X$ also covers $v_{k}$ or $v_{k+(n-3) / 2}$. Let the right potential of $v_{i}$ be the minimum of the sizes of half-circles covering both $v_{i}$ and $v_{k+(n-3) / 2}$. The algorithm computes the right potential $p_{r}$ for $v_{k}$ by comparing the values of $s_{k-1}$ and $s_{k}$, that is, $p_{r}\left(v_{k}\right):=\min \left\{s_{k-1}, s_{k}\right\}$. For $i=k+1$ to $k+(n-$ $3) / 2$ set $p_{r}\left(v_{i}\right):=\min \left\{p_{r}\left(v_{i-1}\right), s_{i}\right\}$. Analogously let the left potential of $v_{i}$ be the minimum of the sizes of half-circles covering both $v_{i}$ and $v_{k}$. The computation of the left potentials $p_{l}$ is similar. Obviously the potential of $v_{i}$ is $\min \left\{p_{l}\left(v_{i}\right), p_{r}\left(v_{i}\right)\right\}$. The computations are done in time $O(n)$.

The potential of any element of $X$ is at least as big as the potential of any element of $H$ due to the minimality of $H$. Therefore $p(V)$ is equal to the maximal potential on $X$. If $p(V) \geq|V| / 2$, then the algorithm returns an element of potential $p(V)$ in time $O(n)$. This will be Alice's first turn and all her other turns will be shifts that can be computed in time $O(1)$.

From now on we assume that $p(V)<|V| / 2$. The algorithm finds the index $j \in X$ for which $p_{l}\left(v_{j}\right)+p_{r}\left(v_{j}\right)$ is minimal among all $j$ such that both $p_{l}\left(v_{j}\right)$ and $p_{r}\left(v_{j}\right)$ do not exceed $p(V)$. There exists such a $j \in X$ as a consequence of Claim 39 and Claim 41, Let $H_{1}$ be the half-circle that gives the left potential $p_{l}\left(v_{j}\right)$ for $v_{j}$, and $H_{2}$ the half-circle that gives the right potential $p_{r}\left(v_{j}\right)$ for $v_{j}$. Then $H, H_{1}$ and $H_{2}$ form a minimal triple. Indeed, suppose that there is a half-circle in the triple that can be replaced by a 
half-circle of strictly smaller size. Clearly, this half-circle is not $H$ but $H_{1}$ or $H_{2}$. A contradiction to the choice of $j$. We get that the triple is minimal.

Knowing the minimal triple the algorithm computes $A, B, C, D, E, F$ and $V^{\prime}$ in time $O(n)$. If $p\left(V^{\prime}\right) \geq\left|V^{\prime}\right| / 2$, a slice of potential $p\left(V^{\prime}\right)$ can be found in time $O(n)$. Otherwise, the algorithm computes the arcs $A^{\prime}, B^{\prime}, C^{\prime}, D^{\prime}, E^{\prime}, F^{\prime}$ on $V^{\prime}$ similarly as above in time $O(n)$. A median slice of $B^{\prime}$ can be found in time $O(n)$ by traversing $B^{\prime}$ twice. At first the algorithm computes $\left|B^{\prime}\right|$. Then it adds the sizes of the elements one by one again and checks in every step if the sum exceeds $\left|B^{\prime}\right| / 2$. That will occur at a median slice.

The algorithm orders $a+b+c, c+d+e$ and $e+f+a$. Assume without loss of generality that $a+b+c \leq c+d+e \leq e+f+a$. According to subsection 4.2.9 Alice has three strategies with gains $g_{1}:=e+f+a, g_{2}:=b / 2+e / 4+c+d$ and $g_{3}:=f / 2+c / 4+a+b$. These strategies were computed in time $O(n)$ as described above. Alice chooses one of the three strategies corresponding to $\max \left\{g_{1}, g_{2}, g_{3}\right\}$. Once the strategy is known, Alice's turn can be computed in time $O(1)$ in any position of the game.

\subsubsection{Optimal strategies}

The following result implies, for example, that Alice can be forced to make only jumps (except $A_{1}, A_{n}$ ) in her optimal strategy.

Observation 57. (i) For any odd $n \geq 3$ and for any of the $2^{n-2} n$ permutations allowed in the game on $n$ slices, the pizza can be cut into $n$ slices in such a way that if both Alice and Bob make only optimal turns then the order of taken slices is the chosen permutation.

(ii) For any even $n \geq 4$ and for any of the $2^{n-3} n$ plausible permutations in which Alice's second turn is a jump, the pizza can be cut into $n$ slices in such a way that if both Alice and Bob make only optimal turns then the order of taken slices is the chosen permutation.

Proof. We give the sizes $1,1 / 2,1 / 4, \ldots$ in the order in which we want the slices to be taken.

Now we describe an algorithm that computes both player's optimal strategy for a given cutting of the pizza with $n$ slices in time $O\left(n^{2}\right)$.

Proof of Claim 36. A position of a game is an $\operatorname{arc} X$ characterized by its leftmost slice $x_{l}$ and its rightmost slice $x_{r}$ or the empty-set if there are no more slices left. If $l(X)=1$, then $x_{l}=x_{r}$. There are $n^{2}-n+2$ possible positions $X$. The parity of $l(X)$ determines whose turn it will be. For $i=0$ to $n-1$ the algorithm traverses all $X$ with $l(X)=i$ and decides the best 
strategy for the player on turn. The best possible gain on $X$ is the value of $X$, denoted by $v(X)$. The algorithm stores $v(X)$ for all positions $X$. For $i \in\{0,1\}$ the strategy is obvious and $v(X)=|X|$. Let $X-x$ be the arc $X$ omitting the slice $x$. For $i \geq 2, v(X)=|X|-\min \left\{v\left(X-x_{j}\right), v\left(X-x_{r}\right)\right\}$ and the player takes the corresponding slice yielding the minimum in the previous expression. All this can be done in time $O\left(n^{2}\right)$.

A program implementing the algorithm described above can be downloaded from the following webpage: http://kam.mff.cuni.cz/ cibulka/pizza. The program can be used to verify Claims 46, 49 and 56. 


\section{Acknowledgement}

I would like to thank to my advisor Péter Hajnal for his fruitful ideas and suggestions and for all his help during my years in Szeged.

I would like to thank to my advisor Pavel Valtr for the enormous amount of time that he devoted to our meetings in Prague to guide our research with his ideas. 


\section{Bibliography}

[1] M. Abellanas, J. García, G. Hernandez, M. Noy, P. Ramos, Bipartite embeddings of trees in the plane, Discrete Appl. Math. 93 (1999), 141-148.

[2] M. Abellanas, A. Garcia, F. Hurtado, and J. Tejel: Caminos alternantes, in: X Encuentros de Geometria Computacional (in Spanish), Sevilla, 2003, 7-12.

[3] O. Aichholzer, S. Cabello, R. Fabila-Monroy, D. Flores-Pen aloza, T. Hackl, C. Huemer, F. Hurtado, D.R. Wood, Edge-removal and noncrossing configurations in geometric graphs, Discrete Math. Theor. Comput. Sci. 12 (2010), no. 1, 75-86.

[4] U. Brandes, C. Erten, A. Estrella-Balderrama, J. Fowler, F. Frati, M. Geyer, C. Gutwenger, Seok-Hee Hong, M. Kaufmann, S. Kobourov, G. Liotta, P. Mutzel, A. Symvonis, Colored Simultaneous Geometric Embeddings and Universal Pointsets, Algorithmica, to appear, available online at http://dx.doi.org/10.1007/s00453-010-9433-x .

[5] P. Brass, W. Moser, J. Pach, Research Problems in Discrete Geometry, Springer, New York, 2005.

[6] J. Černý, Z. Dvořák, V. Jelínek, J. Kára, Noncrossing Hamiltonian paths in geometric graphs, Discrete Appl. Math. 155 (2007), no. 9, 1096-1105.

[7] J. Cibulka, J. Kynčl, V. Mészáros, R. Stolař, P. Valtr, Hamiltonian alternating paths on bicolored double-chains, in: I. G. Tollis, M. Patrignani (Eds.), Graph Drawing 2008, Lecture Notes in Computer Science 5417, Springer, New York, 2009, pp. 181-192.

[8] J. Cibulka, J. Kynčl, V. Mészáros, R. Stolař, P. Valtr, Graph sharing games: complexity and connectivity, submitted. Extended abstract 
in: TAMC 2010, Lecture Notes in Computer Science 6108, 340-349, Springer, Berlin, 2010.

[9] J. Cibulka, J. Kynčl, V. Mészáros, R. Stolař, P. Valtr, The Solution of Peter Winkler's Pizza Problem, Fete of Combinatorics, Bolyai Society Mathematical Studies, Vol. 20, 63-93, Springer, 2010. Extended abstract was published in Combinatorial Algorithms (proceedings of IWOCA 2009), Lecture Notes in Computer Science 5874, 356-367, Springer, Berlin, 2009.

[10] J. Cibulka, J. Kynčl, V. Mészáros, R. Stolař, P. Valtr, Universal Sets for Straight-Line Embeddings of Bicolored-Graphs, invited to the Geometric Graph Theory volume that János Pach is editing for Springer.

[11] Paul Erdős, Personal communication to János Pach (see [23])

[12] A. García, M. Noy, J. Tejel, Lower bounds on the number of crossingfree subgraphs of $K_{N}$, Comput. Geom. 16 (2000), 211-221.

[13] E. Di Giacomo, G. Liotta, F. Trotta, On embedding a graph on two sets of points, Int. J. of Foundations of Comp. Science 17(2006), no. 5, 1071-1094.

[14] E. Di Giacomo, G. Liotta, F. Trotta, How to embed a path onto two sets of points, in: P. Healy, N. Nikolov (Eds.), Graph Drawing 2005, Lecture Notes in Computer Science 3843, Springer, New York, 2006, pp. $111-116$

[15] P. Gritzmann, B. Mohar, J. Pach, R. Pollack, Embedding a planar triangulation with vertices at specified points, in: Am. Math. Monthly 98 (1991), 165-166 (Solution to problem E3341)

[16] H. Gourvest, LPSolve IDE v5.5, http://www.progdigy.com M. Berkelaar, J. Dirks, K. Eikland and P. Notebaert, lp_solve 5.5, http://lpsolve.sourceforge.net/5.5

[17] P. Hajnal, V. Mészáros, A note on noncrossing path in colored convex sets, accepted to Discrete Mathematics and Theoretical Computer Science.

[18] A. Kaneko and M. Kano: Discrete geometry on red and blue poins in the plane - a survey, in: Discrete and Computational Geometry (B. Aronov et al., eds.), Springer-Verlag, Berlin, 2004, 551-570. 
[19] A. Kaneko, M. Kano, K. Suzuki, Path coverings of two sets of points in the plane, in: J. Pach (Ed.), Towards a Theory of Geometric Graphs, Contemporary Mathematics 342 (2004), 99-111.

[20] M. Kaufmann, R. Wiese, Embedding vertices at points: Few bends suffice for planar graphs, Journal of Graph Algorithms and Applications 6 (2002), no. 1, 115-129.

[21] K. Knauer, P. Micek and T. Ueckerdt, How to eat 4/9 of a pizza, manuscript.

[22] Jan Kynčl, Personal communication

[23] J. Kynčl, J. Pach and G. Tóth , Long alternating paths in bicolored point sets in: Graph Drawing (J. Pach, ed.), Lecture Notes in Computer Science 3383, Springer-Verlag, Berlin, 2004, 340-348. Also in: Discrete Mathematics 308 (2008), 4315-4322.

[24] C. Merino, G. Salazar and J. Urrutia, On the length of the longest alternating path for multicoloured point sets in convex position. Discrete Mathematics Vol. 360, no. 15, pp. 1791-1797, 2006.

[25] V. Mészáros, Separated matchings on colored convex sets, manuscript.

[26] J. Pach, R. Wenger, Embedding planar graphs at fixed vertex locations, Graphs and Combinatorics 17 (2001), no. 4, 717-728.

[27] Richard P. Stanley, Enumerative Combinatorics, Vol. II., Cambridge University Press, 1999. 


\section{Summary}

In the first part of my thesis I investigate the problem of long noncrossing, alternating paths and separated matchings that are closely related to each other. There is a $2 n$-element equicolored point set in the plane. We would like to determine or estimate the number of points on the longest, noncrossing alternating path. Edges are straight line segments connecting points of different color.

In the first chapter we exhibit a class of convex configurations showing the currently known best upper bound [17] of $\frac{4 n}{3}+O(\sqrt{n})$ points. This bound is conjectured to be asymptotically tight. Previously, there existed only two very similar single constructions for the upper bound of the same order of magnitude in [2, 23]. Our class of configurations differs from the earlier constructions in an important characteristic. The previous ones contained exactly one interval with alternating short monochromatic arcs. Our class contains two such intervals. In its extreme cases our configuration coincides with the [23] construction.

We also improved the best known lower bound to $n+O(\sqrt{n})$ [17]. It should be possible to still improve this bound although additional techniques are needed to the previous ones. One of our main ideas is to code the point set as a Dyck path. We can imagine the circular colored point set as steps up and steps down depending on the color of the passed point. This vizualization determines levels in the point set. We cut the circular sequence at a point which belongs to the lowest level and that is how we gain our Dyck path. This path posesses all the combinatorial information about the colored point set that we need to consider the problem with. By this new coding we managed to find an unbalanced arc that leads to the improvement of the lower bound. But our method has limits. It chooses the starting point of the arc that is the essence of the proof from the lowest level of the diagram. If an adversary party decides according to this logics which arc we may use, then our bound cannot be improved.

The proof techniques introduced the notion of separated matchings. These are geometrically noncrossing matchings where the set of all edges can be 
crossed by a single line. At some colorings searching for separated matchings or searching for long noncrossing, alternating paths is the same problem. First of all if there is a separated matching, we can always complete it to a noncrossing, alternating path. In the literature the number of alternations between the colors along the circle is $o(n)$ in the considered examples. The reason for this is the following. If the number of alternations is linear in $n$, then the length of the noncrossing, alternating path on the point set easily beats the currently known best lower bound. While if we set the number of alternations to $o(n)$, then the existence of a long noncrossing, alternating path implies the existence of a separated matching of the same size.

The second chapter contains several other constructions [25] that allow at most $\frac{4}{3} n+O(\sqrt{n})$ points in any separated matching. There are two main configurations and a third, a generalization of one of the previous constructions. I describe a class of configurations that significantly differs from all known other contsructions. It contains arbitrary many intervals of alternating short monochromatic arcs. The idea of it originates from the [23] configuration. I cut it into two parts and glue the parts together in arbitrary order an equal number of times. I also show a type of coloring such that in the optimal coloring there are at most $\frac{4}{3} n+O(\sqrt{n})$ points in any separated matching.

We define types of separated matchings [17]. The axe that intersects all the edges divides the circle into two intervals. Each interval contains an endpoint of each edge. If there is no alternation between the colors of endpoints on any of these intervals, then we call our matching an Erdös matching. In some sense this is the simplest case. Erdös paired the points in this way when he gave the trivial lower bound of $n$ points.

The number of the alternations between the colors of endpoints on the previous two intervals has a significant effect on the lower bound. This number is bounded from above by a constant in each of the matchings that were used so far in the proofs. In the case of an Erdös matching this constant is zero. In [23] and in our approach [17] it is one as there is at most one alternation in the constructed matchings. If we insist to come up with a matching part with constant alternation parameter, then we cannot beat the obvious bound $n$ by more than a constant. So the conclusion is that we should include a lot of alternations and choose the axe carefully in order to obtain a large separated matching.

Proving the following conjecture would also settle the conjecture on alternating paths. The size $\frac{4}{3} n+O(\sqrt{n})$ is feasible below as well.

Conjecture. Every equicoloring of $2 n$ points in convex position admits a separated matching of size $\frac{4}{3} n+o(n)$. 
Investigating the case of small discrepancy gave interesting results and also a hope to get a better understanding of the problem. When the discrepancy is two or three I prove that there are at least $\frac{4}{3} n$ points in the maximum separated matching [25]. Although the truth might be much closer to $2 n$ by our current methods it is not easy to reveal it. A pairing algorithm of intervals yields the result. It would be feasible to improve it by new ideas. Also the case of the subsequent relatively small discrepancies seems promising. Just by our current methods it gets rather extensive.

In the third chapter we consider a non-convex special position of the equicolored $2 n$-element point set. The points are on a double-chain which consists of a convex and a concave chain, respectively. We can imagine both the convex and concave chain as flipped semi-circles. We place them so that no line determined by any of the chains intersects the other chain. We show [7] that if both chains contain at least one fifth of all the points, then there is a noncrossing, alternating Hamiltonian path on the point set. While this does not hold if one of the chains contain at most $\approx 1 / 29$ of all the points.

It is not clear what role convexity plays in the problem. The previous result suggests that the convex position might be an extremal case. Regarding the general position there is not so much known. A couple of papers are dealing with some special cases [1, 18, 19]. We know that if the color classes are separated by a line, then there is a noncrossing, alternating Hamiltonian path [1]. Together with the existence of halving lines this result implies that there are at least $n$ points on the longest noncrossing, alternating path for an arbitrary position of the points. There is no non-trivial lower bound known in the general case while the best upper bound is for convex position.

In the fourth chapter we study the following combinatorial game played by two players. Alice and Bob are sharing a pizza by alternately taking turns. The pizza is cut into not necessarily equal slices. There is one slice taken in each turn. The first turn is Alice's when she may take any of the slices. In all other turns only such a slice may be taken which has a neighbor slice already taken. We show that Alice always has a strategy to obtain 4/9 of the pizza [9]. We characterize her gain based on the number of slices. We also devise an algorithm that computes her strategy in $O(n)$ time for a given cutting of the pizza into $n$ slices [9]. We distinguish two types of turns of a player. We call it a shift when the player takes a neighboring slice to the previously taken slice. Otherwise it is a jump. We determine Alices best possible gain when the number of jumps is restricted. We describe the minimal pizza cuttings (regarding the number of slices and also regarding the number of weights of slices) where Bob has a strategy to gain 5/9 of the pizza. We give a quadratic algorithm that stores an optimal turn for the player on turn for each position of the game [9]. 
The research presented in the thesis was continued. I sketch some further results (not included in the thesis). The previous problem can be generalized. We may look at it as follows. Given a connected graph $G$ with nonnegative weights assigned to its vertices, the players alternately take one vertex of $G$ in each turn. The first turn is Alice's. The vertices are to be taken according to one (or both) of the following two rules: (T) the subgraph of $G$ induced by the taken vertices is connected during the whole game, $(\mathrm{R})$ the subgraph of $G$ induced by the remaining vertices is connected during the whole game. In the continuation of our research we showed [8] that under all the three combinations of rules (T) and (R), for every $\varepsilon>0$ and for every $k \geq 1$ there is a $k$-connected graph $G$ for which Bob has a strategy to obtain $(1-\varepsilon)$ of the total weight of the vertices. This contrasts with the original Pizza game played on a cycle.

We also showed that the problem of deciding whether Alice has a winning strategy (that is, a strategy to obtain more than half of the total weight) is PSPACE-complete if condition $(\mathrm{R})$ or both conditions $(\mathrm{T})$ and $(\mathrm{R})$ are required. We considered two variations of the game. Canonical game TR: the first player who violates condition $(T)$ or $(R)$ loses the game. Misere game TR: the first player who has no move satisfying conditions $(\mathrm{T})$ and $(\mathrm{R})$ wins the game. We proved [8] that it is PSPACE-complete to decide who has the winning strategy in the canonical game TR and in the misere game TR.

Numerous open problems remain in this research. We could not determine what the complexity is of deciding who has the winning strategy in game $\mathrm{T}$. It would be also interesting to investigate what the complexity is of deciding who has the winning strategy in game $R$ and in game $T$ when the input graph $G$ is a tree. 


\section{Összefoglaló}

Doktori értekezésem első felében a hosszú metszésmentes, alternáló utak és a szeparált párosítások kérdését vizsgáltam, amelyek egymással szorosan összefüggnek. Vegyünk egy tetszőleges $2 n$ elemü, kiegyensúlyozott színezésű, síkbeli ponthalmazt. A feladat meghatározni vagy megbecsülni a leghosszabb metszésmentes, alternáló úton lévő pontok számát. Az élek különböző színü pontokat összekötő egyenes szakaszok.

Az első fejezetben szerkesztettünk egy konvex helyzetű konfiguráció osztályt, amely a legjobb ismert, $\frac{4 n}{3}+O(\sqrt{n})$, felső korlátot bizonyítja [17]. Ez a korlát a sejtés szerint aszimptotikusan éles. Korábban két, nagyon hasonló, egyedi konstrukció létezett ugyanilyen nagyságrendü felső korláttal [2, 23]. A mi konstrukció osztályunk különbözik az előbbiektől egy fontos tulajdonságban. Az előbbi két konstrukció pontosan egy-egy intervallumot tartalmazott, ahol rövid monokromatikus ívek váltották egymást. Az általunk adott konstrukció osztály két ilyen intervallumot tartalmaz, és a paraméterek szélsőértékeire egybeesik a [23] konstrukcióval.

Az alsó korlátot megjavítottuk $n+O(\sqrt{n})$-re [17]. Ez a korlát még biztosan javítható, de új technikára van szükség az eddigi technikák mellett. Az egyik fö ötletünk a ponthalmaz Dyck-útként való kódolása. Ez a megjelenítés szinteket határoz meg a ponthalmazon belül. Pontjaink körkörös sorrendjét elvágjuk egy, a legalsó szinten lévő, pontnál, és így nyerjük Dyck-utunkat. Ez az út minden kombinatorikus információt magába foglal, amelyre szükségünk van a probléma kezeléséhez. Az új kódolás segítségével sikerült rámutatnunk egy kiegyensúlyozatlan ívre, amely az alsó becslés javítását eredményezte. De módszerünknek vannak korlátai. Módszerünk a bizonyítást mozgató ívet a diagram leglasó szintje alapján keresi. Ha egy ellenfél mondja meg, hogy ezen logikát követve, melyik ívet használjuk, akkor becslésünk nem javítható.

A bizonyítási technikák természetes módon vezetnek el a szeparált párosítás fogalmához. Ezek geometriailag metszésmentes párosítások, ahol az élek halmaza egyetlen egyenessel elmetszhető. Bizonyos színezésekben hosszú metszésmentes, alternáló utakat vagy szeparált párosításokat keresni ugyanazt jelenti. Először is, ha van egy szeparált párosításunk, azt mindig ki tudjuk 
bővíteni metszésmentes, alternáló úttá. Az irodalomban vizsgált példákban a színek közötti alternálások száma a kör mentén $o(n)$. Ennek oka a következő. Ha az alternálások száma lineáris volna, akkor a leghosszabb metszésmentes, alternáló út hossza könnyen meghaladná a jelenlegi legjobb alsó korlátot. Míg, ha az alternálások számát $o(n)$-re rögzítjük, akkor a hosszú metszésmentes, alternáló út léte maga után vonja az ugyanolyan méretű szeparált párosítás létét.

A második fejezet tartalmaz jónéhány másik konstrukciót [25], amelyek $\frac{4}{3} n+O(\sqrt{n})$ pontot engednek meg tetszőleges szeparált párosításban. Két fó konfigurációt adtam meg, majd egy harmadikat, amely az egyikük általánosítása. Leírtam egy konfiguració osztályt, amely lényegesen eltér az összes korábbi konstrukciótól. Tetszőlegesen sok intervallumot tartalmaz, amelyben rövid monokromatikus ívek alternálnak. Az ötlete a [23] konfiguráción alapszik. Ezt két részre vágtam, és a részeket tetszőleges sorrendben, azonos multiplicitással megismételtem a kör mentén. Egy színezési formát is meghatároztam úgy, hogy közülük az optimális színezésben legfeljebb $\frac{4}{3} n+O(\sqrt{n})$ pont van minden szeparált párosításban.

Definiáltuk a szeparált párosítások típusait [17]. Az egyenes, amely elmetszi az összes élet, a kört két intervallumra osztja. Mindkét intervallum tartalmazza minden él egy-egy végpontját. Ha a végpontok színei között nincs alternálás az egyik intervallumon (ekkor a másikon sincs), Erdős-párosításról beszélünk. Bizonyos értelemben ez a legegyszerübb eset. Erdős ily módon párosította a pontokat, amikor a triviális $n$-es alsó korlátot igazolta.

A végpontok színei közti alternálások száma az említett két intervallumon nagy hatással van a kapott alsó korlátra. Ez a szám minden eddigi párosításnál, amelyet a bizonyításokban használtunk, konstanssal van felülről korlátozva. Erdős esetében ez a konstans nulla. A [23] cikkben és a mi megközelítésünkben [17] egy, mivel a szerkesztett párosítások legfeljebb egy alternálást tartalmaznak. Ha olyan párosítást adunk, amelyben konstans az alternálások száma, akkor a nyílvánvaló $n$-es korlátot nem tudjuk több, mint konstanssal meghaladni. Tehát, arra a következtetésre jutottunk, hogy sok alternálást kell beiktatni, és körültekintően kell megválasztani a fenti két intervallumot ahhoz, hogy nagy szeparált párosítást kapjunk.

Ha a következő sejtés igazolást nyer, akkor ez az alternáló utakra vonatkozó sejtést is bebizonyítja. Elképzelhető, hogy $\frac{4}{3} n+O(\sqrt{n})$ is teljesül alább.

Sejtés. Minden konvex helyzetü, $2 n$ elemü, kiegyensúlyozott színezésü ponthalmazon van $\frac{4}{3} n+o(n)$ méretü szeparált párosítás.

A kis diszkrepanciájú színezések érdekes eredménnyel szolgáltak, és reményt adtak a probléma mélyebb megértésére. Ha a diszkrepancia kettő vagy 
három, beláttam, hogy legalább $\frac{4}{3} n$ pont van a maximális szeparált párosításban [25]. Habár az igazság $2 n$-hez sokkal közelebb lehet, az alkalmazott módszerekkel ezt nem könnyü felfedni. Intervallumok egy szembeállítása adja ezt az eredményt, amely egy jobb párosító algoritmussal javítható lenne. A rákövetkező kis diszkrepanciák esete sem tűnik nehéznek, de a jelenlegi módszerekkel eléggé terjedelmes.

A harmadik fejezetben egy speciális nem konvex helyzetü kiegyensúlyozott színezésü, $2 n$ elemü ponthalmazt vizsgálunk meg. A pontok egy kettős íven helyezkednek el, amely egy konvex és egy konkáv ívből tevődik össze. Mind a konvex, mind a konkáv ívet elképzelhetjük úgy, mint egy-egy egymásnak háttal fekvő félkört. Úgy helyezzük őket a síkba, hogy egyikük által meghatározott tetszőleges egyenes sem metszi a másik ívet. Beláttuk [7], ha mindkét ív magába foglalja a pontok legalább egyötödét, akkor létezik metszésmentes, alternáló Hamilton út a ponthalmazon. Viszont ha az egyik ív a pontok legfeljebb $\approx 1 / 29$-ét tartalmazza, akkor nincs ilyen út.

Nem egyértelmü, hogy a konvexitás milyen szerepet játszik a kérdésben. Az előbbi eredmény azt sugallja, hogy a konvex helyzet lehet egy extremális eset. Az általános helyzetet illetően nem sok minden ismert. Néhány cikk pontok speciális elhelyezkedésével foglalkozik [1, 18, 19]. Tudjuk, hogy ha egy egyenes választja el a színosztályokat, akkor van metszésmentes, alternáló Hamilton út [1]. Együtt a felező egyenesek létével az előbbi eredményből következik, hogy pontok tetszőleges helyzetére a síkon legalább $n$ pont van a leghosszabb metszésmentes, alternáló úton. Nem ismert nem triviális alsó korlát az általános esetre vonatkozóan, amíg a legjobb ismert felső korlátot a konvex helyzet adja.

A negyedik fejezetben megvizsgáltuk a következő két játékos által játszott kombinatorikus játékot. Alice és Bob tetszőleges nagyságú körcikkekre felszeletelt pizzát oszt. A játékosok váltják egymást, és minden lépésben egy szeletet vesz el a soron lévő. Az első lépés Alice-szé, amikor ő bármelyik szeletet elveheti. Minden más lépésben csak olyan szelet vehető el, amelynek van elvett szomszédja. Beláttuk, hogy Alice-nak mindig van stratégiája megszerezni a pizza 4/9-ét [9]. Karakterizáltuk, mennyit nyerhet a szeletek száma alapján. Megadtunk egy algoritmust, amely $O(n)$ időben kiszámítja Alice stratégiáját a pizza $n$ szeletre való adott felszeletelésekor [9]. Megkülönböztettünk kétféle lépést. Csúszásznak neveztük, ha a játékos az előző lépésben elvett szelet melletti szeletet választotta. Egyébként pedig ugrásnak. Meghatároztuk, Alice mennyit nyerhet el legfeljebb, ha az ugrásai számát korlátozzuk. Leírtuk a minimális pizza szeleteléseket (szeletek számára és a szeletek súlyainak számára vonatkozóan), amikor Bobnak van stratégiája a pizza 5/9-ét elnyerni. Adtunk egy kvadratikus dinamikus algoritmust, amely tárol egy optimális lépést a soron lévő játékos számára a játék minden 
lehetséges pozíciójára [9].

További (a tézisben nem szereplö) kérdések vizsgálhatók. Az előbbi probléma általánosítható, amelyet tekinthetük a következő módon. Adott egy összefüggő $G$ gráf nemnegatív, a pontjaihoz rendelt súlyokkal. A játékosok váltakozva vesznek el egy-egy pontot $G$-ből lépésenként. Az első lépés Aliceszé. A pontokat a következő szabályok egyike vagy együttese alapján kell elvenni: (T) az elvett pontok által feszített részgráf összefüggő az egész játék során, (R) a nem elvett pontok által feszített részgráf összefüggo” az egész játék során. Ezen kutatás folytatásában megmutattuk [8], hogy a (T) és (R) szabályok mindhárom kombinációjára, minden $\varepsilon>0$-ra és minden $k \geq 1$-re létezik $k$-összefüggő $G$ gráf, ahol Bobnak van stratégiája $(1-\varepsilon)$-szeresét elnyerni a pontok együttes súlyának. Ez ellentétben áll az eredeti Pizza játékkal a körön.

Szintén túlmutat a tézis keretein a kérdéskör bonyolultságelméleti vonatkozása. További kutatásainkban igazoltuk, hogy annak eldöntése, hogy Alicenek van-e nyerő stratégiája (vagyis stratégiája az össz súlymennyiség több, mint felének megszerzésére) PSPACE-teljes, ha (R) szabály vagy (T) és $(\mathrm{R})$ együttesen van megkövetelve. A játék két további változatát is vizsgáltuk. Kanonikus TR játék: az első játékos, aki megszegi a $(\mathrm{T})$ és $(\mathrm{R})$ szabályok valamelyikét, veszít. Misere TR játék: az első játékos, aki nem tud a (T) és (R) szabályoknak megfelelően lépni, nyer. Bebizonyítottuk [8], hogy PSPACE-teljes annak eldöntése, hogy kinek van nyerő stratégiája a kanonikus TR játékban és a misere TR játékban.

Számos nyitott kérdés marad ezen a területen. Nem sikerült meghatároznunk, milyen bonyolultságú annak eldöntése, hogy kinek van nyerő stratégiája a T játékban. Érdekes lenne megválaszolni azt a kérdést, milyen bonyolultságú annak eldöntése, hogy kinek van nyerő stratégiája az $\mathrm{R}$ és a $\mathrm{T}$ játékban, ha az input $G$ gráf fa. 